\author{
Universidade de São Paulo \\ Instituto de Física
}

\title{
Estudo e Caracterização de Pátinas em Cobre e Bronze com Técnicas PIXE e ED-XRF
}

\author{
Pedro Herzílio Ottoni Viviani de Campos
}

Orientadora: Profa. Dra. Márcia de Almeida Rizzutto

Dissertação de mestrado apresentada ao Instituto de Física para a obtenção do título de Mestre em Ciências

Banca Examinadora:

Profa. Dra. Márcia de Almeida Rizzutto (IF - USP)

Prof. Dr. Shigueo Watanabe (IF - USP)

Prof. Dr. Carlos Roberto Appoloni (CCE - UEL) 
FICHA CATALOGRÁFICA

Preparada pelo Serviço de Biblioteca e Informação do Instituto de Física da Universidade de São Paulo

Campos, Pedro Herzílio Ottoni Viviani de

Estudo e Caracterização de Pátinas em Cobre e Bronze com Técnicas PIXE e ED-XRF. - São Paulo, 2010.

Dissertação (Mestrado) - Universidade de São Paulo. Instituto de Física, Depto. de Física Nuclear

Orientador: Profa. Dra. Márcia de Almeida Rizzutto

Área de Concentração: Física Experimental com aceleradores

Unitermos: 1. Acelerador de partículas; 2.Física atômica; 3. Espectroscopia atômica 
Dedico este trabalho a todos aqueles que nos ajudam a realizar os nossos sonhos, e principalmente a minha querida mãe, que é a luz do meu caminho. 


\section{Agradecimentos}

Gostaria de agradecer imensamente a todas as pessoas que me ajudaram para que este trabalho se tornasse possível:

Gostaria de agradecer à Profa. Márcia Rizzuto pela orientação, por acreditar em mim, pela paciência, pelo carinho e por tanto me ensinar.

Ao Prof. Augusto Neiva por não medir esforços para ajudar, e pela enorme contribuição e parceria neste trabalho.

À Rócio por sempre atenciosa ajuda.

Ao Prof. Nemitala por seu estimulo, confiança e bom humor.

Ao Prof. Manfredo por instigar o pensar científico

Ao Marcel e Marquinhos pelo apoio técnico.

À Profa. Ewa por sua ajuda sempre atenciosa.

Ao Laboratório de Análise de Materiais por Feixes lônicos.

Ao Instituto de Física por me abrigar e fornecer recursos para estes anos de pesquisa.

À Comissão e a Secretaria de pós-graduação do IFUSP por seu belo trabalho.

Ao CNPq pelo suporte financeiro.

À minha mãe, Maluh Barciotte, por sempre confiar em mim todos estes anos, e por me ensinar a ser quem eu sou.

A toda minha família, principalmente ao meu pai, Herzílio, minha irmã, Bruna, e meu irmão, André.

À Stella, por estar ao meu lado nesse caminho. 


\section{Resumo}

No acervo que compõem o patrimônio cultural, há muitos utensílios, obras de arte, monumentos, etc., que são feitos de metais. Mas dentre os diversos metais existentes, o cobre possui uma posição de destaque na história, pois este foi o primeiro utilizado pela humanidade. Os metais quando expostos à atmosfera podem sofrer processos de corrosão, o que pode comprometer um artefato histórico. No cobre e suas ligas, o produto dos processos de corrosão é denominado pátina. $\mathrm{O}$ estudo das pátinas e das ligas que compõe a matriz, no qual a pátina se forma, é de fundamental importância para a compreensão dos processos de corrosão. Com esta informação, puderam-se determinar as melhores técnicas de conservação e restauração que devem ser aplicadas. No presente estudo utilizou-se pátinas artificiais, que já são amplamente conhecidas, e possibilitam a simulação de pátinas naturais, além de ser possível utilizá-las na recolocação de pátinas que fora removidas e/ou perdidas de peças metálicas. Em um estudo anterior foram produzidas pátinas artificiais a partir de três soluções utilizando dois procedimentos de preparação e a análise foi realizada através das técnicas: EIS (Espectroscopia por Impedância Eletroquímica), MEV (Microscopia Eletrônica de Varredura), e XRD (Difração de Raio $X$ ), que são consideradas técnicas micro-destrutivas. No presente estudo, destas mesmas pátinas, utilizou-se para análise as técnicas de PIXE (Emissão de Raio X Induzido por Partícula) e ED-XRF (Fluorescência de Raio X por Dispersão de Energia), ambas não destrutivas e, no caso de ED-XRF, mais frequentemente, possível ser utilizada in situ. Estas técnicas permitem a analise de obras de arte em atmosfera, em um arranjo externo, o que contribui para a análise de peças de diferentes formas e tamanhos. Os resultados obtidos mostraram que 0 PIXE possui uma melhor caracterização de elementos leve, enquanto que o ED-XRF é melhor para elemento pesados. Na comparação entre PIXE interno e externo, observou-se que a montagem externa é suficiente na análise desse tipo de material. As medidas de padrões de aço validaram a técnica PIXE para análise de alvos grossos e permitiram quantificar os elementos presentes nas amostras. Tanto PIXE, quanto ED-XRF, mostraram nas análises das amostras os elementos que estão presentes nas soluções aplicadas. Além disso, houve um aumento do enxofre em algumas amostras e pátinas, e isto pode indicar que este elemento foi agregado com o tempo nas amostras, devido à exposição à atmosfera. Em comparação ao estudo 
anterior, que caracterizou a composição das camadas de pátinas em amostras semelhantes, foi possível mostrar que se pode determinar e quantificar com PIXE e ED-XRF os elementos presentes sem que seja necessária a retirada do material a ser analisado, principalmente se aplicadas para a análise de peças com valor histórico e cultural. O estudo utilizando as técnicas PIXE e/ou ED-XRF, juntamente com técnicas EIS, SEM e XRD, torna as respostas mais completas, mas nem sempre isso é possível em se tratando de bens do patrimônio histórico, cultural e artístico.

Palavras chave: alvos grossos, arranjo externo, bronze, cobre, corrosão, ED-XRF, metais, pátina, PIXE. 


\begin{abstract}
The collection that composes the cultural patrimony has many utensils (vessels, pottery, adornment), works of art, monuments, etc., that are made of metals. However amongst the diverse existing metals, copper possesses a position of historical prominence, since this metal was the first one to be used by humanity. Metals when displayed in the atmosphere, can suffer processes corrosion which can destroy partially or completely the historical object. In copper and its alloys, the product of the corrosion processes is called patina. Analyses of the patina and the matrix alloy material are necessary to understand the corrosion processes and its development. The analyses are also needed to study the alterations imposed on an artifact in order to develop an adequate conservation and restoration treatment techniques. In the present work well known artificial patinas were used and can simulate the natural ones besides permitting to use them in the replacement of lost patinas that have been removed and/or lost in metallic parts. A previous study was realized with artificial patinas produced from three solutions and two different procedures of application. These patinas were analyzed by different techniques such as: EIS (Electrochemical Impedance Spectroscopy), SEM (Scanning Electron Microscopy), and XRD (X-ray Diffraction), which are micro-destructive methods. In the present study, the same samples were analyzed by PIXE (Particle Induced X-ray Emission) and ED-XRF (Energy Dispersive X-ray Fluorescence) techniques, both not destructive, and in the case of ED-XRF, more frequently, it can be used in situ. These methods allow the analyses of works of art of different forms and sizes in the atmosphere, in an external arrangement. The results have shown that PIXE has a better characterization of light elements, whereas the ED-XRF is better for heavy elements. The comparison of internal and external PIXE measurements showed that the PIXE external setup is enough for the analysis of this type of material. The PIXE results of steel standards had validated the technique PIXE for analysis of thick targets and had allowed the quantification of the elements presents in the samples. PIXE and ED-XRF analyses had shown the principal elements present in the samples and in the solutions. Moreover, it was possible detect an increase of sulphur in some samples and patinas, indicating that this element is being absorbed by the samples due to the exposition to the atmosphere. This work also shows that it is possible to determine and quantify with PIXE and ED-XRF the elements present in
\end{abstract}


the samples, without any extraction of material and it is important mainly if applied to the analysis of historical and cultural objects. A study using suitable combination of techniques, as used in the previous study (EIS, SEM e XRD) coupled to PIXE and/or ED-XRF techniques can give a complete characterization of the corrosion compounds, but sometimes the complete combination of techniques is impossible if dealing with artistic and cultural historic objects.

Keywords: thick targets, external arrangement, bronze, corrosion, ED-XRF, PIXE, metals, patina. 


\section{Sumário}

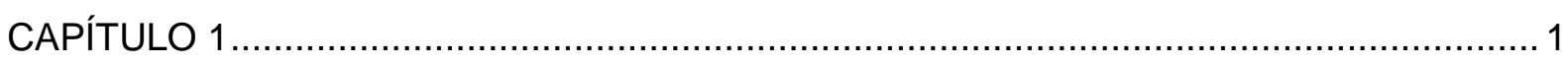

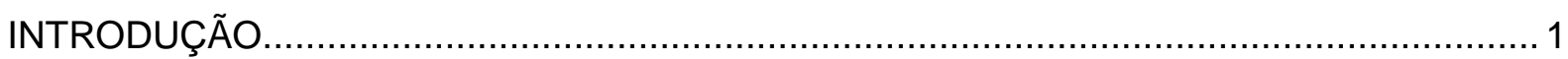

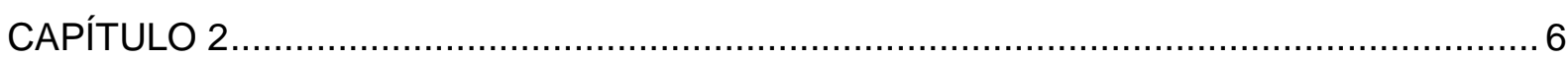

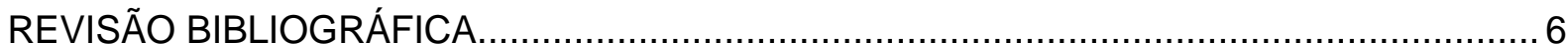

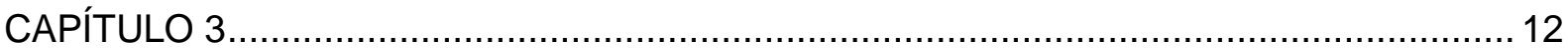

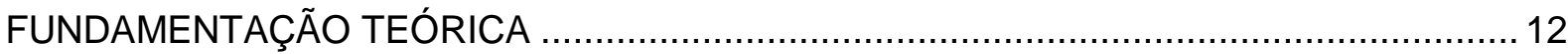

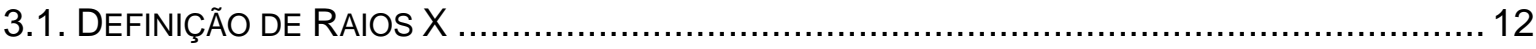

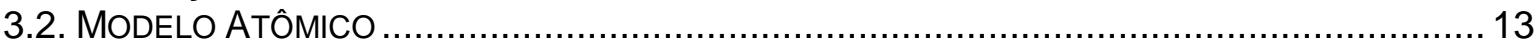

3.3. INTERAÇÃO DO RAIO X COM A MATÉRIA ............................................................ 16

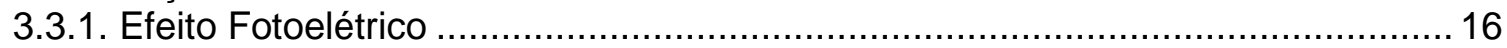

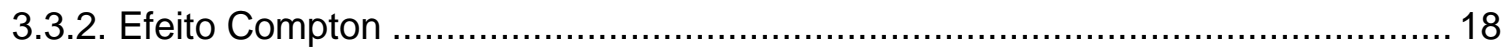

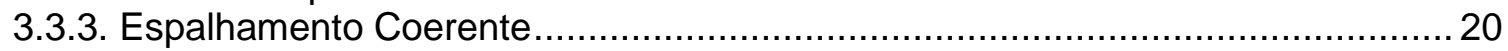

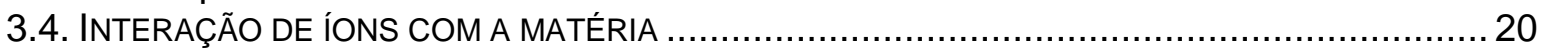

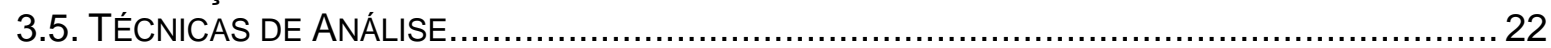

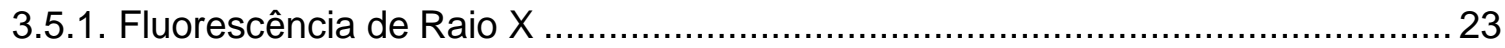

3.5.1.1. Fluorescência de Raio X por dispersão de comprimento de onda (WD-XRF)

3.5.1.2. Fluorescência de Raio X por dispersão de energia (ED-XRF) .....................26

3.5.1.3. Formulação do método de Fluorescência de Raio X por dispersão de energia

(ED-XRF) ............................................................................................... 27

3.5.2. Emissão Induzida de Raio X por Partículas (PIXE) ………………………….....34

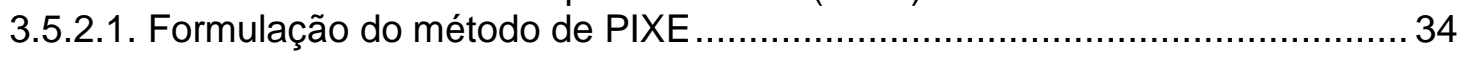

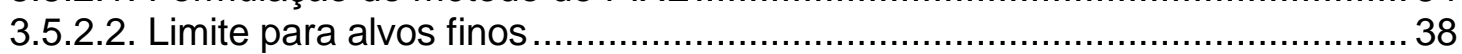

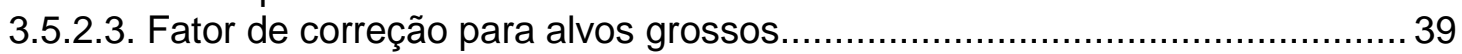

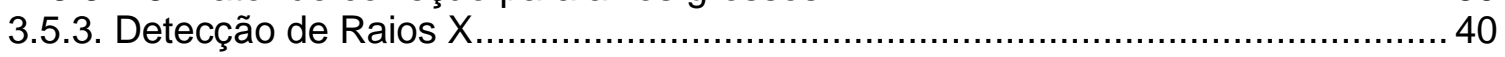

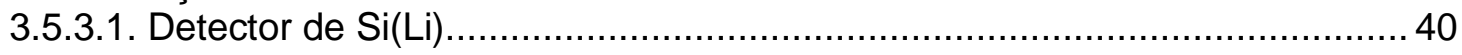

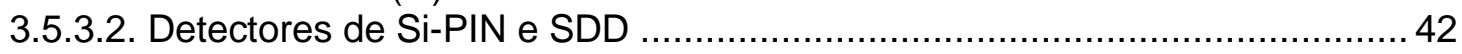

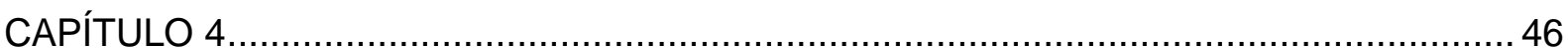

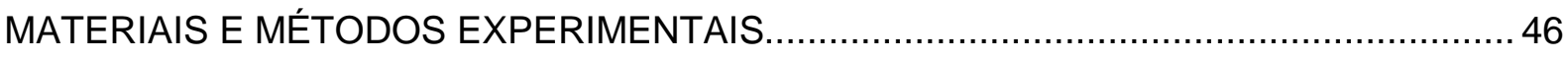

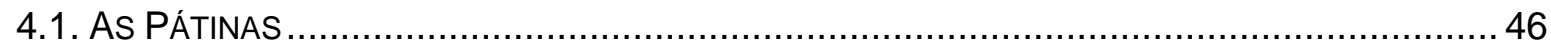

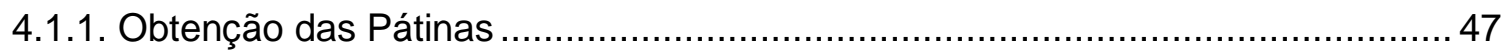

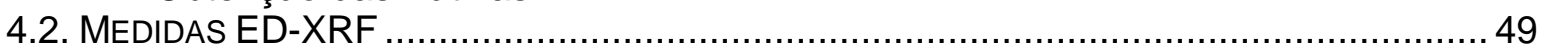

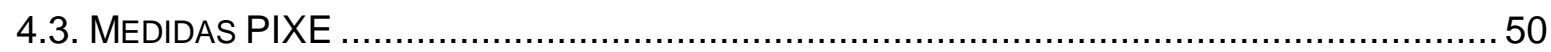

4.3.1. Arranjo Experimental para medidas de PIXE interno .........................................52

4.3.2. Arranjo Experimental para Medidas de PIXE Externo …………………….......53

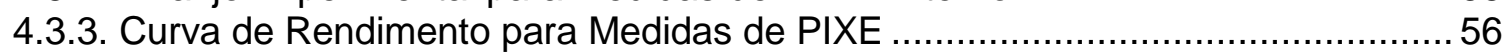

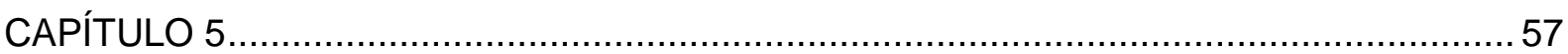

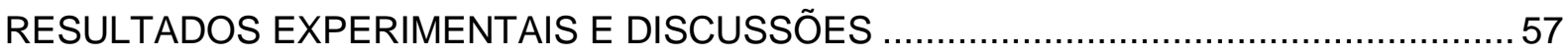

5.1. ESPESSURA E COMPOSIÇÃO DAS CAMADAS DAS AMOSTRAS ………............................5

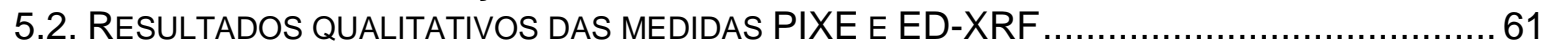

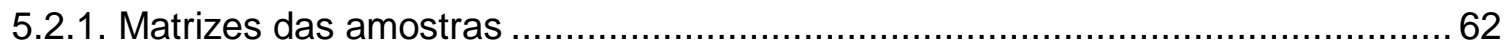

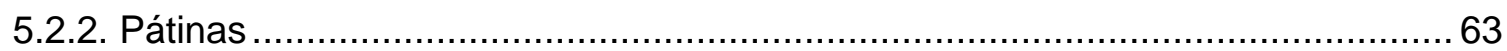

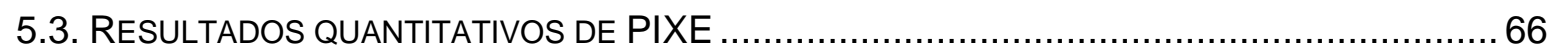

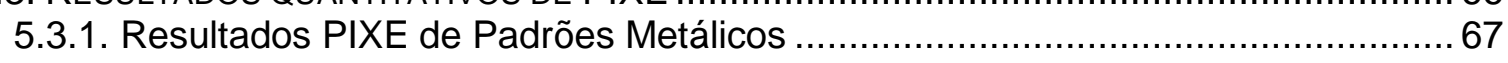

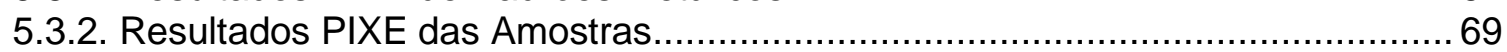

5.4. COMPARAÇÃO QUANTITATIVA DAS MEDIDAS PIXE E ED-XRF ....................................74 


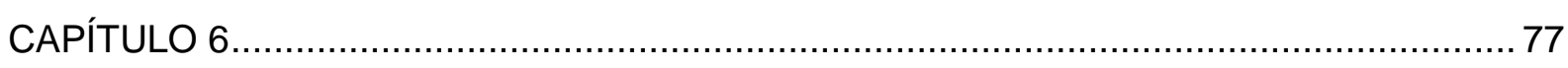

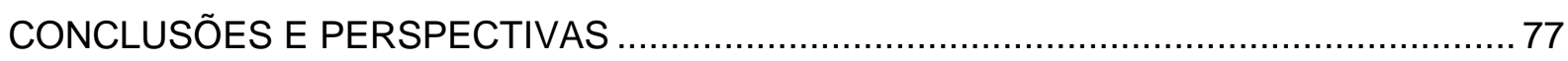

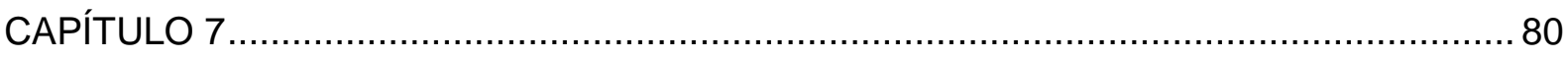

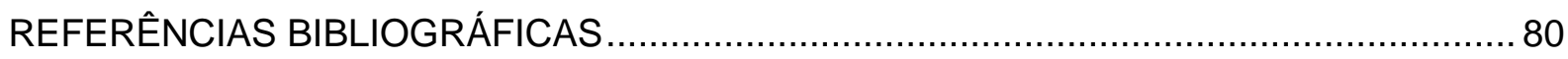

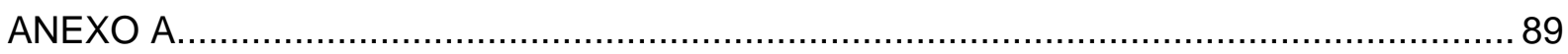




\section{Lista de Figuras}

Figura 3.1 - Diagrama energético e as transições de raio $X$ mais importantes com os respectivos números máximos de elétrons em cada camada, e os números quânticos $n, l$ e $j$ para cada camada e subcamada (CESAREO, 2000)...........14

Figura 3.2 - A ionização por efeito fotoelétrico pode ser seguida tanto por uma desexcitação radioativa, causando a emissão de um raio $X$ fluorescente característico, quanto por uma desexcitação não radioativa, envolvendo a emissão de um elétron Auger (JANSSENS, 2004).

Figura 3.3 - Efeito Compton observado de espalhamento de um feixe de raio $\mathrm{X}$, proveniente de um tubo de raio $X$ de Mo, sobre um alvo de carbono, e o espectro observado para diferentes ângulos de detecção do raio $X$ espalhado (NAVE).

Figura 3.4 - No espalhamento elástico, quando a onda de raio $X$ colide com o átomo, os elétrons desse átomo espalham o raio $\mathrm{X}$. A onda espalhada elasticamente é imediatamente re-emitida em todas as direções e pode ser imaginada como uma frente de onda esférica (JANSSENS, 2004).

Figura 3.5 - Os princípios físicos das técnicas IBA (CALLIGARO; DRAN; SALOMON, 2004).

Figura 3.6 - Os diferentes modos de interação entre fótons e a matéria para um alvo de chumbo, em função da energia do fóton. Cada processo possui um domínio energético particular. $\mathrm{Na}$ faixa das baixas energias (0-100 keV), o efeito foto elétrico é dominante. No regime intermediário (100-1000 keV), o espalhamento Compton é predominante. Na região das altas energias (acima de $1 \mathrm{MeV}$ ), a produção de pares tem a principal contribuição (CALLIGARO; DRAN; SALOMON, 2004).

Figura 3.7 - Probabilidade relativa de emissão de fluorescência de raio X (linha tracejada) e Auger (linha contínua) (HUBIN; TERRYN, 2004). 25

Figura 3.8 - A difração do raio $X$ por um cristal, de acordo com Bragg, sendo $\lambda \circ$ comprimento de onda, $\theta$ o ângulo difração de Bragg e $d$ o espaçamento interplanar dos planos que estão difratando (MOENS; BOHLEN; VANDENABEELE, 2000).

Figura 3.9 - Representação esquemática da geometria de excitação para feixe monoenergético em fluorescência de raios X (NASCIMENTO FILHO, 1999). . 27

Figura 3.10 - Dependência do coeficiente de absorção de massa em função da energia, para os elementos cálcio, cobre e urânio (NASCIMENTO FILHO, 1999).....

Figura 3.11 - Valores da razão de salto (jump ratio) em função do número atômico (NASCIMENTO FILHO, 1999).

Figura 3.12 - Representação esquemática da dependências entre as variáveis na equação fundamental de fluorescência de raios $X$ para feixe monoenergético (NASCIMENTO FILHO, 1999)................................................................. 32

Figura 3.13 - Geometria do arranjo PIXE (Aburaya, 2005). 
Figura 3.14 - Desenho esquemático dos fenômenos que seguem a absorção de um fóton num cristal de $\mathrm{Si}(\mathrm{Li})$, usado em medidas de raios $\mathrm{X}$ (modificado de Janssens, 2004).

Figura 3.15 - Largura à meia altura de uma distribuição gaussiana ( $F W H M)$ e definição de resolução. Note que $F W H M=2,35 \sigma$ (KNOLL, 1979) ....................................... 42

Figura 3.16 - Curvas de eficiência intrínseca de um detector de Si(Li) (CANBERRA) .......... 42

Figura 3.17 - Esboço ilustrando o funcionamento de um fotodiodo convencional (site do fabricante Amptek).

Figura 3.18 - Esboço ilustrando o funcionamento do detector de SSD (site do fabricante Amptek).

Figura 3.19 - Curvas de eficiência intrínseca de um detector de Si-PIN (AMPTEK). 44

Figura 3.20 - Curvas de eficiência intrínseca de um detector de SSD (AMPTEK). 45

Figura 3.21 - Distribuição da resolução dos detectores SDD e Si-PIN (site do fabricantes Amptek).....

Figura 4.1 - Amostras de pátinas artificiais com a área superficial de aproximadamente $1 \mathrm{~cm}^{2}$........

Figura 4.2 - Amostras do substrato e de pátinas artificiais produzidas pela aplicação das substâncias S1 e S2 sobre cobre, com a área superficial de aproximadamente $0.3 \mathrm{~cm}^{2}$ 48

Figura 4.3 - Arranjo experimental para as medidas de ED-XRF feitas em conjunto com o Prof. Neiva no Departamento de Química da Poli, USP

Figura 4.4 - Vista geral do LAMFI (Laboratório de Análise de Materiais por Feixes lônicos) do Instituto de Física da Universidade de São Paulo. (LAMFI)...... 50

Figura 4.5 - Diagrama esquemático da montagem do acelerador do LAMFI (modificado de SANTOS, 2009).

Figura 4.6 - Arranjo experimental para análise PIXE em vácuo do LAMFI. D1 [detector $\mathrm{K}($ Baixa)] e D2 [detector $\mathrm{L}$ (Alta)] são detectores de Si(Li), C é um colimador, T é o porta-alvo e $F$ é o copo de Faraday, (ABURAYA, 2005)... 52

Figura 4.7 - Imagens do arranjo experimental PIXE no LAMFI. Na imagem inferior temos a vista da canalização a $30^{\circ}$, juntamente com os detectores e a câmara PIXE. Na imagem superior temos a vista do interior da câmara de radiação para PIXE interno do LAMFI (ABURAYA, 2005) ............................................................. 53

Figura 4.8 - Arranjo experimental do PIXE externo. 54

Figura 4.9 - Desenho esquemático do arranjo experimental do método PIXE para feixe externo. 
Figura 4.10 - Fator de resposta de alvo fino para linhas $\mathrm{K}_{\alpha}$ e $\mathrm{L}_{\alpha}$, para um arranjo de PIXE externo, com um feixe de prótons de 1,77MeV (curva obtida em outubro de 2007- LAMFI).....

Figura 5.1 - Simulação de prótons incidindo a $90^{\circ} \mathrm{com} 1,77 \mathrm{MeV}$ de energia, interagindo com a amostra de S1 sobre bronze (camada 1 de 7,9 $\mu \mathrm{m}$; camada 2 de 2,4 $\mu \mathrm{m}$; o restante de bronze). À esquerda: a penetração dos íons e seu alcance na amostra. À direita: o histograma do alcance dos íons, com média de penetração de 21,8 $\mu \mathrm{m}$ (TRIM/SRIM 2003).

Figura 5.2 - Simulação de prótons incidindo a $90^{\circ} \mathrm{com} 1,77 \mathrm{MeV}$ de energia, interagindo com a amostra de S1 sobre bronze (camada 1 de com 7,9 $\mu \mathrm{m}$; camada 2 de 2,4 $\mu \mathrm{m}$; o restante é bronze). Ionização pelos íons incidentes, pela perda de energia na amostra (TRIM/SRIM 2003).... .58

Figura 5.3 - Espectros PIXE (esquerda) e ED-XRF (direita) da matriz de cobre descoberto (pastilha). Para o espectro PIXE: a) Interno; b) Externo; c) Externo, 16 meses antes. 62

Figura 5.4 - Espectros PIXE (esquerda) e ED-XRF (direita) da matriz de bronze descoberto (pastilha). Para o espectro PIXE: a) Interno; b) Externo; c) Externo, 16 meses antes.

Figura 5.5 - Espectros PIXE (esquerda) e EDXRF (direita) do cobre coberto com a pátina S1 (chapa). Para o espectro PIXE: a) Interno; b) Externo. Para o espectro ED-XRF: a) 45-edxrf; b) 0-edxrf. 64

Figura 5.6 - Espectros PIXE (esquerda) e EDXRF (direita) do cobre coberto com a pátina S2 (chapa). Para o espectro PIXE: a) Interno; b) Externo. Para o espectro ED-XRF: a)45-edxrf; b)0-edxrf.

Figura 5.7 - Espectros PIXE (esquerda) e EDXRF (direita) do cobre coberto com a pátina S4 (pastilha). Para o espectro PIXE: a) Interno; b) Externo; c) Externo, 16 meses antes. Para o espectro ED-XRF: a) 45-edxrf; b) 0-edxrf.

Figura 5.8 - Espectros PIXE (esquerda) e EDXRF (direita) do bronze coberto com a pátina S1 (pastilha). Para o espectro PIXE: a) Interno; b) Externo; c) Externo, 16 meses antes. Para o espectro ED-XRF: a) 45-edxrf; b) 0-edxrf. 65

Figura 5.9 - Comparação dos valores relativos de cloro e enxofre contido nas pátinas sobre cobre. Para o PIXE, os valores representam o cálculo de concentração obtido pelo programa CLARA.Para o ED-XRF, eles representam a razão da área do pico de $\mathrm{Cl} / \mathrm{Cu}$ e $\mathrm{S} / \mathrm{Cu}$, multiplicados por 10000. 


\section{Lista de Tabelas}

Tabela 4.1 - Solução de preparação das camadas de pátinas e o modo de aplicação

Tabela 4.2 - Datas de produção e das analises realizadas nas pátinas artificiais e a relação das respectivas análises.

Tabela 5.1 - Medidas das espessuras das camadas e da composição, por MEV e XRD, para S1 e S2 sobre cobre e bronze (HERNÁNDEZ, 2004).

Tabela 5.2 - Simulação do coeficiente de atenuação de massa para o raios $X$ para uma amostra, sendo a camada 1: $\mathrm{Cu}_{2}\left(\mathrm{NO}_{3}\right)(\mathrm{OH})_{3}$; a camada 2: $\mathrm{CuCl}+\mathrm{Cu}_{2} \mathrm{O}+$ $\mathrm{Cu}_{2} \mathrm{Cl}(\mathrm{OH})_{3}$; e a camada 3 : bronze. Os resultados foram gerados no programa e base de dados XCOM 1.2 (BERGER et al. 1998)....

Tabela 5.3 - Resultado do cálculo de transmissão de um feixe de raio $X$ passando inicialmente pela camada 1, e posteriormente pela camada 2 e bronze, respectivamente, para uma configuração estabelecida abaixo e também na Tabela 5.2.

Tabela 5.4 - Resultado da concentração em massa obtido para o metal Certificado JK-49, pela técnica PIXE, a partir dos dados adquiridos em três períodos.

Tabela 5.5 - Resultado da concentração em massa obtido para o metal Certificado CRM 298-1, pela técnica PIXE, a partir dos dados adquiridos em três períodos.

Tabela 5.6 - Resultado da concentração em massa obtido para a pastilha de cobre comercial descoberta, pela técnica PIXE, a partir dos dados adquiridos em três períodos.

Tabela 5.7 - Resultado da concentração em massa obtido para uma pastilha de cobre + S4, pela técnica PIXE, a partir dos dados adquiridos em três períodos.

Tabela 5.8 - Resultado da concentração em massa obtido para a pastilha de bronze comercial descoberta, pela técnica PIXE, a partir dos dados adquiridos em três períodos. 70

Tabela 5.9 - Resultado da concentração em massa obtido para uma pastilha de bronze + S1, pela técnica PIXE, a partir dos dados adquiridos em três períodos.

Tabela 5.10 - Resultado da concentração em massa obtido para uma chapa de cobre comercial, pela técnica PIXE, a partir dos dados adquiridos em dois períodos. 
Tabela 5.11 - Resultado da concentração em massa obtido para uma chapa de cobre + S1 (com apenas um dia de aplicação da substância S1), pela técnica PIXE, a partir dos dados adquiridos em dois períodos.

Tabela 5.12 - Resultado da concentração em massa obtido para uma chapa de cobre + S1, pela técnica PIXE, a partir dos dados adquiridos em dois períodos.

Tabela 5.13 - Resultado da concentração em massa obtido para uma chapa de cobre + S2 (com apenas um dia de aplicação da substância S2), pela técnica PIXE, a partir dos dados adquiridos em dois períodos. 73

Tabela 5.14 - Resultado da concentração em massa obtido para uma chapa de cobre + S2, pela técnica PIXE, a partir dos dados adquiridos em dois períodos. 73

Tabela 5.15 - Concentrações em massa (\%) dos elementos presentes no bronze comercial sem pátina, obtidas pelas técnicas PIXE e ED-XRF 


\section{Capítulo 1 \\ Introdução}

A história da humanidade nos é revelada através dos estudos de indícios deixados em outras épocas, que resistiram ao tempo, e assim, nos permitindo vislumbrar uma parte do passado. Respeitando a importância deste acervo de indícios, criou-se o conceito de patrimônio cultural.

A Conferência Geral da Organização das Nações Unidas para a Educação, Ciência e Cultura (UNESCO), reunida em Paris de 1972, definiu patrimônio cultural como:

Os monumentos - Obras arquitetônicas, de escultura ou de pintura monumentais, elementos de estruturas de caráter arqueológico, inscrições, grutas e grupos de elementos com valor universal excepcional do ponto de vista da história, da arte ou da ciência;

Os conjuntos - Grupos de construções isoladas ou reunidas que, em virtude da sua arquitetura, unidade ou integração na paisagem têm valor universal excepcional do ponto de vista da história, da arte ou da ciência;

Os locais de interesse - Obras do homem, ou obras conjugadas do homem e da natureza, e as zonas, incluindo os locais de interesse arqueológico, com um valor universal excepcional do ponto de vista histórico, estético, etnológico ou antropológico.

Mas o conceito de patrimônios cultural também pode ser aplicado para objetos de menores dimensões, como ferramentas, adornos, cerâmicas, representações artísticas, etc.

Mesmo antes de 1972, a Commissione Franceschini, uma comissão de inquérito para a tutela e valorização do patrimônio histórico, arqueológico, artístico e 
paisagístico, da Itália, que se desfez em 1966, conceituou "patrimônio cultural" como sendo "tudo o que constitui uma prova material que tem o valor da civilização" (PaBAAC).

Pelo respeito e zelo ao patrimônio cultural, deve sempre haver uma busca por melhores técnicas para a conservação, a restauração e a compreensão desses bens culturais.

Para o exame, caracterização, e análise de artefatos ou objetos de arte do patrimônio cultural, a ciência da conservação necessita de um acervo de técnicas não destrutivas e não invasivas a fim de promover a compreensão de sua manufatura, e sua evolução e/ou degradação através do tempo. Esse entendimento é necessário para dar uma base e ampliar o repertório da ciência da restauração e conservação.

O primeiro museu laboratório com o objetivo de estudar problemas dirigidos à conservação do patrimônio cultural foi estabelecido em 1888 por Friedrich Rathgen, quando ele exerceu a chefia de uma nova instituição cientifica, o Laboratório de Química do Museu Real de Berlim. Este laboratório foi criado com o propósito de contribuir na compreensão da deterioração dos objetos da coleção e no desenvolvimento de tratamentos que parassem tais fenômenos (BOUTAINE, 2006).

Tais técnicas, nos dias atuais, possibilitam ainda ampliar a capacidade de investigação sobre os bens do patrimônio cultural, pesquisando técnicas de manufatura e estilo, determinando as matérias primas utilizadas e os processos criativos, determinando a datação e contextualização, realizando o mapeamento de origem, e observando se há intervenções anteriores, e como foram feitas.

Dentre o vasto conjunto de objetos que compõe o patrimônio cultural, 0 acervo de peças metálicas contribuiu muito para a história da humanidade e das civilizações, a partir do descobrimento do cobre. Este metal, por suas diversas características, foi amplamente utilizado pelos povos na história, podendo encontrálo em ferramentas, utensílios, adornos, obras de arte, monumentos, obras arquitetônicas, etc. 
No início de sua utilização, os metais eram usados como encontrados na natureza, na sua forma natural, sendo trabalhados e moldados de acordo com suas finalidades. Com o passar do tempo ocorreu a utilização das ligas metálicas, devido à observação de que certos metais com acréscimo de outros metais e/ou "impurezas" (e metais de algumas minas específicas), possuíam propriedades diferentes, que facilitavam o seu manuseio, por exemplo. Um posterior desenvolvimento da metalurgia e da obtenção dos metais a partir de seus minérios trouxe uma série de benefícios e de novas possibilidades técnicas e de produção.

Artefatos arqueológicos de cobres e suas ligas, como o bronze, podem ser encontrados por todo o mundo e todos estão expostos a algum tipo de atmosfera, seja esta a do interior de um museu, ou ao do ambiente externo. Desta forma, estas peças metálicas estão suscetíveis a processos de corrosão. Esta camada, do produto de corrosão, que se forma sobre o cobre, e suas ligas, é denominada de pátina.

Logo, o estudo dos processos de corrosão, os fatores que contribuem para o seu desenvolvimento, a caracterização das pátinas formadas, a constituição das ligas metálicas da matriz sob a pátina, são informações importantes para determinar que tipo de ações deve-se tomar para a conservação de uma peça metálica, pois a pátina pode estar protegendo ou deteriorando a matriz metálica.

Este estudo também pode favorecer dados sobre a cultura das civilizações, sua metalurgia, pela composição da liga, suas fontes de minério, pela observação dos elementos traço na liga, assim como questões econômicas, como a quantidade de metais nobres na liga, ou questões de autenticidade.

A produção de pátina de forma artificial é um artifício artístico antigo, pois tem a propriedade de atribuir cores aos metais, o que pode trazer informações sobre uma civilização. Mas as pátinas artificiais também podem ser utilizadas, assim como no presente estudo, como simulação de pátinas naturais, pois possuem um tempo de produção muito inferior, e são produzidas em condições controladas, o que favorece a análise posterior. Algumas pátinas podem proteger a matriz metálica do meio externo, e desta forma, há a possibilidade da aplicação de pátinas artificiais sobre monumentos metálicos expostos ao intemperismo, com a finalidade de 
protegê-los. A pátina artificial também pode ser aplicada em regiões onde as pátinas naturais originais foram arrancadas, ou perdidas, e deste modo ser usada para restabelecer o padrão artístico anterior.

Dentre as muitas técnicas não destrutivas e não invasivas conhecidas, que são utilizadas para analisar, caracterizar e estudar as pátinas, inexiste uma única técnica que nos forneça um quadro completo com todas as informações contidas em uma amostra. Cada uma das técnicas pode nos fornecer um conjunto de informações especificas e um tipo de interpretação, que pode contribuir no estudo, o que torna mais amplo e completo este "leque" de informações.

Baseando-se nos estudos anteriores de Hernández (2004, 2009), que caracterizaram pátinas artificiais sobre cobre e bronze, utilizando técnicas microdestrutivas, como a espectroscopia por impedância eletroquímica (Electrochemical Impedance Spectroscopy, EIS), a microscopia eletrônica de varredura (MEV; Scanning Electron Microscopy, SEM), e a difração de raio X (X-ray Diffraction, XRD). O presente trabalho propôs o estudo destas mesmas pátinas, mas com a utilização de duas outras técnicas não destrutivas, a analise por emissão de raio $X$ induzido por partículas (Particle Induced X-ray Emission, PIXE), e a análise por fluorescência de raio $X$ por dispersão de energia (Energy Dispersive $X$-ray Fluorescence, ED$\mathrm{XRF})$.

As técnicas PIXE e ED-XRF são amplamente utilizadas nas mais diversas áreas do conhecimento, por serem capazes de determinar a composição elementar de uma amostra, observando simultaneamente quase todos os elementos da tabela periódica. Estas técnicas podem ser utilizadas nas análises biológicas, geológicas, arqueológicas, de materiais, etc. Além disso, estas técnicas podem ser utilizadas em ambiente atmosférico, com uso de feixes externos, como discutido no Capítulo 4, possibilitando medir amostras de diferentes tamanhos e formas, sem que haja a necessidade da retirada de uma pequena amostra, ou uma fração desta para ser levada a uma câmara de vácuo. O arranjo experimental da técnica ED-XRF é mais frequentemente montado em uma configuração portátil, o que possibilita medidas in situ. 
Assim, o presente trabalho tem como objetivo estudar e caracterizar pátinas artificiais com as técnicas não destrutivas PIXE e ED-XRF com a finalidade de gerar um conhecimento técnico e científico para ser aplicado posteriormente em estudos de pátinas naturais e artificiais, e suas ligas, em peças metálicas pertencentes ao patrimônio cultural. 


\section{Capítulo 2 \\ Revisão Bibliográfica}

Dentre o vasto estudo sobre a história da humanidade, há uma linha que se debruça sobre os artefatos arqueológicos encontrados em diversos sítios, pois estes podem nos revelar muitas informações sobre os povos antigos. Os primeiros artefatos de metais utilizados pelo homem eram feitos de cobre. Descoberto há pelo menos dez mil anos atrás, no oriente médio, era utilizado como encontrado em sua forma natural. Objetos de cobre tiveram seu início de produção realmente só após o quarto milênio antes de Cristo. (TYLECOTE, 1992), quando começou a ser utilizado como um substituto para artefatos de pedra (CSA), tornando-se um grande recurso para o desenvolvimento da humanidade e para a composição da história.

Pelo cobre possuir características como a durabilidade, resistência à corrosão, maleabilidade, e fácil manejo, este metal foi amplamente utilizado na história, e vem sido muito utilizado até os dias de hoje.

Assim como o cobre, suas ligas também são muito encontradas em artefatos arqueológicos. Á partir de mil e quinhentos antes de Cristo há o predomínio de bronze latão no oriente próximo (DE RYCK; ADRIAENS; ADAMS, 2005), pois se descobriu que 0 acréscimo de pequenas porções de outros metais criava uma liga metálica que possuía propriedades superiores às do cobre puro. A mina de origem do cobre também poderia dar essa contaminação que favorecia a liga.

Historicamente, as ligas mais importantes do cobre são as que possuem adição de estanho, zinco e chumbo, sendo o bronze uma liga de cobre e estanho, e o latão uma liga de cobre e zinco, podendo o chumbo estar presente em ambas as ligas. Desde a sua descoberta, o cobre e suas ligas são vastamente utilizados, por suas diversas características e propriedades. Desta forma, artefatos, esculturas, monumentos, peças e obras de arte de grande valor histórico, cultural e patrimonial, que remontam a historia da humanidade, e possuem um enorme valor cultural e artístico, feitos de cobre ou de suas ligas, estão espalhados pelo mundo. Por isso, as 
pesquisas nas áreas da restauração e conservação de metais são tão importantes para a preservação desse enorme acervo metálico de bens culturais.

Mas qualquer metal exposto a ação climática está sujeito a sofrer um processo de corrosão, responsável pela maior parcela da deterioração de peças metálicas (NAIXIN et al., 2002; WEIL, 2007).

Dentre os diversos metais e ligas existentes, este presente estudo se debruçou sobre os processos de corrosão em peças de cobre e suas ligas. Quando a superfície do cobre, ou da liga de cobre, desenvolvem uma camada de produto de corrosão, esta é normalmente denominada de pátina, cuja composição e coloração são altamente dependentes do tempo de exposição, da umidade e dos compostos (ou poluentes) presentes no ambiente (HUGHES; ROWE, 1991).

A primeira referência escrita a pátina (ou patena) proveio de Filippo Baldinucci como um termo usado por pintores que se refere a um tom escuro geral que com o tempo aparece em pinturas (BALDINUCCI, 1681). A mudança de sentido e referência da palavra para referir a pátina com um produto de corrosão verde em escultura de bronze e artefatos parece ter chegado com a adaptação francesa do italiano, quando é definida, na Encyclopédie francesa de 1751, como um termo emprestado do italiano e que descreve a "bela e brilhante cor do verdete que o cobre nem sempre assume" (LAGO; MIRANDA; SATHLER,2003).

A constituição química das pátinas de cobre é bem conhecida, e está relacionada como os elementos presentes na atmosfera, como pode ser verificado no trabalho de Leygraf e Graedel (2000).

Muitos trabalhos foram feitos com o objetivo de esclarecer os fenômenos de corrosão que ocorrem em diferentes meios corrosivos e desenvolver saberes para a prevenção de processos de corrosão em patrimônios culturais (GRAEDEL; NASSAU; FRANEY, 1987; PAPARAZZO; MORETTO, 1999; SQUARCIALUPI et al., 2002; INGO et al., 2006). Também houve estudos de comparação entre a corrosão do bronze e a corrosão do cobre e do estanho puros. Apesar de ter menor potencial de corrosão e estar presente em quantidade significativamente menor do que o cobre, o estanho se mostrou altamente influente no comportamento de corrosão de 
bronze. Foi relatado que o aumento do teor de estanho influencia beneficamente as propriedades protetoras da camada superficial de bronze (KRÄTSCHMER; WALLINDER; LEYGRAF, 2002; FITZGERALD et al., 2006).

Os mecanismos de corrosão e formação de pátinas naturais formadas sobre artefatos arqueológicos de bronze têm sido estudados em vários casos (ROBBIOLA; BLENGINO; FIAUD, 1998; SOUISSI et al., 2003; SERGHINI-IDRISSI et al., 2005; MURESAN et al., 2007). Dois tipos de estruturas foram encontrados por Robbiola, Blengino e Fiaud (1998) no caso da corrosão dos artefatos enterrados. Uma estrutura denominada "superfície única" ou camadas "passiva" (Tipo I), que ocorrem principalmente em condições de corrosão de baixa agressividade, formada através da oxidação do estanho, acompanhadas de dissolução seletiva do cobre, onde são formadas camadas relativamente finas (alguns micrômetros) de estanho enriquecido. Nestas corrosões de estrutura tipo I há presença de elementos do solo, principalmente $\mathrm{O}, \mathrm{Si}, \mathrm{P}, \mathrm{Al}, \mathrm{Fe}$ e $\mathrm{Cl}$ gerando óxidos ou hidróxidos. O outro tipo de camada foi denominado como estrutura "grosseira" (Tipo II), que foi atribuída às condições de corrosão da alta agressividade, muitas vezes na presença de ânions de cloro, resultando na formação de uma estrutura de três grossas camadas, com baixa capacidade de proteção.

Estudos recentes abordam a corrosão atmosférica de bronze nos seguintes formas: através da análise das camadas de produtos de corrosão nas esculturas expostas às condições atmosféricas de um longo período de tempo (CICILEO; CRESPO; ROSALES, 2004; CHIAVARI et al., 2007; ROBBIOLA et al., 2008), através da polarização anódica, a fim de acelerar o processo de corrosão (SIDOT et al., 2006; MABILLE et al., 2003), e através de testes de simulação do cair da chuva (BERNARDI et al., 2009). O ânion de sulfato foi relatado como uma das principais causas de corrosão do bronze no solo e em camada de água formada na superfície devido à chuva ou à umidade atmosférica. A corrosão de bronze nos meios de sulfato foi estudada em alguns casos (MABILLE et al., 2003; SOUISSI et al., 2003; SIDOT et al., 2006). Nestes estudos os processos de corrosão em ligas de bronze foram simulados por imersão em solução aquosa de sulfato e pela posterior aplicação da polarização anódica, a fim de acelerar o processo de corrosão. A análise da camada do produto de corrosão mostrou que uma camada de estanho 
enriquecido havia sido formada na superfície (MABILLE et al., 2003; SIDOT et al., 2006), e que a corrosão do bronze na solução de sulfato se desenvolveu através do mecanismo do Tipo I.

Cada ambiente possui características atmosféricas específicas, e por isso, muitos trabalhos foram feitos para caracterizar as corrosões consequentes destes ambientes, como é o caso do estudo de Hernández (2009) e Hernández et al. (2010), que caracteriza as pátinas de cobre formadas por águas de chuva sintéticas de São Paulo e Rio de Janeiro.

A caracterização das pátinas, para se determinar os processos de corrosão presentes, pode ser realiza por inúmeras técnicas. Dentre estas técnicas, existem as de caráter destrutivo, quando se destrói totalmente, ou parcialmente, a amostra para se realizar a análise. Existem também as técnicas micro-destrutivas, que preservam a amostra após a realização da análise, mas que necessitam da retirada de uma amostra do objeto a ser analisado, dependendo de suas dimensões e características.

As técnicas mais utilizadas em análise de pátinas são: a espectroscopia por impedância eletroquímica (Electrochemical Impedance Spectroscopy, EIS) (XUEYUAN ZHANG et al., 2002); a microscopia eletrônica de varredura (MEV, Scanning Electron Microscopy, SEM), que muitas vezes tem associada à análise a espectroscopia por dispersão de energia (Energy Dispersive Spectroscopy, EDS) (DE RYCK; ADRIAENS; ADAMS, 2005); a difração por raio $X$ (X-ray Diffraction, XRD) (NASSAU; MILLER; GRAEDEL, 1987; STRANDBERG, 1998a; STRANDBERG, 1998b; LAGO; MIRANDA; SATHLER, 2003); e a espectroscopia de fotoelétron de raio X (X-Ray Photoelectron Spectroscopy, XPS) (DACCÀ et al., 2000). Estas são as técnicas que nos fornecem análises mais completa da caracterização dos processos eletroquímicos da corrosão que formam as pátinas em metais, no entanto há necessidade de analisar uma amostra e nunca o objeto como um todo.

Outras técnicas que necessitam da retirada de uma pequena amostra da peça original, mas preservam a amostra, são a analise da emissão de raios gama induzidos por partículas (Particle Induced Gamma-ray Emission, PIGE), a 
espectroscopia por elétron Auger (Auger Electron Spectroscopy, AES), e a espectroscopia por retroespalhamento Rutherford (Rutherford Backscattering Spectroscopy, RBS) presentes no estudo de Climent-Font et al. (1998) sobre peças de bronze arqueológicas encontradas na península ibérica. Ainda temos as análises por reações nucleares (Nuclear Reaction Analysis, NRA), como no trabalho de Kalliabakos et al. (2000) que estuda o perfil S e Cu nas camadas de pátinas, além de análises por ativação neurônica (Neutron Activation Analysis, NAA), que se utiliza reatores nucleares (FIKRLE; FRÁNA; DROBERJAR, 2006). Mas como estamos interessados em análises de materiais de patrimônio histórico e cultural, estes tipos de técnicas invasivas muitas vezes não são possíveis ou desejáveis. Por isso, há sempre uma busca por técnicas não destrutivas, que mesmo após a análise das peças em questão, estas mantenham sua constituição original.

Existem técnicas que são não destrutivas no amplo senso e não há necessidade da retirada de nenhum fragmento da amostra, pois utilizam arranjos externos, em atmosfera. Estas análises utilizam feixes de partículas ou feixes de raio $X$, onde há a detecção dos raios $X$ característicos da amostra, como é o caso do PIXE e do ED-XRF (ver em detalhes no Capítulo 3). O uso do arranjo de feixe externo é um fator que contribui para análise de artefatos e peças de valor histórico e cultural, pois pode ser utilizado em grandes peças, ou em peças que não podem ser submetidas à vácuo (GYODI et al., 1999; DRAN, 2002; RIZZUTTO et al., 2002; CALLIGARO; DRAN; KLEIN, 2003; RIZZUTTO et al., 2007). Estas técnicas são utilizadas há anos nos estudos de materiais com valor histórico cultural e em arqueologia (GOFFER, 1983; KATSANOS, 1986; ABRAHAM, 2004; DRAN, 2004; ADRIAENS, 2005; UDA; DEMORTIER; NAKAI, 2005; APPOLONI; PARREIRA, 2007; RIZZUTTO, 2007).

$O$ estudo arqueológico de moedas também vem utilizando muito as técnicas PIXE e ED-XRF (KALHTHRAKAS-KONTOS et al., 1996; DACCÀ et al., 2000; LINKE; SCHREINER; DEMORTIER, 2004; DENKER et al., 2004), a fim de determinar a composição das ligas utilizadas na cunhagem, e assim estudar a autenticidade, e até mesmo questões econômicas da época, como a proporção de metais nobres na liga. 
As técnicas PIXE e ED-XRF também são muito aplicadas em análises de pátinas metálicas e suas matrizes. Na maioria dos estudos, as técnicas são uma das varias técnicas utilizadas para a análise de pátinas. Respaldiza et al. (1994) utiliza a análise por transmissão de raios gama (Gamma Ray Transmission, GRT), conjuntamente com o PIXE ou ED-XRF para analisar diversos fragmentos arqueológicos de ligas de cobre encontrados na atual Espanha, datados de diversas épocas. Como também mostra o trabalho de Mathis et al. (2009), que utiliza a técnica PIXE em conjunto com outras, na caracterização de ligas de cobre e suas pátinas, sendo estas artificiais ou naturais.

O estudo de OLARIU et al. (2008) analisou uma espada encontrada na atual Romênia datada da idade do bronze. Utilizando a técnica PIXE, as análises determinaram a composição da liga metálica e da concentração de elementos traços presentes na mesma. Com isso, o estudo, a partir da comparação com outra seis espadas já analisadas, foi capaz de colocar a espada encontrada em um contexto regional, datando-a tipológica e geograficamente.

Ainda utilizando o método PIXE, Rizzutto et al. (2005) fizeram um estudo do produto de corrosão sobre estatuetas de Edans masculinos da sociedade secreta Ogboni, encontradas na Nigéria, pertencentes ao acervo do Museu de Arqueologia e Etnologia da Universidade de São Paulo (MAE-USP). A partir de um arranjo externo e utilizando um programa para a quantificação elementar em alvos grossos pela técnica PIXE (ABURAYA, 2005, 2006), determinaram a composição das ligas metálicas, que se mostram predominantemente de cobre com zinco e/ou chumbo. Alem disto determinaram quais os elementos presentes nas pátinas, fornecendo dados para que a os pesquisadores do museu identificassem os mecanismos e agentes de corrosão, auxiliando no padrão de conservação do museu.

Nestas técnicas ainda existe a possibilidade de utilizar um arranjo portátil, tanto para o ED-XRF (APPOLONI; PARREIRA, 2007; NEIVA; DRON, 2008), quanto para o PIXE (PAPPALARDO; ROMANO; GARRAFFO, 2003), o que possibilita realizar medidas in situ, abrindo uma grande perspectiva de analises de diferentes materiais em qualquer lugar onde o patrimônio histórico estiver. 


\section{Capítulo 3 \\ Fundamentação Teórica}

\subsection{Definição de Raios $X$}

Os raios $X$ são radiações eletromagnéticas na faixa de energia que vai de 0.1 $\mathrm{eV}$ até $100 \mathrm{keV}$, aproximadamente. Os raios $\mathrm{X}$ são também conhecidos como radiação Röntgen, em homenagem a Wilhelm Conrad Röntgen, o primeiro a descrever-los, (RÖNTGEN, 1895; BERTIN, 1975; BUTCHER; PONTING; CHANDLER, 1997).

Os raios $X$ são produzidos principalmente pela interação de fótons ou partículas carregadas (elétrons ou partículas carregadas mais pesadas) com a matéria.

Quando uma partícula carregada é desacelerada sobre a matéria, uma radiação contínua de raios $X$ é gerada, chamada Bremsstrahlung, ao mesmo tempo em que raios $X$ característicos quase mono-energético são emitidos pelo meio de acordo com a energia da partícula incidente e do meio em si.

Além disso, íons e fótons também podem interagir com a matéria através do efeito fotoelétrico, o que pode ser seguido pela emissão de raios $X$ característicos do meio de interação. Os raios $X$ são também espalhados e diminuídos em energia através do efeito Compton. 


\subsection{Modelo Atômico}

$\mathrm{Na}$ matéria, os raios $X$ são produzidos pela transição eletrônica entre diferentes camadas atômicas.

No modelo atômico, o átomo possui uma distribuição de elétrons em torno do núcleo, confinados em níveis específicos.

O número atômico principal $n=1,2,3, \ldots$ define a camada principal. O número quântico $l=1,2,3, \ldots(n-1)$ é dado como o momento angular do elétron. O numero quântico $j=l \pm 1 / 2$ descreve o vetor da soma de $l$ e $s$, sendo o último, o número quântico de spin intrínseco que vale $\pm 1 / 2$ (spin para cima ou spin para baixo).

O número máximo de elétrons em qualquer subcamada é dado por $2 j+1$. 0 número máximo de elétrons em qualquer camada é dado por $2 n^{2}$.

A camada eletrônica mais fortemente ligada é a que possui o número quântico principal $n=1$, e é denominada como camada $K$ na terminologia para raios X. Esta camada só pode ter apenas 2 elétrons (spin para cima e spin para baixo).

A próxima camada eletrônica mais fortemente ligada é a $n=2$, ou camada $L$, com o número máximo de 8 elétrons, que é composta por três subcamadas: $L_{I}$ ( $n=2, l=0, j=1 / 2)$, com o máximo de 2 elétrons, $L_{I I}(n=2, l=1, j=1 / 2)$, com o máximo de 2 elétrons, e $L_{I I I}(n=2, l=1, j=3 / 2)$, com o máximo de 4 elétrons.

Na camada seguinte temos $n=3$, ou camada $M$, com o máximo de 18 elétrons, com as subcamadas $M_{I}$ (2 elétrons), $M_{I I}$ (2 elétrons), $M_{I I I}$ (4 elétrons), $M_{I V}$ (4 elétrons) e $M_{V}$ (6 elétrons). E assim sucessivamente para as próximas camadas como $n=4$, ou camada $N$, a camada $n=5$, ou camada $O$, conforme exemplificado na Figura 3.1.

Os raios $X$ são produzidos devido às transições de elétrons de uma camada para outra. Quando há uma vacância em uma camada de maior energia de ligação, 
ou de menor número quântico principal, esta pode ser ocupada por um elétron de uma camada de maior nível energético. Como consequência dessa mudança de níveis, um fóton, com energia igual à diferença dos níveis eletrônicos, pode ser emitido pelo átomo. As transições eletrônicas mais importantes para o estudo em questão, que correspondem às séries $K, L$ e $M$ de raios $\mathrm{X}$, são mostradas na Figura 3.1.

Todas as séries de transições $K\left(K_{\alpha 1}, K_{\alpha 2}, K_{\beta 1}, \ldots\right)$ correspondem aos preenchimentos de vacâncias na camada $K$, o mesmo se aplica as demais séries. Mas estas transições só são permitidas para $\Delta l \neq 0$ e $\Delta j=0, \pm 1$.

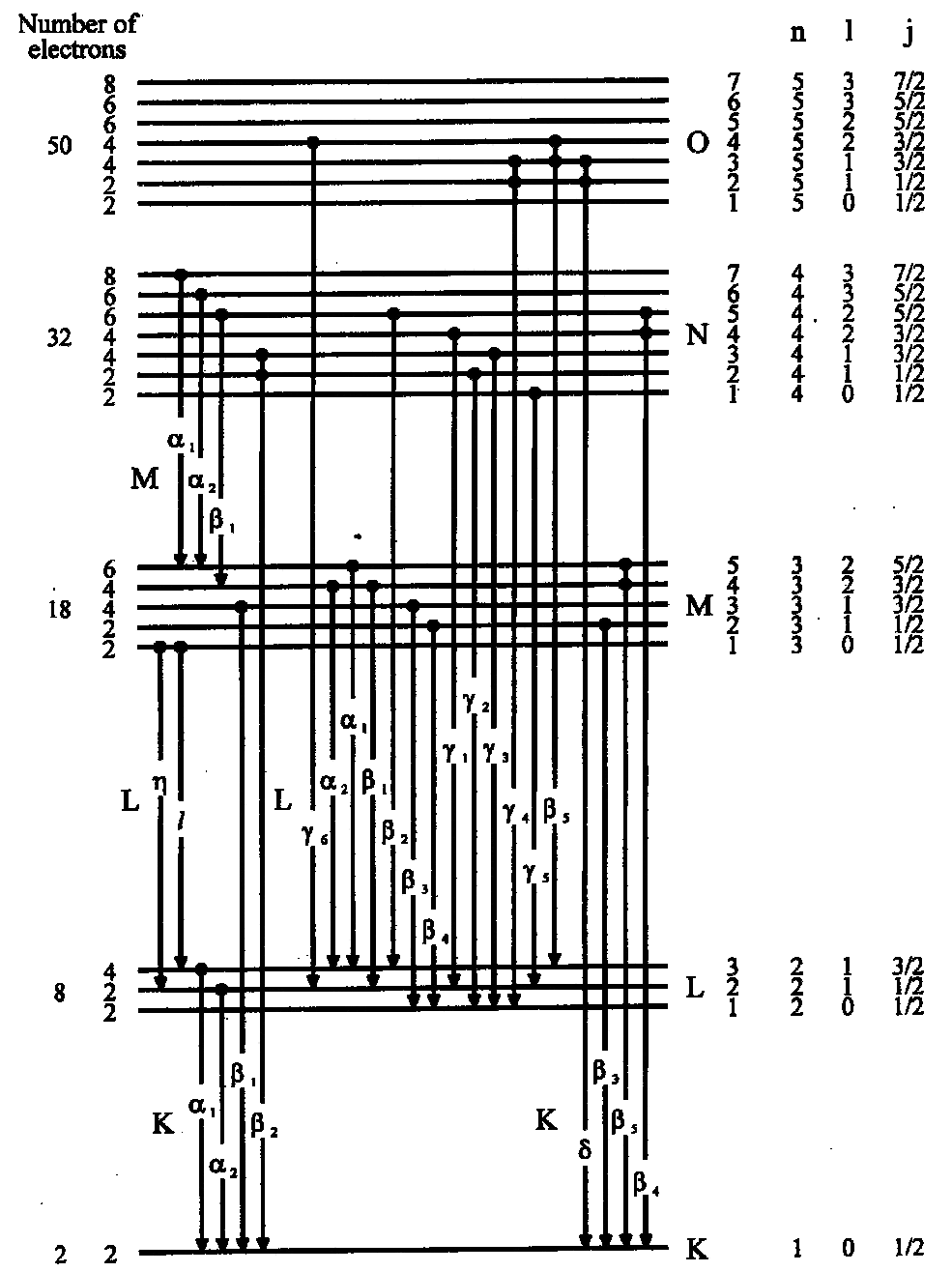

Figura 3.1 - Diagrama energético e as transições de raio $X$ mais importantes com os respectivos números máximos de elétrons em cada camada, e os números quânticos $n, l$ e $j$ para cada camada e subcamada (CESAREO, 2000). 
Uma vez que uma vacância na camada $K$ é criada, ou em qualquer outra camada, o átomo está em estado de excitação. A transição atômica não pode ocorrer, a menos que camadas superiores estejam ocupadas. Por isso, o $\mathrm{H} \mathrm{e} \circ \mathrm{He}$ não possuem raios $\mathrm{X}$, pois suas camadas $L$ não estão ocupadas. Logo, para todos os elementos que possuam número atômico igual ou maior a $Z=3$ (Li) um $K_{\alpha}$ pode ser observado. Sendo $K_{\alpha}$ transições das camadas $L$ para a camada $K$. Os $K_{\beta}$ correspondem a transições eletrônicas das camadas $M\left(K_{\beta 1}, K_{\beta 3}, K_{\beta 5}\right)$ ou $N$ $\left(K_{\beta 2}, K_{\beta 4}\right)$ para a camada $K$, nenhum raio $\mathrm{X} K_{\beta}$ será emitido antes que $Z$ seja igual ou maior que $11(\mathrm{Na})$.

A série $L$ de raios $X$ corresponde ao preenchimento de uma vacância de uma subcamada $L$, no qual raios $X L_{\alpha 1}$ e $L_{\alpha 2}$ correspondem à transição de um elétron de uma subcamada $M_{V}$ e $M_{I V}$, respectivamente, para a subcamada $L_{I I I}$, ao passo que as linhas $L_{\beta 1}$ e $L_{\beta 2}$ correspondem à transição da subcamada $M_{I V}$ e $N_{V}$ para uma vacância em $L_{I I}$ e $L_{I I I}$, respectivamente.

Na prática, as linhas das séries $K$ e $L$ são as mais utilizadas para auxiliar na caracterização do átomo, por serem a maior mudança de energia que o elétron pode se submeter. Por esta razão, os valores energéticos e as razões de intensidades dos raios $X K$ e $L$ são parâmetros mais utilizados tanto em análises qualitativas, quanto quantitativa. Apenas em aplicações especiais os raios $X M$ são utilizados. Os valores energéticos das linhas $K$ e $L$ tabelados para vários elementos podem ser vistas no Anexo A.

Cada elemento possui um conjunto de camadas eletrônicas orbitais características, isso se deve ao seu número atômico e às interações dos elétrons entre si, que cria uma eletrosfera única, no qual as distâncias energéticas entre as camadas são específicas para cada átomo. Deste modo, a radiação eletromagnética consequente do decaimento entre tais camadas é característica de um átomo.

$\mathrm{O}$ valor da energia do raio $\mathrm{X}$ característico emitido está relacionado com o número atômico, $Z_{a}$, do material pela lei de Moseley: 
(Eq. 1)

$$
E_{i}=C_{i}(Z-s)^{2}
$$

onde $C$ é uma constante diferente para cada serie espectral e $s$ é uma constante de blindagem, próxima de 1. Logo, os valores energéticos das linhas $K_{\alpha}$ podem ser calculados por:

$$
E_{K \alpha}=10.212(Z-1)^{2} e V
$$

Os valores experimentais se ajustam bem aos valores teóricos para números atômicos baixos ou médios. Se usarmos os valores $Z=10,20,30,40$ e 50, pela Equação 2 teremos os valores 0,$83 ; 3,69 ; 8,6 ; 15,5 ; 24,5 \mathrm{keV}$, enquanto os valores experimentais vistos no Anexo A são 0,83; 3,69; 8,6; 15,7; 25,2 keV. Mostrando deste modo o bom acordo na determinação das energias para $Z$ baixos.

\subsection{Interação do raio $X$ com a matéria}

Quando o raio $X$ interage com a matéria há três modos primários de interação: o efeito fotoelétrico, o espalhamento Compton e espalhamento coerente.

O efeito fotoelétrico é a interação mais freqüente na faixa de energia de raio $X$, sendo cerca de $80 \%$ das interações para elemento com $Z$ maiores que 40 . Nesta mesma faixa de energia, o efeito coerente (efeito Compton) é cerca de 5 a $10 \%$ das interações (CESAREO, 2000), onde sua contribuição se torna mais importante em raios $X$ de altas energias e para elementos de baixo $Z$.

\subsubsection{Efeito Fotoelétrico}

No efeito fotoelétrico, um fóton interage com um elétron das camadas eletrônicas mais internas do átomo. O fóton é absorvido e o elétron é ejetado de sua órbita. O elétron toma como energia cinética toda a energia proveniente do fóton incidente, menos a energia de ligação entre átomo e elétron. Dessa maneira, foi criada uma vacância onde anteriormente estava o elétron. 
Pela conservação de energia temos:

(Eq. 3)

$$
E_{e}=E_{0}-\phi_{i}
$$

onde $E_{0}$ é a energia do fóton incidente, $E_{e}$ é a energia cinética do elétron ejetado, e $\phi_{i}$ é a energia de ligação do elétron da camada $i$ do átomo.

Uma expressão semi-empírica para a energia de ligação em $K$, para elementos com número atômicos não muito baixos, é dada por:

$$
\phi_{K}=13.6 Z_{i}^{2} \mathrm{eV},
$$

onde:

$$
Z_{i}=Z-2.5(\text { para } Z=10-18) ; Z_{i}=Z-3(\text { para } Z=19-70) ; \text { e } Z_{i}=Z-
$$

1.5 (para $Z=71-95)$.

Após a nova vacância ser criada, há duas possibilidades de ocorrer dois processos:

- Um elétron de uma orbita superior (na camada $L$, por exemplo) ocupa a vacância criada (no orbital $K$ ), havendo, conjuntamente, a emissão de um fóton com energia igual à energia da diferença entre os dois orbitais $\left(\phi_{K}-\phi_{L}\right)$.

- O elétron de uma camada superior ocupa um orbital mais baixo. A energia liberada no fóton retira outro elétron do orbital superior, liberando um elétron com energia cinética de $\phi_{K}-\phi_{L}-\phi_{L^{\prime}}$. Este elétron é chamado de elétron Auger.

Após o elétron ser ejetado, a radiação em fótons emitida pode ter energia na faixa do raio $X$, dependendo da diferença energética entre os orbitais da interação. Esta interação de radiação e a emissões características são apresentadas esquematicamente na Figura 3.2. 

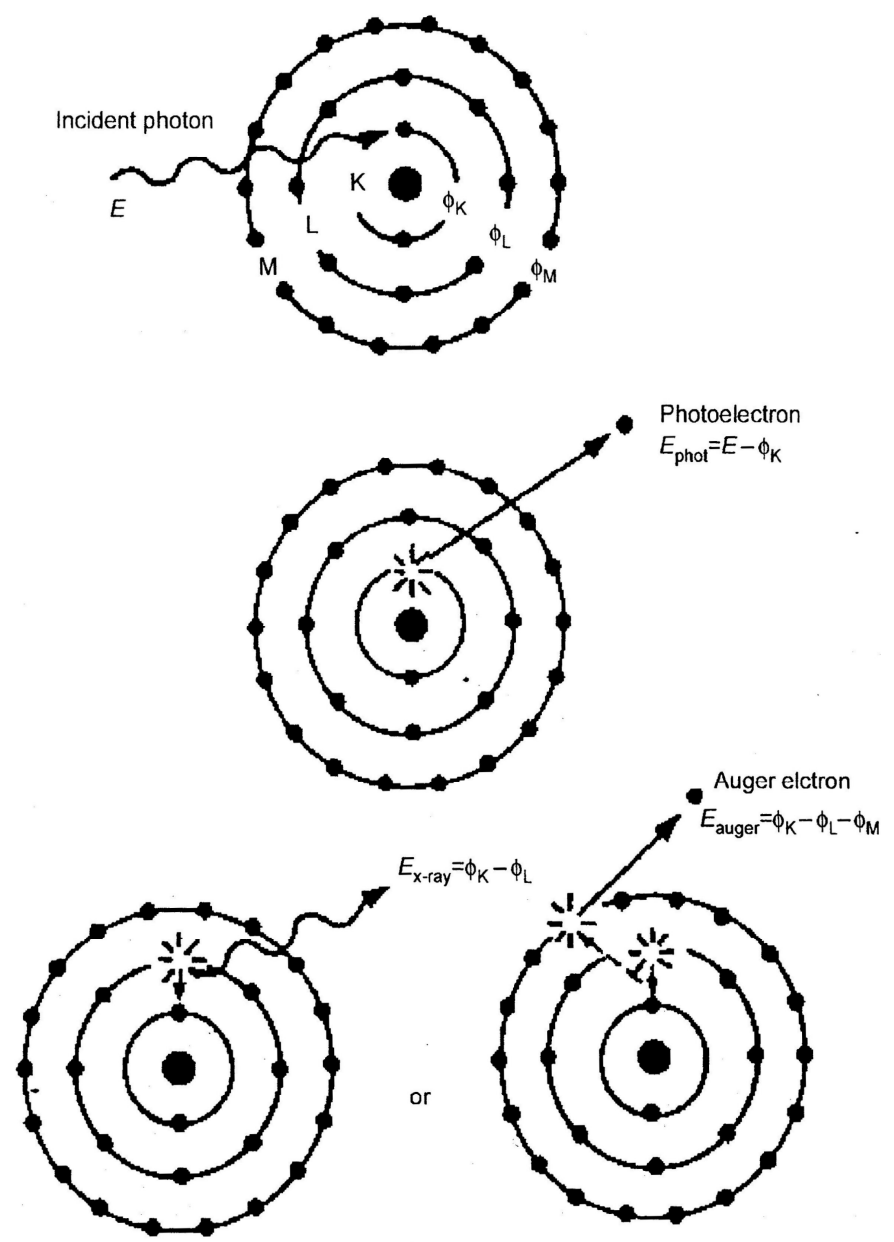

Figura 3.2 - A ionização por efeito fotoelétrico pode ser seguida tanto por uma desexcitação radiativa, com a emissão de um raio $X$ fluorescente característico, quanto por uma desexcitação não radiativa, pela emissão de um elétron Auger (JANSSENS, 2004).

\subsubsection{Efeito Compton}

Tem-se um espalhamento Compton (COMPTON, 1923) (também chamado de espalhamento incoerente) quando um fóton colide com um elétron e perde parte de sua energia e sofre uma deflexão da sua trajetória original. Neste efeito, uma condição importante é a interação se dar com um elétron fracamente ligado ao átomo.

No espalhamento Compton, um fóton com energia $E_{0}$ colide com um elétron, após a colisão, teremos o elétron com energia $E_{e}$ e um fóton com energia $E_{c}$, que forma um ângulo $\theta$ com a direção do fóton incidente. Pela conservação de energia e momento, para um elétron livre ou uma interação com energia suficiente para retirar o elétron do seu orbital, temos: 
(Eq. 5)

$$
E_{c}=\frac{E_{0}}{1+\alpha(1-\cos \theta)},
$$

onde $\alpha=E_{0}(\mathrm{keV}) / 511(\mathrm{keV})$, no qual $551 \mathrm{keV}$ é a massa de repouso do elétron. A Figura 3.3 mostra uma representação do espalhamento Compton para diferentes ângulos $\theta$.

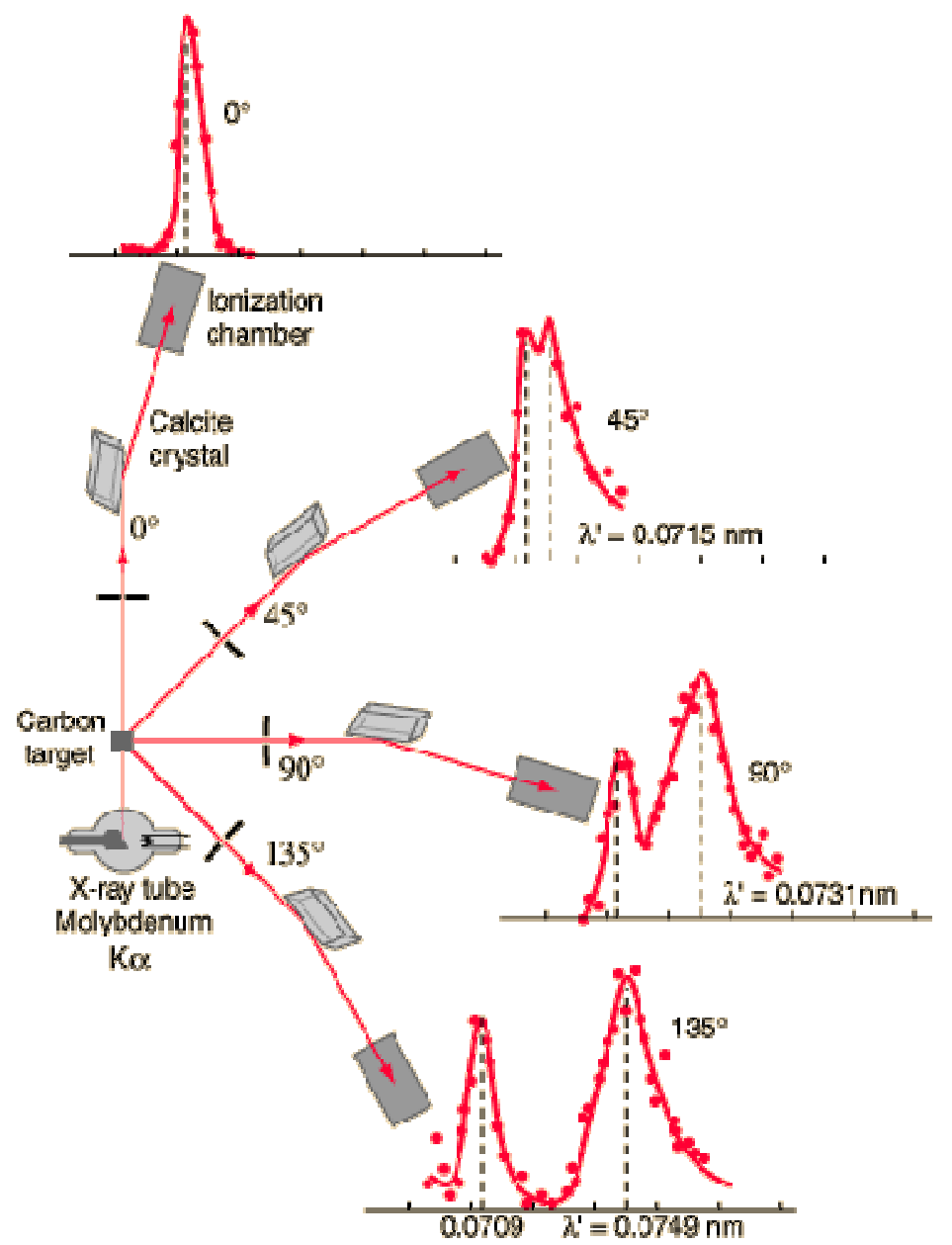

Figura 3.3 - Efeito Compton observado de espalhamento de um feixe de raio $\mathrm{X}$, proveniente de um tubo de raio $\mathrm{X}$ de Mo, sobre um alvo de carbono, e o espectro observado para diferentes ângulos de detecção do raio $\mathrm{X}$ espalhado (NAVE). 


\subsubsection{Espalhamento Coerente}

O espalhamento coerente (também chamado de Rayleigh ou elástico) é quando fótons são espalhados por elétrons ligados aos átomos e onde o átomo não se torna ionizado e nem excitado. Este processo ocorre principalmente em baixas energias e para materiais com $Z$ altos.

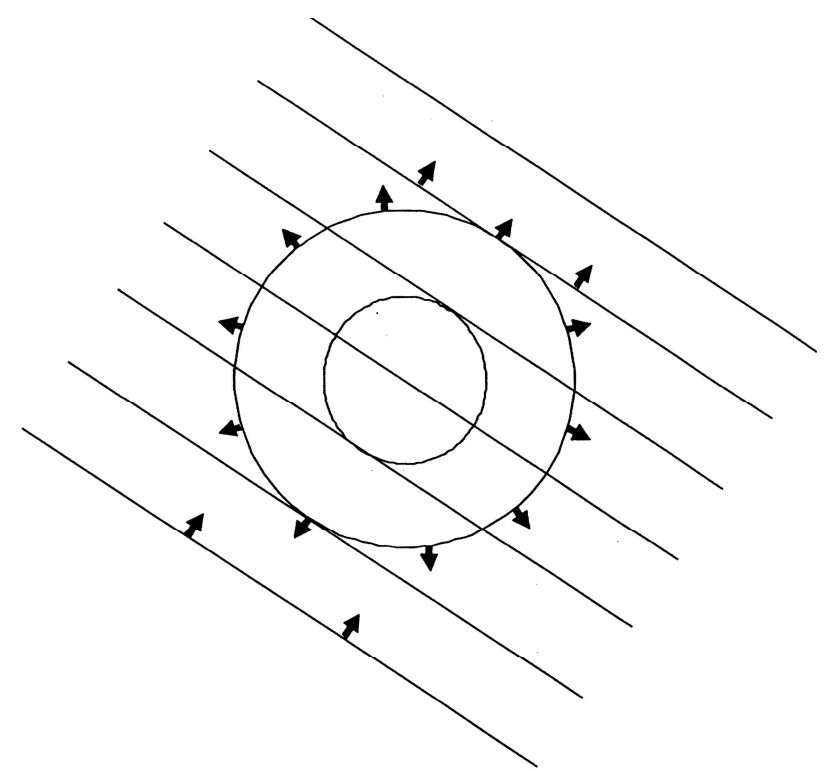

Figura 3.4 - No espalhamento elástico, quando a onda de raio X colide com o átomo, os elétrons desse átomo espalham o raio $\mathrm{X}$. A onda espalhada elasticamente é imediatamente re-emitida em todas as direções e pode ser imaginada como uma frente de onda esférica (JANSSENS, 2004).

\subsection{Interação de íons com a matéria}

Nos métodos de análise por feixes de íons (Ion Beam Analysis, IBA) a identificação dos alvos consiste em fazer medições da energia da radiação emitida pela amostra sujeita a um bombardeamento de partículas carregadas.

A compreensão da maneira pela qual um íons com energia cinética da ordem de MeV perdem energia através de materiais é essencial para o desenvolvimento de métodos de IBA. Os íons perdem sua energia durante sua passagem pela matéria por colisão com nuvens eletrônicas ou núcleos dos átomos do alvo. 
A perda de energia por unidade de comprimento de penetração no alvo, $d E / d x$, é convenientemente descrita em dois regimes, para altas e para baixas energias. No regime de altas energias, no qual $\mathrm{H}$ tem energia acima de $25 \mathrm{keV}$ e $\mathrm{He}$ acima de $100 \mathrm{keV}, \mathrm{o} d E / d x$ é proporcionalmente aproximado por $Z_{i}^{2} Z_{a} / E$, onde $Z_{i}$ e $Z_{a}$ são, respectivamente, o número atômico do íon incidente e o número atômico do elemento do alvo. Portanto, $d E / d x$ diminui quando $E$ aumenta. Por causa da dependência de $Z_{i}^{2}$, a perda de energia de íons de hélio é quatro vezes maior do que a dos prótons. No regime de baixa energia a situação é invertida, pois $d E / d x$ diminui com a energia do íon. Mas o regime de baixas energias não é importante para as técnicas de IBA, porque os sinais usualmente utilizados são provenientes do início da trajetória, quanto os íons possuem altas energias (CALLIGARO; DRAN; SALOMON, 2004).

Íns com energia de $\mathrm{MeV}$ perdem continuamente sua energia cinética nas colisões até parar em alguma profundidade do material. A taxa de perda de energia aumenta cada vez mais, atingindo o máximo perto do fim da trajetória. Para um íon com energia inicial $E_{0}$, seu alcance médio $(R)$ ao viajar pela matéria, até atingir o repouso, é definido como:

$$
R=\int_{0}^{E_{0}}\left(\frac{d E}{d x}\right)^{-1} d E
$$

Como podemos ver na Figura 3.5, para as três principais técnicas de análise com feixes de íons há princípios físicos diferentes na interação do íon com a matéria. $\mathrm{Na}$ técnica de análise pela emissão de raio $\mathrm{X}$ induzido por partícula (Particle Induced $X$-Ray Emission, PIXE) o processo tem dois passos: um elétron de uma camada mais interna de um átomo do alvo é expelido devido a interação com a partícula incidente, na sequência, há um rearranjo eletrônico acompanhado por uma emissão de raio $X$ característico. $\mathrm{Na}$ espectroscopia por retro-espalhamento Rutherford (Rutherford Backscattering Spectrometry, RBS), é observada a colisão elástica de um íon energético projetado sobre o átomo da amostra, espalhado pela força coulombiana da carga positiva do núcleo atômico da amostra. Na análise por reação nuclear (Nuclear Reaction Analysis, NRA) o projétil e o núcleo se aproximam 
suficientemente para ocorrer uma reação nuclear, havendo a emissão de fótons característicos e partículas carregadas. A técnica PIXE foi a mais utilizada nas análises e por isso será mais aprofundada na secção 3.5.2.1.

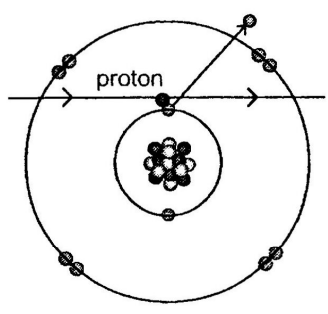

PIXE step 1

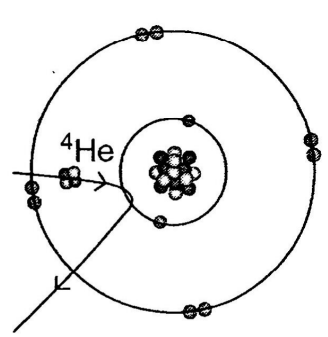

RBS

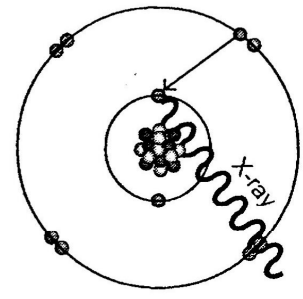

PIXE step 2

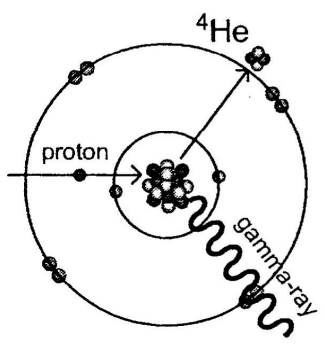

NRA

Figura 3.5 - Os princípios físicos das técnicas IBA (CALLIGARO; DRAN; SALOMON, 2004).

\subsection{Técnicas de Análise}

Como mencionado anteriormente, os raios $X$ são gerados pelo bombardeamento do alvo por meio de fótons ou partículas carregadas (elétrons, ou íons), e cada elemento emite raios $X$ com energia específica que o caracteriza. Esta radiação característica detectada é representada graficamente por um espectro de raio $\mathrm{X}$ característico. As linhas de emissão atômica do espectro de raio $\mathrm{X}$ característico são muito mais simples do que as linhas no ultravioleta (UV) e no visível. Não mais do que 600 linhas de raio $X$ são relevantes para a espectrometria de raio $X$, suficientes para a caracterização de quase todos os elementos, enquanto só o Fe possui 6000 linhas de emissão no UV (MOENS; BOHLEN; VANDENABEELE, 2000).

De modo geral, nenhuma diferenciação pode ser feita por raios $X$ para isótopos de um mesmo elemento. $A$ energia do raio $X$ emitido nos permite identificar 
o elemento presente na amostra, enquanto que a intensidade do sinal individual nos possibilita, por proporcionalidade, determinar a concentração desse elemento.

\subsubsection{Fluorescência de Raio $X$}

O processo de absorção de um fóton pela matéria para a posterior emissão pela matéria de um elétron Auger ou um fóton característico é denominado de fluorescência de raio X ( $X$-Ray Fluorescence, $\mathrm{XRF}$ ).

No presente trabalho, o nosso interesse são as linhas características dos elementos. Mas a intensidade de emissão de tais fótons característicos depende de alguns fatores como:

- Probabilidade de um fóton ionizar o átomo em uma camada mais interna.

- Probabilidade da vacância criada em tal camada ser ocupada por um elétron de uma camada superior

- Probabilidade do fóton emergente não ser absorvido pelo próprio átomo pelo efeito Auger.

A primeira condição está relacionada com a absorção do fóton pela matéria, caracterizada pelo coeficiente de absorção de massa $\mu$, que é a soma da contribuição do efeito fotoelétricos, do espalhamento Compton e da produção de pares, como pode ser visto na Figura 3.6.

Para a faixa de energia de 0 a $100 \mathrm{keV}$, o coeficiente de absorção do efeito fotoelétrico é predominante no coeficiente de absorção total. Na Figura 3.6, as descontinuidades na linha de absorção pelo efeito fotoelétrico são chamadas linhas de bordas de absorção, sendo as energias associadas às energias para que se consiga superar a energia de ligação do elétron ao átomo e promover a ionização da camada ocupada por tal elétron. 


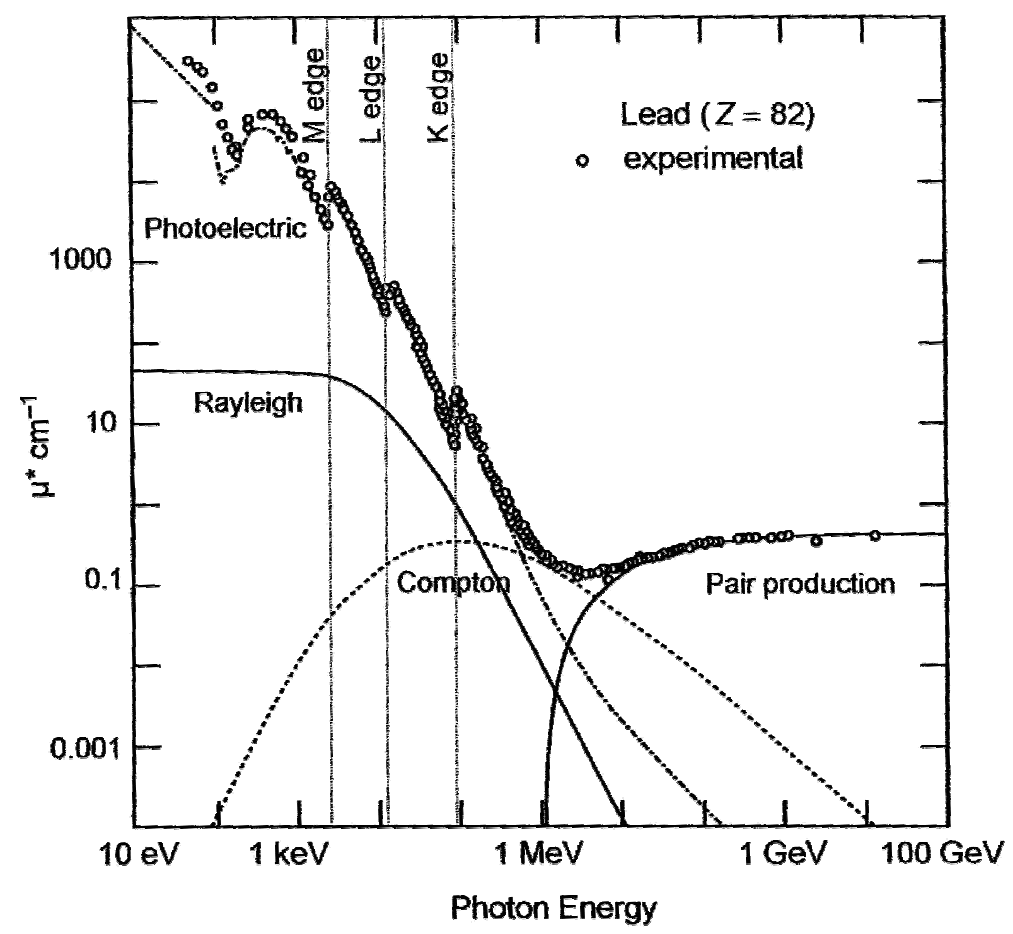

Figura 3.6 - Os diferentes modos de interação entre fótons e a matéria para um alvo de chumbo, em função da energia do fóton. Cada processo possui um domínio energético particular. $\mathrm{Na}$ faixa das baixas energias (0-100 keV), o efeito foto elétrico é dominante. No regime intermediário (100-1000 $\mathrm{keV}$ ), o espalhamento Compton é predominante. Na região das altas energias (acima de $1 \mathrm{MeV}$ ), a produção de pares tem a principal contribuição (CALLIGARO; DRAN; SALOMON, 2004).

A segunda condição, que é a probabilidade de transição, é governada pelas regras de seleção da mecânica quântica.

A terceira e última condição é a probabilidade de não ocorrer o efeito Auger, e essa probabilidade está relacionada ao rendimento de florescência $\omega_{i}$, que é a razão entre o número de raios $X$ característicos emitidos e o número total de vacâncias nas camadas mais internas, no qual a vacância ocorre, sendo $i$ a camada em questão.

Para elementos leves, onde $Z<20$, a produção de elétrons Auger é predominante, sendo $\omega_{K}<0.2$, mas para elementos médios e pesados há o predomínio da produção de raios X característico, no qual $0.2<\omega_{K}<1$. Veja a Figura 3.7, onde temos a dependência de $\omega_{K}, \omega_{L 3}, \omega_{M 5}$ em relação a $Z$. 


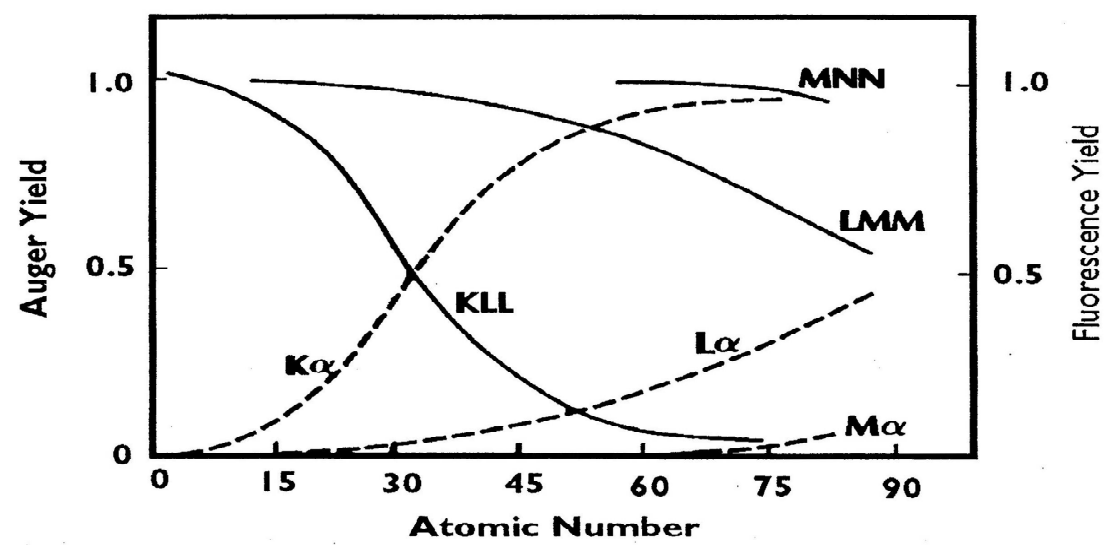

Figura 3.7 - Probabilidade relativa de emissão de fluorescência de raio X (linha tracejada) e Auger (linha contínua) (HUBIN; TERRYN, 2004).

A espectroscopia de fluorescência de raios $X$ baseia-se na emissão de raios $X$ característicos dos elementos presentes na amostra, a partir da excitação por meio de um feixe de raios $X$. Existem dois tipos de técnicas por fluorescência de raios $X$, que são conhecidas como fluorescência por dispersão de comprimento de onda (Wavelength Dispersive X-Ray Fluorescence, WD-XRF) e por dispersão de energia (Energy Dispersive X-Ray Fluorescence, ED-XRF).

\subsubsection{Fluorescência de Raio $X$ por dispersão de comprimento de onda (WD-XRF)}

Sendo uma radiação eletromagnética, o raio $\mathrm{X}$ pode ser descrito como onda ou como partícula. Pela teoria das ondas, as interferências mostradas pelo raio $\mathrm{X}$ podem ser explicadas. Um destes efeitos é o espalhamento coerente, interpretado por Bragg como um fenômeno ondulatório, ao sofrer reflexão nos planos atômicos de um cristal. Quando um feixe de raio $\mathrm{X}$ de comprimento de onda $\lambda$ incide sobre um cristal com planos de espaçamento $d$ com um ângulo em relação ao cristal, ver Figura 3.8, há uma reflexão por espalhamento apenas a situação nas condições da lei de Bragg:

$$
n \lambda=2 d \cdot \operatorname{sen} \theta
$$

onde $n$ é um número inteiro. 
Desta maneira, a reflexão de Bragg nos possibilita selecionar o raio $X$ característico, que possui um $\lambda$ especifico proveniente da amostra pela seleção do seu $\theta$ correspondente. Esta técnica é denominada espectrometria de fluorescência de raio $X$ por dispersão de comprimento de onda (Wavelength-Dispersive $X$-ray Fluorescence Spectrometry, WD-XRF).

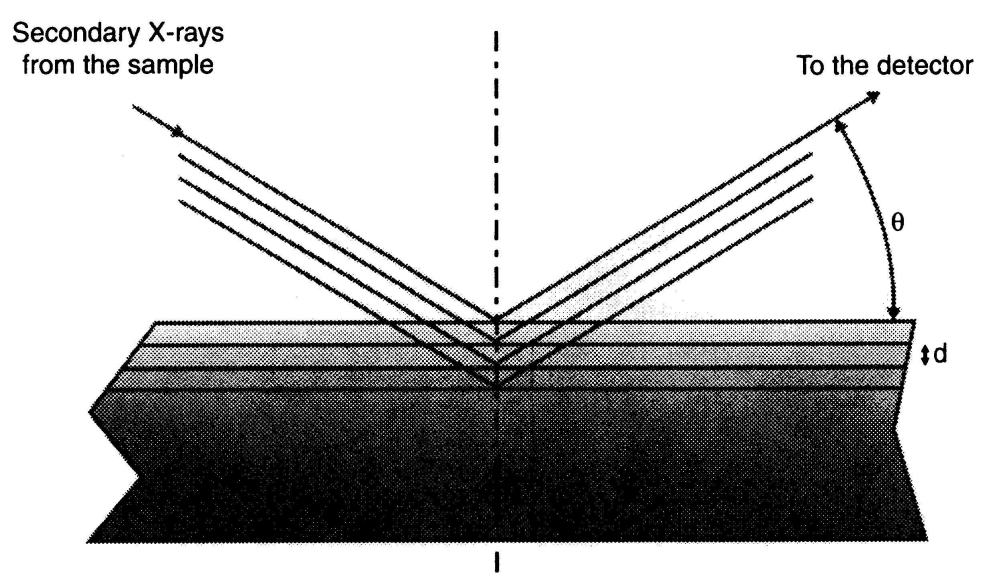

Figura 3.8 - A difração do raio $X$ por um cristal, de acordo com Bragg, sendo $\lambda$ o comprimento de onda, $\theta$ o ângulo difração de Bragg e $d$ o espaçamento inter-planar dos planos que estão difratando (MOENS; BOHLEN; VANDENABEELE, 2000).

\subsubsection{Fluorescência de Raio X por dispersão de energia (ED-XRF)}

O desenvolvimento de materiais semicondutores trouxe novas características à espectrometria de raios $\mathrm{X}$, pois através da resolução de energia dos detectores de $\mathrm{Si}$, que é suficientemente alta, pode-se realizar uma espectrometria de raio $X$ sem uma dispersão prévia em um cristal refletor de Bragg. Assim, foi desenvolvida uma técnica de espectrometria de fluorescência de raio $X$ por dispersão de energia (Energy-Dispersive $X$-ray Fluorescence Spectrometry, ED-XRF). Esta é uma técnica analítica não destrutiva, multielementar e simultânea, que permite a determinação de teores totais de elementos químicos, através da detecção das linhas de raios $X$ característicos $K$ e $L$ dos elementos que estão presentes em uma dada amostra. A técnica ED-XRF pode atingir limites de detecção da ordem de 1 a 20 ppm para amostras sólidas (sem tratamento químico) e da ordem de 1 a 20 ppb para amostras líquidas (com tratamento de pré-concentração) (NASCIMENTO FILHO, 1999). 


\subsubsection{Formulação do método de Fluorescência de Raio X por dispersão de energia (ED-XRF)}

A formulação para o método ED-XRF foi retirada do trabalho de Nascimento Filho (1999).

Para uma excitação monoenergética, admitindo uma amostra homogênea com espessura uniforme $D$ e desprezando os efeitos de reforço (enhancement), a intensidade da linha $K_{\alpha}$ de um elemento de interesse produzida numa camada $d x$ a uma profundidade $x$, como pode ser visto na Figura 3.9, é produto de três probabilidades:

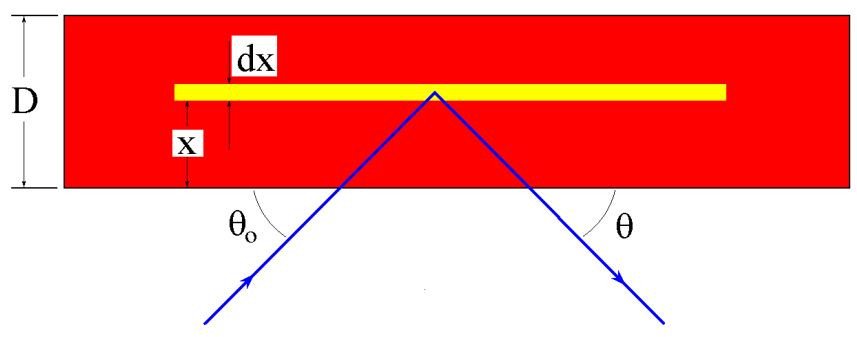

Figura 3.9 - Representação esquemática da geometria de excitação para feixe monoenergético em fluorescência de raios X (NASCIMENTO FILHO, 1999).

A probabilidade $P_{1}$ da radiação de excitação atingir a camada $d x$ a uma profundidade $x$ :

$$
P_{1}=e^{-\mu_{0} \rho_{0} x / \operatorname{sen} \theta_{0}},
$$

onde $\mu_{0}$ é coeficiente de absorção de massa da matriz na energia dos fótons incidentes, $\rho_{0}$ é a densidade da matriz e $\theta_{0}$ é o ângulo de incidência (entre a direção do feixe incidente e a superfície da amostra).

O valor de $\mu_{0}$ pode ser calculado como a somatória dos produtos dos coeficientes de absorção de massa pela fração em massa de todos os elementos presentes na amostra. A Figura 3.10 ilustra a dependência deste coeficiente em função da energia da radiação para os elemento $\mathrm{Ca}, \mathrm{Cu}$ e $\mathrm{U}$, onde pode ser notada as bordas de absorção da camada $\mathrm{K}$ para os dois primeiros elementos, e as bordas K, L (com 3 sub-níveis) e M (com 5 sub-níveis) para o U. 


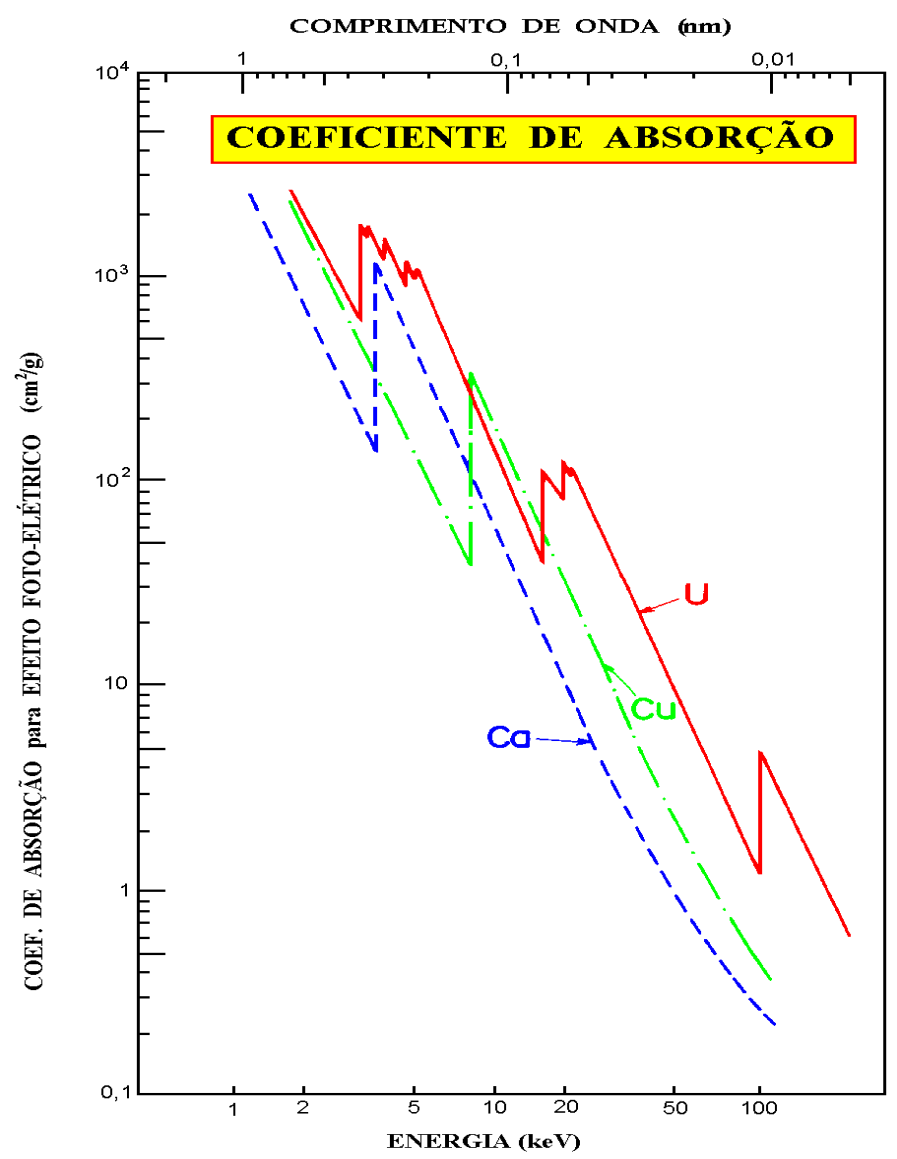

Figura 3.10 - Dependência do coeficiente de absorção de massa em função da energia, para os elementos cálcio, cobre e urânio (NASCIMENTO FILHO, 1999).

A probabilidade $P_{2}$ da radiação de excitação produzir uma vacância nos átomos de um elemento de interesse contidos na espessura $d x$, com consequente produção de raios $\mathrm{X}$ característicos, é dada por:

$$
P_{2}=\tau \cdot w \cdot\left(1-\frac{1}{j}\right) \cdot f \cdot \rho \cdot d x,
$$

onde $\tau$ é o coeficiente de absorção de massa para o efeito foto-elétrico do elemento de interesse na energia de excitação, $w$ é o rendimento de fluorescência da camada $\mathrm{K}, j$ é a razão de salto (jump ratio) da camada $\mathrm{K}$ para $\mathrm{L}, f$ é fração de fótons $\mathrm{K}$ emitidos como raios $\mathrm{X} K_{\alpha}$, característicos, e $\rho$ é a "densidade", ou concentração do elemento de interesse em base de volume na espessura $d x$.

O coeficiente de absorção para o efeito foto-elétrico exatamente na energia da borda de absorção (Figura 3.10) tem dois valores: um superior, que 
indica a probabilidade de se retirar elétrons de todas as camadas $\mathrm{K}, \mathrm{L}, \mathrm{M}$, etc., e um inferior, que indica a probabilidade de se retirar elétrons de todas as camadas, com exceção da camada K (ou seja, camadas L, M, etc.).

Desse modo, a razão entre os valores superior e inferior, denominada de razão de salto ou jump ratio (Figura 3.11) indica a probabilidade de se retirar elétrons de todas as camadas em relação à probabilidade das camadas $L, M$, etc. Por outro lado, o termo $(1-1 / j)$ representa a probabilidade de se ionizar a camada $\mathrm{K}$ em relação a todas as camadas $\mathrm{K}, \mathrm{L}, \mathrm{M}$, etc., e assim o termo $\tau \cdot(1-1 / j)$ representa o número de ionizações ocorridas na camada $K$.

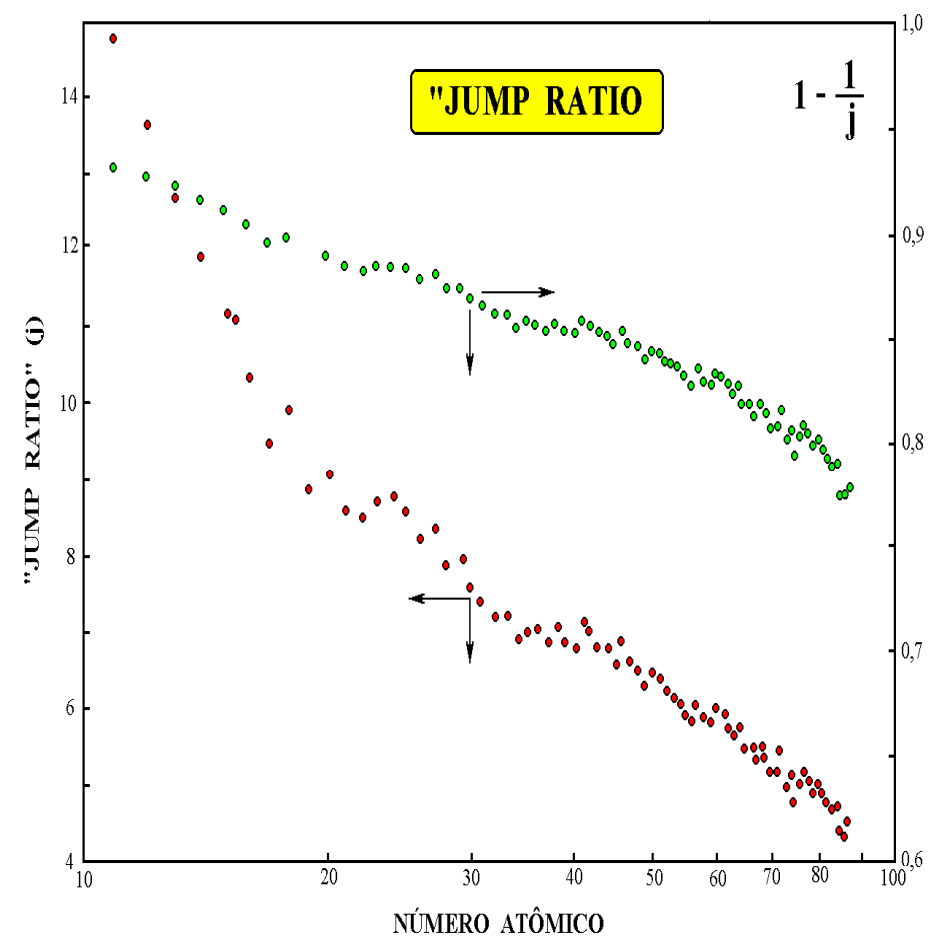

Figura 3.11 - Valores da razão de salto (jump ratio) em função do número atômico (NASCIMENTO FILHO, 1999).

Os parâmetros fundamentais $\tau, w, j$ e $f$ para um dado elemento depende unicamente da energia de excitação e podem ser agrupados em um único termo $K$, denominado de constante dos parâmetros fundamentais, e a assim a Equação 9 pode ser reescrita como:

$$
P_{2}=K \cdot \rho \cdot d x,
$$

onde: 
(Eq. 11)

$$
K=\tau \cdot w \cdot\left(1-\frac{1}{j}\right) \cdot f
$$

A probabilidade $P_{3}$ do raio $\mathrm{X} K_{\alpha}$ característico produzido na camada $d x$ não ser absorvido na espessura $x$ e atingir o detector, produzindo um pulso eletrônico (ou uma contagem), é dada por:

$$
P_{3}=\varepsilon \cdot e^{-\mu \cdot \rho_{0} \cdot x / \operatorname{sen} \theta},
$$

onde, $\mathcal{E}$ é a eficiência do detector na energia dos fótons característicos, $\mu$ é o coeficiente de absorção de massa da matriz, e $\theta$ é o ângulo de emergência.

A eficiência $\varepsilon$ do detector pode ser calculada teoricamente a partir das dimensões dos componentes do detector (camadas ativa e morta de Si, camada de ouro, janela de Be, etc.) especificados pelo fabricante, distância entre a amostra e detector, e condições de excitação (sob vácuo, ar ou gás hélio).

Assim, a intensidade fluorescente $d I$ (ou a taxa de contagem) produzida pelo elemento de interesse contido na espessura $d x$ pode então ser escrita como:

$$
d I=G \cdot e^{-\mu_{0} \cdot \rho_{0} \cdot x / \operatorname{sen} \theta_{0}} \cdot \tau \cdot w \cdot\left(1-\frac{1}{j}\right) \cdot f \cdot \rho \cdot d x \cdot \mathcal{E} \cdot e^{-\mu \cdot \rho_{0} \cdot x / \operatorname{sen} \theta}
$$

onde a variável $G$, denominada de fator de geometria, é uma constante de proporcionalidade e depende da geometria do sistema de excitação-detecção, da corrente do tubo ou da atividade da fonte, etc., mas não do próprio elemento de interesse.

Esta última equação pode ser reescrita como:

$$
d I=G \cdot e^{-\left(\mu_{0} / \operatorname{sen} \theta_{0}+\mu / \operatorname{sen} \theta\right) \rho_{0} \cdot x} \cdot \tau \cdot w \cdot\left(1-\frac{1}{j}\right) \cdot f \cdot \rho \cdot \mathcal{E} \cdot d x
$$

Definindo-se o coeficiente de absorção de massa total $\chi$ como:

$$
\chi=\frac{\mu_{0}}{\operatorname{sen} \theta_{0}}+\frac{\mu}{\operatorname{sen} \theta}
$$


e utilizando-se a Equação 11, pode-se rescrever a Equação 14 na forma:

(Eq. 16)

$$
d I=G \cdot \mathcal{E} \cdot K \cdot e^{-\chi \cdot \rho_{0} \cdot x} \cdot \rho \cdot d x
$$

Integrando a Equação 16 ao longo da espessura total da amostra, $D$, obtem-se a intensidade fluorescente $I$ para um dado elemento de interesse:

$$
I=G . \varepsilon . K . \rho \cdot \frac{1-e^{-\chi \cdot \rho_{0} . D}}{\chi \cdot \rho_{0}}
$$

A razão $\rho / \rho_{0}$ representa a "densidade" do elemento de interesse em relação à densidade da matriz, e portanto, é a própria concetração $C$ do elemento de interesse na amostra, ou seja, a concentração fracional do elemento em base de massa. Sendo assim:

$$
I=G \cdot \mathcal{E} \cdot K \cdot C \cdot \frac{1-e^{-\chi \cdot \rho_{0} \cdot D}}{\chi}
$$

Tomando-se:

$$
S=G \cdot \varepsilon \cdot K,
$$

onde $S$ representa a sensibilidade do espectrômetro de raios $\mathrm{X}$ para o elemento de interesse. A Equação 18 pode ser escrita como:

$$
I=S . C \cdot \frac{1-e^{-\chi \cdot \rho_{0} \cdot D}}{\chi}
$$

Em alguns casos, ao invés de se referir à concentração $C$ do elemento em base de massa, prefere-se referir à densidade superficial $c$ do elemento na amostra, ou seja:

$$
c=\frac{C}{\rho_{0} . D}
$$

e portanto a Equação 20 pode ser reescrita na forma: 
(Eq. 22)

$$
I=S . c . \frac{1-e^{-\chi \cdot \rho_{0} \cdot D}}{\chi \cdot \rho_{0} \cdot D}
$$

A razão apresentada na Equação 22 é denominada de fator de absorção $A$ para o elemento de interesse:

$$
A=\frac{1-e^{-\chi \cdot \rho_{0} \cdot D}}{\chi \cdot \rho_{0} \cdot D},
$$

e desse modo a Equação 22 pode ser reescrita na forma:

$$
I=S \cdot c \cdot A
$$

Uma representação esquemática da dependência entre estas variáveis é mostrada na Figura 3.12. Como mencionado no início deste item, foi apresentado um modelo para os raios $\mathrm{X}$ característicos da camada $K$, especificamente para a linha $K_{\alpha}$. De maneira análoga, as mesmas equações podem ser obtidas para as linhas $L_{\alpha}$, onde logicamente, os parâmetros fundamentais terão outros valores.

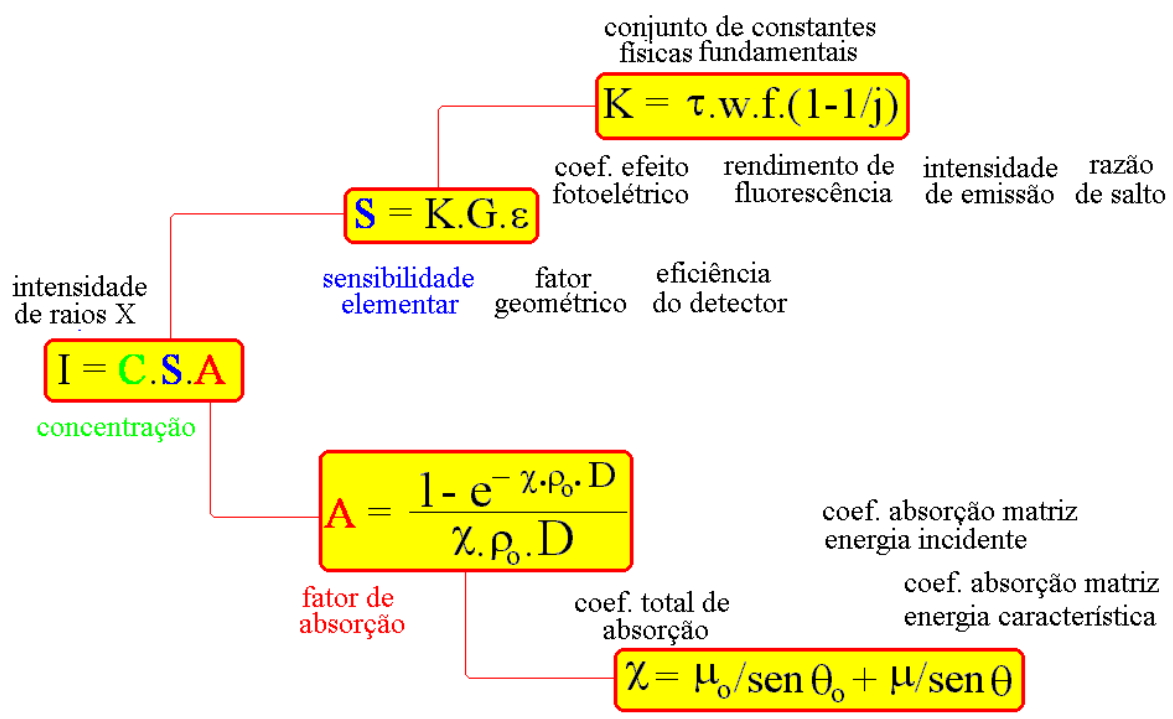

Figura 3.12 - Representação esquemática da dependências entre as variáveis na equação fundamental de fluorescência de raios X para feixe monoenergético (NASCIMENTO FILHO, 1999). 
Deve ser ressaltado que para amostras consideradas finas, o termo $\chi \cdot \rho_{0} . D$ tende a zero, e o termo $e^{-\chi \cdot \rho_{0} \cdot D}$ tende a $1-\chi \cdot \rho_{0} D$. Logo, nestas condições, o fator de absorção tem valor unitário:

$$
\text { Amostra fina } \rightarrow \quad \mathrm{A}=1
$$

No extremo oposto, ou seja, para amostras consideradas espessas, o termo $\chi \cdot \rho_{0} . D$ tende a infinito, e o termo o $e^{-\chi \cdot \rho_{0} \cdot D}$ tende a zero. Nestas condições, o fator de absorção assume o valor:

$$
\text { Amostra espessa } \rightarrow \quad A=\frac{1}{\chi \cdot \rho_{0} \cdot D}
$$

O levantamento da curva de sensibilidade elementar pode ser feita utilizandose amostras padrões espessas finas. Neste caso, pode-se calcular o fator de absorção $A$ para estes padrões, pela Equação 23, e com base na medida da taxa de contagem $I$ pode-se estimar a sensibilidade elementar $S$ pela Equação 20 ou 22.

Por outro lado, a sensibilidade elementar $S$ é relacionada aos parâmetros fundamentais $K$ e à eficiência de detecção $\mathcal{E}$ através de uma constante elementar independente, chamada de fator de geometria $G$, como mostra a Equação 19, que pode ser reescrita na forma:

$$
G=\frac{S}{\varepsilon . K}
$$

Este fator de geometria deve permanecer constante para todas as energias, e desse modo, pode-se obter um fator de geometria médio, a ser utilizado posteriormente nas análises quantitativas. 


\subsubsection{Emissão Induzida de Raio $X$ por Partículas (PIXE)}

O método de PIXE (Particle Induced X-Ray Emission) foi proposto em 1970 por Johansson, Akselsson e Johansson (1970), em decorrência ao desenvolvimento do detector do tipo $\mathrm{Si}(\mathrm{Li})$. No método PIXE, há a indução da emissão de raios $\mathrm{X}$ característicos de uma amostra, irradiando-a com um feixe de íons (prótons ou alfas) com alguns $\mathrm{MeV} / \mathrm{u}$ de energia. Os raios $\mathrm{X}$, provenientes da amostra, são detectados com um detector de $\mathrm{Si}(\mathrm{Li})$, atualmente também utilizado detectores de Si-PIN e SDD (Silicon Drift Detector), e o sinal é armazenado em um analisador multicanal. Como na análise XRF, a posterior "redução" dos espectros de raios $X$ identifica e quantifica os elementos constituintes. Mas o método PIXE é limitado pela absorção na janela do detector, que absorve os raios $\mathrm{X}$ de menor energia, sendo capaz de identificar e quantificar elementos com $Z>10$, com limite de detecção de $10^{-6} \mathrm{~g} / \mathrm{g}$ (ppm), ou $10^{14}$ at $/ \mathrm{cm}^{2}$ no caso de filmes finos, e precisão absoluta de 5 a $30 \%$. A dimensão das amostras pode ter $0.5 \mathrm{~cm}^{2}$, até o limite inferior de aproximadamente $1 \mu \mathrm{m}$, no caso do micro PIXE (TABACNIKS, 2005).

Os fundamentos do método PIXE, tabelas e dados de trabalho, detalhes experimentais e várias aplicações podem ser encontrados em artigos de revisão e livros texto (JOHANSSON; JOHANSSON, 1976; PINHOS et al., 1979; KHAN; CRUMPTON; JOHANSSON, 1981; JOHANSSON; CAMPBELL, 1988; JOHANSSON; CAMPBELL; MALMQVIST, 1995; TABACNIKS, 2005) e no banco de dados de raios $X$ mantido na Internet pelo Lawrence Berkeley Laboratory (KORTRIGH; THOMPSON, 2001).

\subsubsection{Formulação do método de PIXE}

A formulação para o método PIXE foi retirada dos trabalhos de Pinhos et al. (1979), Aburaya (2005) e Tabacniks (2005).

A relação entre a quantidade de um elemento químico $i$, presente no alvo em um elemento de volume $d v^{\prime}$, e o número de fótons de raio $\mathrm{X}\left(d X_{i}\right)$ emitido por este elemento é dada por:

$$
d X_{i}=\sigma_{X i}(E) \cdot P\left(x^{\prime}, y^{\prime}\right) \cdot m_{n}\left(x^{\prime}, y^{\prime}, z^{\prime},\right) \cdot d v^{\prime},
$$


onde $m_{n}$ é a densidade atômica elementar referente ao elemento químico no volume $d v^{\prime}$ e $\sigma_{X i}(E)$ é a seção de choque de produção de raio $\mathrm{X}$, usando um feixe de partículas com seção transversal $P\left(x^{\prime}, y^{\prime}\right)$ e energia $E$.

O número de fótons detectados, $d N_{i}$ é uma fração do número de raios $\mathrm{X}$ produzidos, dada a reduzida área de detector, definido por uma fração de ângulo sólido, $\Omega / 4 \pi, T$ a transmitância no caminho $d$ percorrido na matriz, e a eficiência de detecção (detector e absorvedor) $\varepsilon_{i}$, onde:

$$
\varepsilon_{i}=\varepsilon_{\text {filtro }} \varepsilon_{\text {detector }}=\left(T_{\text {filtro }}\right) \cdot T_{\text {janela }} T_{\text {contato }} T_{\text {camada morta }} T_{\text {gelo }}\left(1-T_{\text {cristal }}\right),
$$

sendo $1-T_{\text {cristal }}$ a perda de eventos devido à "transparência" do cristal detector.

O número de raio $X$ detectado é dado por:

$$
d N_{i}=\frac{\Omega}{4 \pi} \varepsilon_{i} \cdot T \cdot d X_{i},
$$

sendo a transmitância $T, I / I_{0}$, calculada a partir da lei de Lambert-Beer (LEIGHTON, 1959).

$$
T=e^{-\mu_{i} d},
$$

onde $\mu_{i}$ é 0 coeficiente total de absorção para uma dada linha de raio $\mathrm{X}$ característico devido a composição do alvo, calculada como combinação linear dos componentes da matriz, a partir da lei de Bragg:

$$
\mu_{i}=\sum_{n} k_{n} \mu_{i n},
$$

no qual $k_{n}$ é a fração atômica, estequiométrica, do $n$-ésimo componente da matriz, considerado homogêneo, mantendo $k_{n}$ constante ao longo de todo o trajeto. 


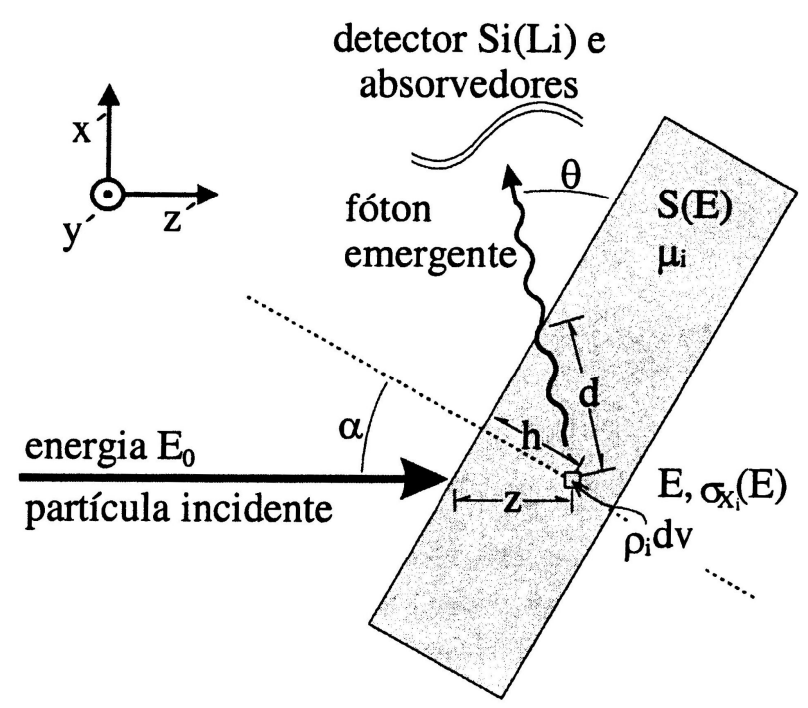

Figura 3.13 - Geometria do arranjo PIXE (Aburaya, 2005)

Observado a geometria do arranjo (Figura 3.13), podemos definir o caminho de saída, $d$, em função da coordenada $z$, e dos ângulos de incidência $\alpha$ e de saída $\theta$ :

$$
d=\frac{\cos \alpha}{\operatorname{sen} \theta} z
$$

Se considerarmos o feixe homogêneo e a carga total $Q$ depositada sobre o alvo, teremos:

$$
P\left(x^{\prime}, y^{\prime}\right)=\frac{Q}{\text { q.e.s. } \cos \alpha},
$$

no qual, $q$ é o estado de carga do íon incidente, e é o valor da carga elementar e s é a secção transversal do feixe incidente.

Se utilizarmos:

$$
m_{n} d v=\frac{N_{0}}{A_{n}} \rho_{n} \cdot s \cdot d z^{\prime},
$$

onde $N_{0}$ é o número de Avogadro, $A_{n}$ é a massa molar e $\rho_{n}$ a densidade do elemento $n$. Se usarmos a Equação 30, temos: 
(Eq. 36)

$$
N_{i}=\frac{\Omega}{4 \pi} \varepsilon_{i} \frac{N_{0}}{A_{n}} \frac{Q}{q \cdot e \cdot \cos \alpha} \rho_{n} \int_{0}^{Z} \sigma_{X i}(E) \cdot e^{-\mu_{i} \frac{\cos \alpha}{\operatorname{sen} \theta} z^{\prime}} d z^{\prime}
$$

Pelo poder de freamento, a dependência de $z$ em função da energia $E$ é:

$$
d z=\frac{1}{\rho} \frac{d E}{S(E)}
$$

no qual $S(E)$ é o poder de freamento total, que pela lei de Bragg é dado por:

$$
S(E)=\sum_{n} k_{n} S_{n}(E)
$$

sendo $S_{n}(E)$ o poder de freamento e $k_{n}$ a fração atômica, na estequiometria, do $n$ ésimo elemento químico da amostra, considerado homogêneo, mantendo $k_{n}$ constante ao longo de todo o trajeto.

Assim, temos a expressão geral da análise PIXE, em função da energia $E$ do íon incidente.

$$
N_{i}=\frac{\Omega}{4 \pi} \varepsilon_{i} \frac{N_{0}}{A_{n}} \frac{Q}{q \cdot e \cdot \cos \alpha} \frac{\rho_{n}}{\rho} \int_{E_{0}}^{E} \frac{\sigma_{X i}\left(E^{\prime}\right) \cdot e^{-\frac{\mu_{i}}{\rho} \frac{\cos \alpha^{E^{\prime}}}{\operatorname{sen} \theta} \int_{E_{0}} \frac{d E^{\prime \prime}}{S\left(E^{\prime \prime}\right)} d E^{\prime \prime}}}{S\left(E^{\prime}\right)}\left(-d E^{\prime}\right),
$$

sendo o limite superior de integração $E$ a energia mínima que possui a partícula ao atravessar toda a amostra ao longo da direção $z$.

O sinal negativo em $d E^{\prime}$ destaca a dependência inversa entre $d z^{\prime}$ e $d E^{\prime}$ e pode ser evitado com a inversão dos limites de integração. Importante ressaltar que a equação anterior só é válida quando o feixe ou a amostra for homogêneo. 


\subsubsection{Limite para alvos finos}

Consideramos um alvo fino quando a transmitância da radiação na amostra é quase total, ou seja, $T \cong 1$, e $\sigma_{i}(E) \cong \sigma_{i}\left(E_{0}\right)$, logo:

(Eq. 40)

$$
\int_{E_{0}}^{E} \frac{\sigma_{X i}\left(E^{\prime}\right) \cdot e^{-\frac{\mu_{i} \cos \alpha^{E^{\prime}}}{\rho \operatorname{sen} \theta} \int_{E_{0}}^{E^{\prime}} \frac{d E^{\prime \prime}}{S\left(E^{\prime \prime}\right)} d E^{\prime \prime}}}{S\left(E^{\prime}\right)}\left(-d E^{\prime}\right) \cong \sigma_{i}\left(E_{0}\right) \cdot \rho \cdot \ell,
$$

no qual $\ell$ é a espessura do alvo fino.

Assim, no limite para alvos finos:

(Eq. 41)

$$
N_{i}=\frac{\Omega}{4 \pi} \varepsilon_{i} \frac{N_{0}}{A_{n}} \frac{Q}{q \cdot e \cdot \cos \alpha} \sigma_{X i}\left(E_{0}\right) \cdot \rho_{n} \cdot \ell
$$

Logo, a relação entre o número de raio $\mathrm{X}$ detectado, de uma linha espectral particular observada, e a concentração do elemento químico presente no alvo, normalizado pela carga total acumulada, pode ser escrita como:

$$
N_{i}=r_{i} \cdot Q \cdot\left(\rho_{n} \cdot \ell\right)
$$

para,

$$
r_{i}=\frac{\Omega}{4 \pi} \varepsilon_{i} \frac{N_{0}}{A_{n}} \frac{1}{q . e \cdot \cos \alpha} \sigma_{X i}\left(E_{0}\right),
$$

no qual $r_{i}$ é o fator de resposta de alvo fino (também chamado rendimento), que é uma característica do particular arranjo experimental, abrangendo parâmetros como: geometria, eficiência de deteç̧ão eletrônica de aquisição de dados, e é único para uma dada linha espectral $i$ do elemento $n$. E pode ser determinado experimentalmente utilizando alvos finos padrão, onde a grandeza $\left(\rho_{n} . \ell\right)$ é a espessura do filme, normalmente da ordem de dezenas de $\mu \mathrm{g} / \mathrm{cm}^{2}$ (veja secção 4.3.3). 


\subsubsection{Fator de correção para alvos grossos}

Por analogia, seguindo a Equação 42 temos:

(Eq. 44)

$$
N_{i}=R_{i} \cdot Q \cdot C_{n},
$$

no qual,

(Eq. 45)

$$
R_{i}=\frac{\Omega}{4 \pi} \varepsilon_{i} \frac{N_{0}}{A_{n}} \frac{1}{q \cdot e \cdot \cos \alpha} \int_{E_{0}}^{E} \frac{\sigma_{X i}\left(E^{\prime}\right) \cdot e^{-\frac{\mu_{i} \cos \alpha^{E^{\prime}}}{\rho \operatorname{sen} \theta} \int_{E_{0}}^{\prime} \frac{d E^{\prime \prime}}{S\left(E^{\prime \prime}\right)} d E^{\prime \prime}}}{S\left(E^{\prime}\right)}\left(-d E^{\prime}\right)
$$

e

(Eq. 46)

$$
C_{n}=\frac{\rho_{n}}{\rho},
$$

sendo $C_{n}$ a concentração do elemento químico, normalmente na grandeza $\mu g / g$.

No trabalho de Aburaya (2005) é proposto um fator de correção para o cálculo do rendimento de produção de raios $\mathrm{X}$ para alvos grossos.

Tal cálculo se propõe a relacionar a grandeza $r_{i}$, conhecida pelo cálculo anterior para alvos finos, e $R_{i}$, fator de resposta para alvos grossos.

Temos que:

$$
F_{i}=\frac{R_{i}}{r_{i}}
$$

logo,

(Eq. 48)

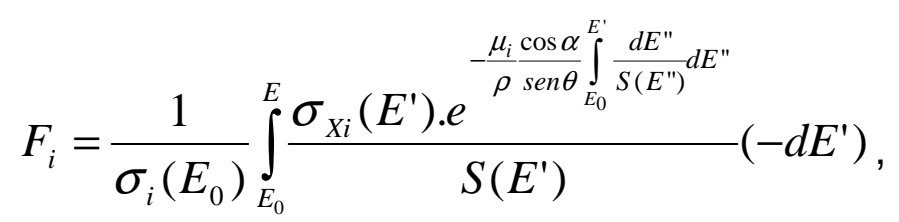


onde os fatores de resposta $r_{i}$ e $R_{i}$ possuem unidades diferentes, \#/ $\mu C . \mu g / g$ e $\# / \mu C . \mu \mathrm{g} / \mathrm{cm}^{2}$, respectivamente, onde \# é a integral do pico espectral referente ao $i-$ ésimo elemento químico da amostra. Assim, o fator de correção de alvos espessos $F_{i}$ tem unidade $\mathrm{g} / \mathrm{cm}^{2}$.

Este cálculo, do fator de correção para alvos espessos, é realizado pelo programa CLARA (ABURAYA, 2005, 2006, 2009), que permite descrição da composição da matriz para tal cálculo.

Assim, utilizando-se da curva de resposta para alvos finos, já calibrada do arranjo, e utilizando o fator de correção de alvos espessos, obtemos o fator de resposta para alvos espessos.

\subsubsection{Detecção de Raios $X$}

\subsubsection{Detector de Si(Li)}

Este detector é um pequeno diodo de Si dopado com $\mathrm{Li}$, denominado $\mathrm{Si}(\mathrm{Li})$. O cristal de Si é um cilindro com aproximadamente $4 \mathrm{~mm}$ de diâmetro por 2 a $3 \mathrm{~mm}$ de espessura. O diodo é polarizado de modo reverso, abaixo do limite de ruptura de condução. Quando um fóton é absorvido no cristal, produz uma cascata de ionizações e igual número de elétrons quase livres. O campo elétrico aplicado faz com que os elétrons sejam recolhidos no ânodo, "antes" de se recombinarem com as vacâncias. Um esquema que ilustra o processo foi reproduzido na Figura 3.14. O pulso formado tem amplitude proporcional ao número de elétrons gerados, que por sua vez é proporcional à energia do fóton absorvido. Com a tecnologia atual, um detector de $\mathrm{Si}(\mathrm{Li})$ tem resolução da ordem de $140 \mathrm{eV}$, suficiente para resolver a linha do silício $(1740 \mathrm{eV})$ da do alumínio (1485 eV), por exemplo. A resolução de um detector de raios $\mathrm{X}$ é usualmente medida pela largura à meia altura da linha $k_{\alpha}$ do Manganês, que tem energia de 5895 eV, como pode ser visto na Figura 3.15. 


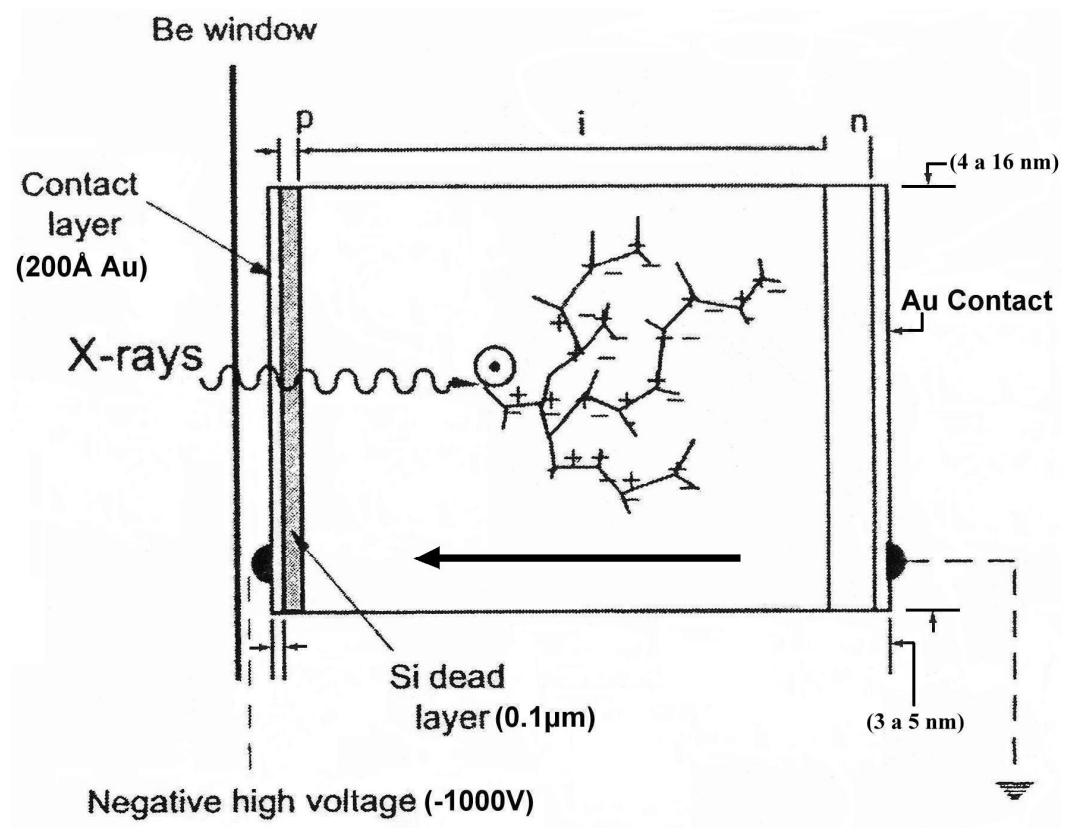

Figura 3.14 - Desenho esquemático dos fenômenos que seguem a absorção de um fóton num cristal de $\mathrm{Si}(\mathrm{Li})$, usado em medidas de raios X (modificado de Janssens, 2004).

A Figura 3.14 mostra um cristal detector de $\mathrm{Si}(\mathrm{Li})$, os contatos elétricos e também uma fina camada morta (insensível à radiação). O cristal é montado num dedo frio mantido em nitrogênio líquido para reduzir o ruído térmico e assim melhorar a resolução. O cristal tem que ser mantido refrigerado e em vácuo. Uma fina janela de Berílio, com espessura entre 5 e $25 \mu \mathrm{m}$ é usada para isolar o cristal de $\mathrm{Si}(\mathrm{Li})$ do meio ambiente. A radiação, para ser detectada, deve atravessar a janela de Berílio, o contato frontal ( $\mathrm{Au} \sim 20 \mathrm{~nm}$ ), a camada morta de Si $(\sim 0,1 \mu \mathrm{m})$ e eventualmente uma fina camada de gelo que com tempo costuma condensar em volta (e na frente) do cristal. As diversas espessuras da janela de Be e do cristal determinam a curva de eficiência de detecção, conforme mostrado na Figura 3.16 (CANBERRA). 


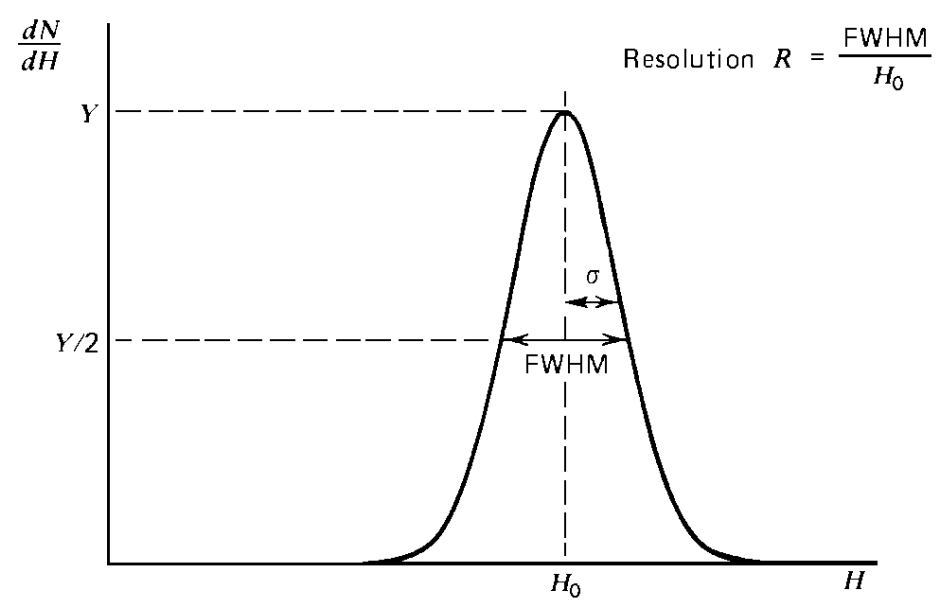

Figura 3.15 - Largura à meia altura de uma distribuição gaussiana ( $F W H M)$ e definição de resolução. Note que $F W H M=2,35 \sigma$ (KNOLL, 1979).

Um detector do tipo $\mathrm{Si}(\mathrm{Li})$ foi o utilizado nas medidas PIXE com amostras em vácuo. As transições eletrônicas de interesse são determinadas pela região útil do detector, entre 1,2 e $30 \mathrm{keV}$. Assim, medem-se as linhas $\mathrm{K}$ para elementos com $13<Z<40$ e as linhas $L$ para elementos com $Z>38$.

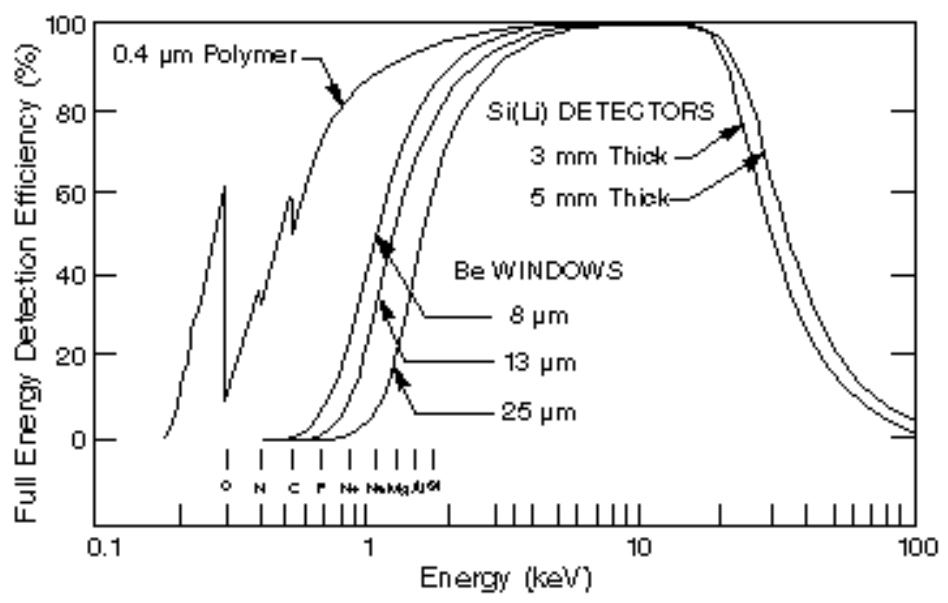

Figura 3.16 - Curvas de eficiência intrínseca de um detector de Si(Li) (CANBERRA)

\subsubsection{Detectores de Si-PIN e SDD}

Os detectores de semicondutores dopados, como o de $\mathrm{Si}(\mathrm{Li})$, utilizam refrigeração por criogenia. Com o desenvolvimento da refrigeração eletrônica por efeito Peltier, foi possível a redução das dimensões dos detectores utilizados na 
detecção de fótons na faixa energética dos raios $X$, tornando-os portáteis. Um exemplo dessa aplicação é o detector de diodos Si-PIN portáteis, que utiliza os mesmos conceitos de detecção de radiação que os detectores de $\mathrm{Si}(\mathrm{Li})$ (PANTAZIS et al., 1994).

Um fotodiodo convencional de Si-PIN é esboçado na Figura 3.17 (AMPTEK). Há dois contatos planos, o anodo e o catodo, com um campo elétrico uniforme entre eles. Um raio $\mathrm{X}$ interage em algum local, ionizando os átomos de silício e produzindo pares elétron-buraco. O campo elétrico leva as cargas para seus respectivos contatos, causando um pulso transiente de corrente $I(t)$ neste diodo. O cátodo é conectado a um pré-amplificador, um amplificador e a um processador de pulso eletrônico que mede o pulso e sua amplitude.

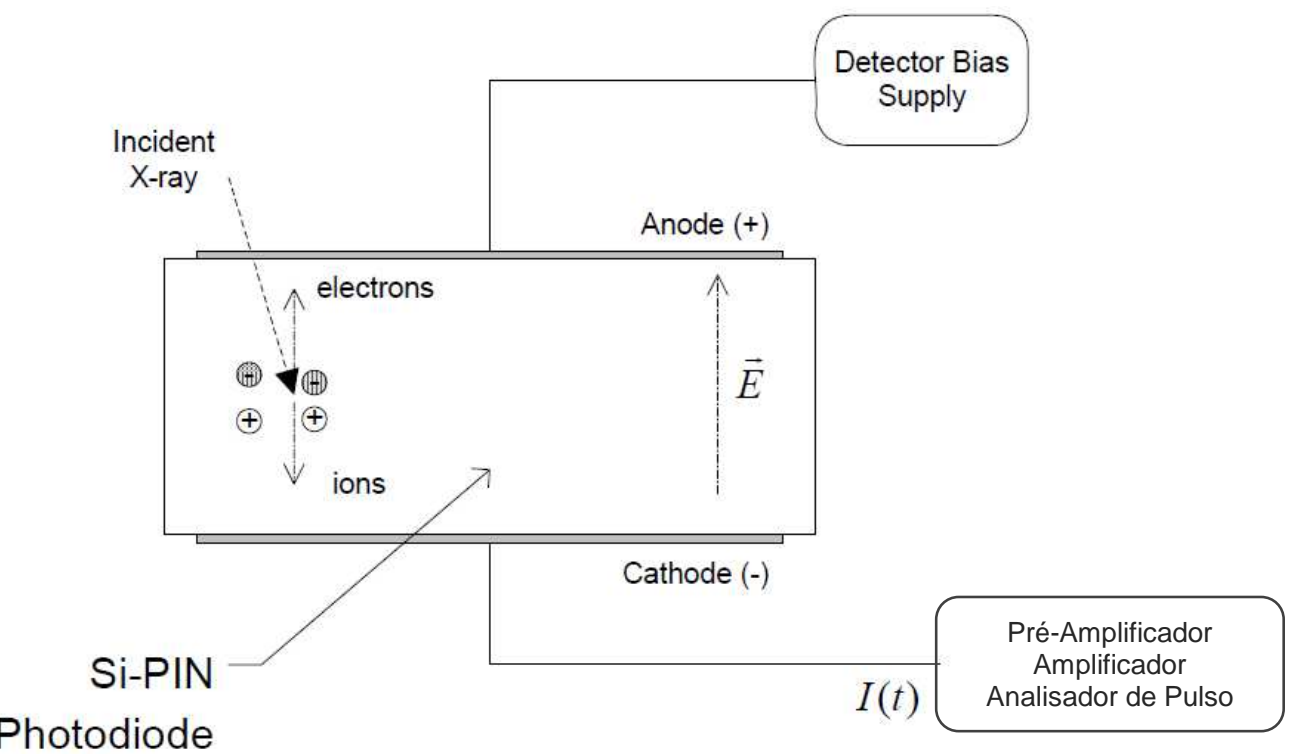

Figura 3.17 - Esboço ilustrando o funcionamento de um fotodiodo convencional (modificado de Amptek).

Outro detector do tipo fotodiodo recentemente desenvolvido para melhorar o desempenho de deteç̧ão é o SSD (Silicon Drift Diode), esboçado na Figura 3.18. Este detector utiliza um cátodo plano e um ânodo pequeno cercado por uma série de eletrodos. O detector SSD possui simetria cilíndrica, de modo que o ânodo é um pequeno círculo e os eletrodos são concêntricos anelares. Estes elétrodos são polarizados criando um campo elétrico que guia os elétrons através do detector até o ânodo. O resto do sistema eletrônico de processamento de sinal é praticamente idêntico ao utilizado no detector de Si-PIN. 


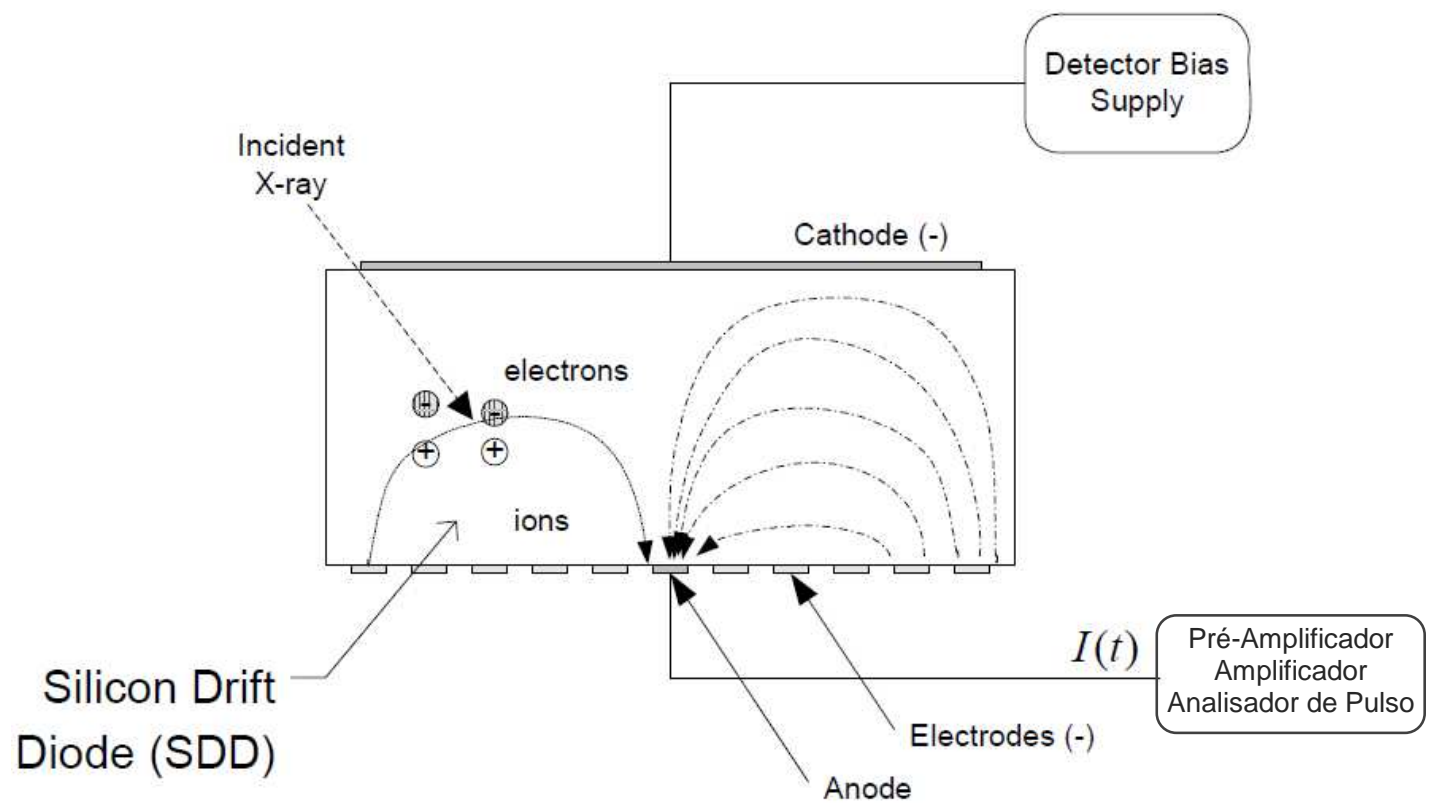

Figura 3.18 - Esboço ilustrando o funcionamento do detector de SSD (modificado de Amptek).

As diversas espessuras da janela de Be e do cristal determinam a curva de eficiência de detecção, conforme mostrado nas Figuras 3.19 e 3.20 (AMPTEK).

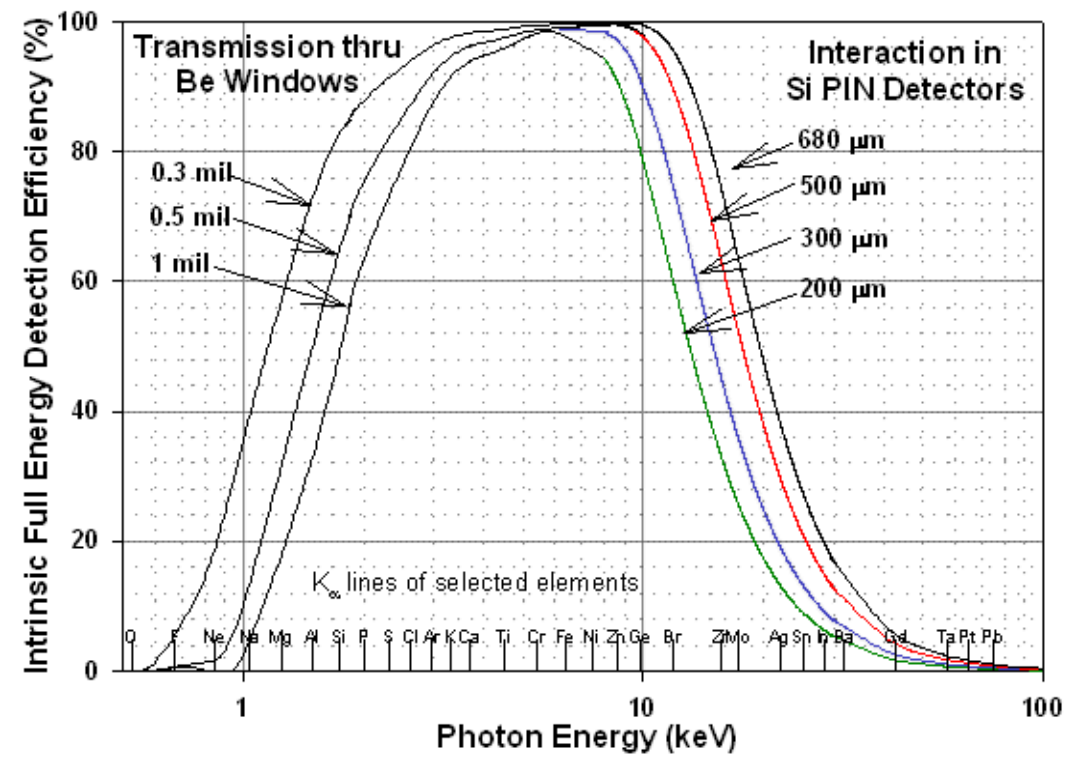

Figura 3.19 - Curvas de eficiência intrínseca de um detector de Si-PIN (AMPTEK). 


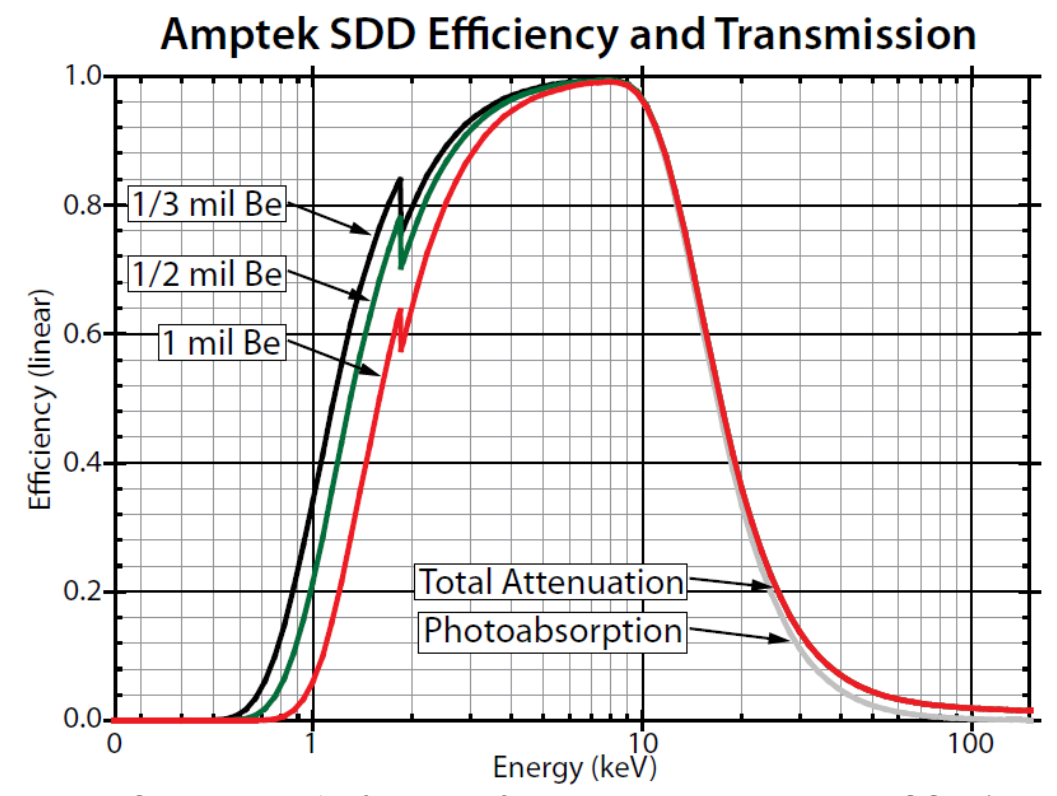

Figura 3.20 - Curvas de eficiência intrínseca de um detector de SSD (AMPTEK).

O SDD possui uma melhor resolução de energia do que um Si-PIN para detectores com a mesma área, como pode ser visto na Figura 3.21. O SDD tem resolução de energia muito melhor quando se utiliza tempos curtos de formação de pulso, que é bastante útil em altas taxas de contagem. O Si-PIN possui modelos com uma área ativa maior e profundidade de depleção mais espessa, assim, possui modelos com maior eficiência de detecção. O SDD é um dispositivo mais complicado para a manufatura, logo, é mais caro do que um Si-PIN.

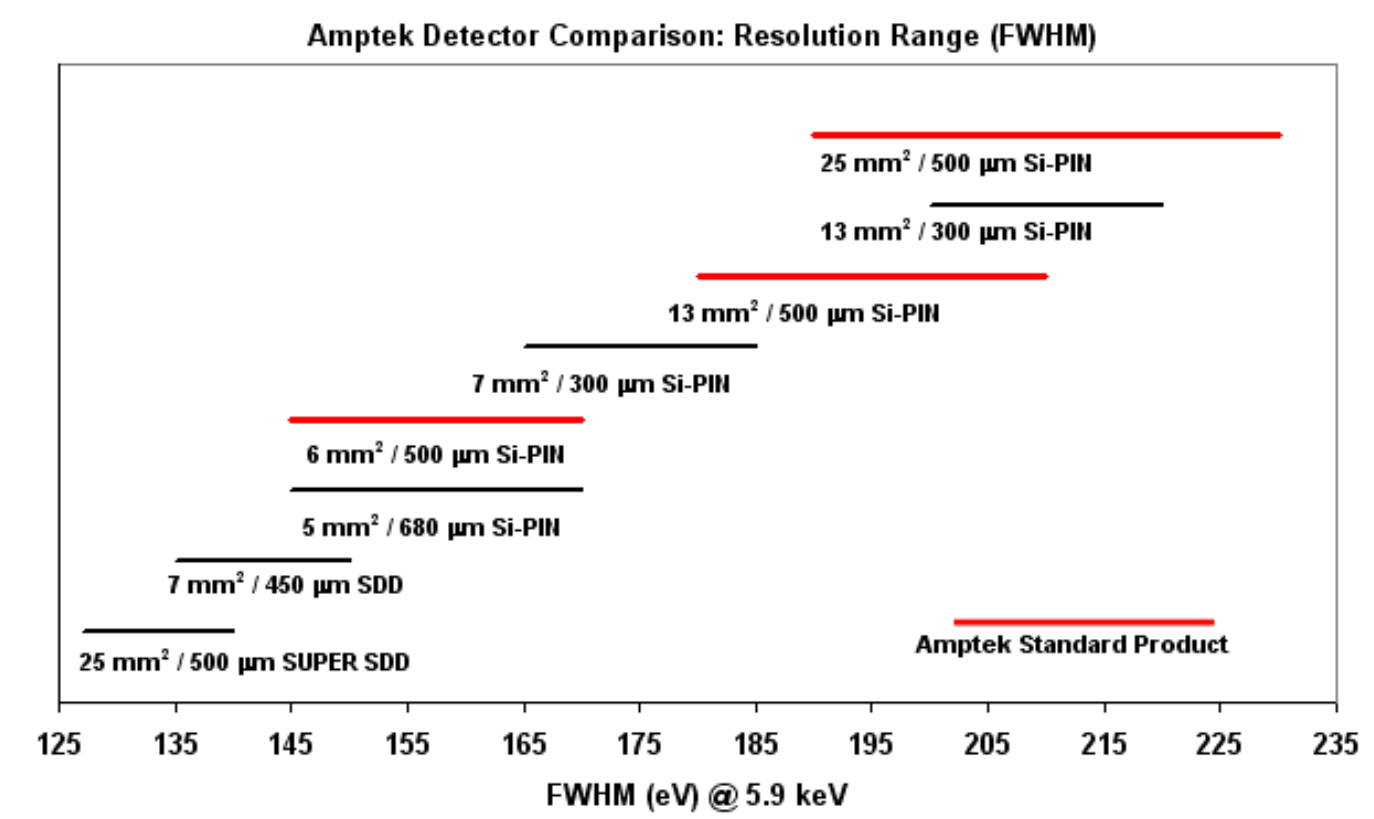

Figura 3.21 - Distribuição da resolução dos detectores SDD e Si-PIN (site do fabricantes Amptek) 


\section{Capítulo 4}

\section{Materiais e Métodos Experimentais}

\subsection{As Pátinas}

A patina artificial é composta por camadas de corrosão obtidas pelo ataque químico sobre o metal do substrato. O seu uso em artefatos ornamentais é uma prática muito antiga, por exemplo, um deus-crocodilo egípcio do décimo nono século a.C. patinado se encontra no Ägyptische Sammlung, em Munique, Alemanha (GIUMLIA-MAIR, 2001). Descrições das técnicas, embora tenham sobrevivido na Ásia, foram mantidas em segredo e finalmente desapareceram no Ocidente. Nos séculos passados, entretanto, os artistas ocidentais desenvolveram muitas técnicas de patinar. Como exemplo, Balta e Robbiola (2003) descrevem técnicas utilizadas por artistas do século dezenove para patinar, especialmente na França, algumas das quais ainda estão em uso até os dias atuais.

Este tipo do tratamento é empregado igualmente por restauradores, para imitar velhas camadas artificiais ou naturais na recolocação de partes ou de superfícies que foram limpas na restauração e conservação, ou retiradas de alguma maneira, de peças metálicas arquitetônica, histórica e etnológica. As estruturas tanto de pátinas naturais quanto de pátinas artificiais são analisadas geralmente por microscopia, pela difração de raio $X$ e pela espectrometria. A maioria delas revela-se ser heterogêneas, com estruturas estratificadas e extremamente dependentes do processo de formação (ROBBIOLA; BLENGINO; FIAUD, 1998; BALTA; ROBBIOLA, 2003; MENDOZA et al., 2004). Uma grande lista de receitas para prepará-las é apresentada por Hughes e Rowe (1991).

Dentre as diversas pátinas artificiais existentes na literatura, as escolhidas para a análise deste trabalho foram aquelas que fizeram parte de uma pesquisa anterior (HERNÁNDEZ, 2004, 2009), sob a orientação do Prof. Dr. Augusto C. Neiva, que visava o aprofundamento do estudo e caracterização das pátinas que possuem maior viabilidade de serem aplicadas em grandes monumentos exposto à atmosfera, como técnicas de preservação e restauro. O método de patinação adotado consistiu 
na aplicação de uma solução por umedecimento, em intervalos regulares, ao longo de alguns dias, em temperatura ambiente.

Além das pátinas mencionadas anteriormente, foram também analisadas amostras de pátinas produzidas por imersão total em banhos térmicos, que simulariam pátinas naturais formadas em um ambiente mais agressivo.

\subsubsection{Obtenção das Pátinas}

As amostras de pastilhas metálicas de bronze e cobre, que formam os substratos das pátinas, e as pátinas artificiais formadas sobre estes substratos foram produzidas pelo Prof. Dr. Augusto C. Neiva e pela Dra. Rocio Hernández pertencentes ao Laboratório de Eletroquímica e Corrosão do Departamento de Engenharia Química da Poli - USP.

Três tipos de camadas de patina, denominadas S1, S2 e S4, foram produzidas nas pastilhas de cobre, de acordo com os procedimentos descritos na Tabela 4.1. Para futura comparação, a solução $S 1$ foi aplicada igualmente em uma pastilha de bronze. Antes da patinação, as pastilhas foram lixadas com papéis de esmeril 400 e 600, e lavadas completamente com água desmineralizada, álcool e acetona. As pastilhas foram feitas a partir de uma haste de bronze comercial e de uma haste ou uma folha de cobre comerciais. Para o S1 e o S2 no cobre, as áreas das chapas eram aproximadamente de $0,3 \mathrm{~cm}^{2}$, e para o $S 1$ no bronze e o $S 4$ no cobre, a área das pastilhas eram de aproximadamente $1 \mathrm{~cm}^{2}$.

\begin{tabular}{|c|c|c|c|c|c|c|}
\hline & \multicolumn{2}{|c|}{ S1 } & \multicolumn{2}{|c|}{ S2 } & \multicolumn{2}{|l|}{ S4 } \\
\hline oluç & $\begin{array}{c}\mathrm{Cu}\left(\mathrm{NO}_{3}\right)_{2} \\
\mathrm{ZnNO} \mathrm{Zn}_{3} \\
\mathrm{FeCl}_{3} \\
\mathrm{H}_{2} \mathrm{O}_{2}\end{array}$ & $\begin{array}{c}85 \mathrm{~g} / \mathrm{L} \\
3 \mathrm{~g} / \mathrm{L} \\
3 \%\end{array}$ & $\begin{array}{c}\mathrm{Cu}\left(\mathrm{NO}_{3}\right)_{2} \\
\mathrm{ZnCl} \\
2\end{array}$ & $\begin{array}{l}200 \mathrm{~g} / \mathrm{L} \\
200 \mathrm{~g} / \mathrm{L}\end{array}$ & $\begin{array}{c}\mathrm{CuSO}_{4} \cdot 5 \mathrm{H}_{2} \mathrm{O} \\
\mathrm{Na}_{2} \mathrm{SO}_{4} \\
\mathrm{KClO}_{3}\end{array}$ & $\begin{array}{l}1-5 \mathrm{~g} / \mathrm{L} \\
2-6 \mathrm{~g} / \mathrm{L} \\
4-8 \mathrm{~g} / \mathrm{L}\end{array}$ \\
\hline in & \multicolumn{2}{|c|}{$\begin{array}{l}\text { Umedecimento da } \\
\text { superfície, duas vezes } \\
\text { ao dia, por cinco dias }\end{array}$} & \multicolumn{2}{|c|}{$\begin{array}{l}\text { Umedecimento da } \\
\text { superfície, duas vezes } \\
\text { ao dia, por cinco dias }\end{array}$} & \multicolumn{2}{|c|}{$\begin{array}{c}\text { Imersão total por } \\
\text { duas semanas a } 25 \\
\text { ou } 50^{\circ} \mathrm{C}\end{array}$} \\
\hline
\end{tabular}

As pátinas produzidas a partir das técnicas e soluções anteriormente mencionadas podem ser vistas nas Figuras 4.1 e 4.2: 


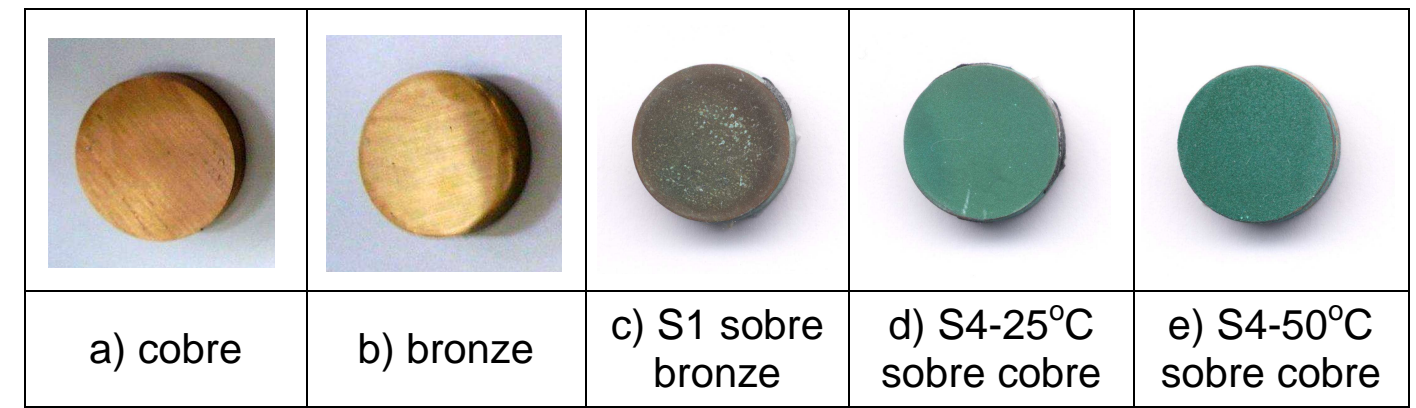

Figura 4.1 - Amostras de pátinas artificiais com a área superficial de aproximadamente $1 \mathrm{~cm}^{2}$.

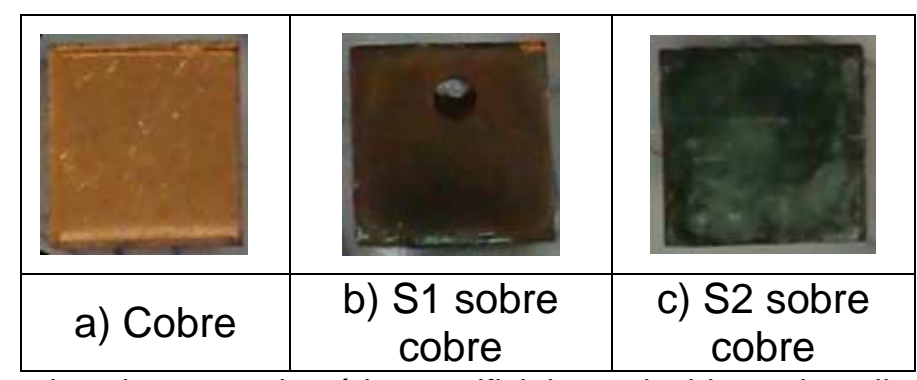

Figura 4.2 - Amostras do substrato e de pátinas artificiais produzidas pela aplicação das substâncias S1 e S2 sobre cobre, com a área superficial de aproximadamente $0.3 \mathrm{~cm}^{2}$.

As datas de produção das pátinas artificiais, assim como das analises realizadas, e quais amostras foram submetidas a quais análises, estão listadas na Tabela 4.2.

Tabela 4.2 - Datas de produção e das analises realizadas nas pátinas artificiais e a relação das respectivas análises.

\begin{tabular}{|c|c|c|c|}
\hline Pátina & $\begin{array}{l}\text { Data de } \\
\text { Produção }\end{array}$ & $\begin{array}{c}\text { Medidas } \\
\text { Submetidas } \\
\end{array}$ & Legenda \\
\hline $\mathrm{Cu}+\mathrm{S} 4$ (pastilha) & \begin{tabular}{|l|} 
jan.-fev. ou \\
jul.-ago./2004 \\
\end{tabular} & $1,2,3,4$ & $\begin{array}{c}\text { - PIXE Externo } \\
\text { 09/06/2006 } \\
\end{array}$ \\
\hline Bronze + S1 (C1) (pastilha) & \begin{tabular}{|c|} 
jan.-fev. ou \\
jul.-ago./2004
\end{tabular} & 2 & $\begin{array}{l}2 \text { - PIXE Interno } \\
\text { 26/09/2007 }\end{array}$ \\
\hline $\begin{array}{c}\text { Bronze + S1 (B4 - C4 - D4) } \\
\text { (pastilha) }\end{array}$ & \begin{tabular}{|c|} 
jan.-fev. ou \\
jul.-ago./2004
\end{tabular} & $1,2,3,4$ & $\begin{array}{c}\text { - PIXE Externo } \\
24 / 10 / 2007\end{array}$ \\
\hline Cobre (pastilha) & $6 / 6 / 2006$ & $1,2,3,4$ & \multirow{2}{*}{$\begin{array}{c}4 \text { - EDXRF Externo } \\
29 \text { e } 31 / 07 ; 07 \text { e } \\
19 / 08 \text { de } 2008\end{array}$} \\
\hline Bronze (pastilha) & 6/6/2006 & $1,2,3,4$ & \\
\hline $\mathrm{Cu}+\mathrm{S} 1$ 1dia (chapa) & $28 / 8 / 2007$ & 2,3 & \\
\hline $\mathrm{Cu}+\mathrm{S} 2$ 1dia (chapa) & $28 / 8 / 2007$ & 2,3 & \\
\hline $\mathrm{Cu}+\mathrm{S} 1$ (chapa) & 6/9/2007 & $2,3,4$ & \\
\hline Cu + S2 (chapa) & 6/9/2007 & $2,3,4$ & \\
\hline Cu (chapa) & $24 / 9 / 2007$ & 2,3 & \\
\hline
\end{tabular}




\subsection{Medidas ED-XRF}

O espectrômetro de ED-XRF mostrado na Figura 4.3, consiste em uma fonte de raios $X$ e um detector de raios $X$, e foi montado na Escola Politécnica da Universidade de São Paulo, no Departamento de Química, pelo professor Augusto C. Neiva. A fonte é um tubo de raio $X$ com alvo de $W$ da Ital Structures, com tensão de 22 a $60 \mathrm{kV}$ e corrente de 0,12 a 1,5 mA. O detector é um Ketek AXAS Si-Drift One, com refrigeração Peltier, ligado a um conversor analógico-digital 4k-canal Ketek. Nas medidas realizadas utilizou-se um colimador de $\mathrm{Pb}$ com $1,3 \mathrm{~mm}$ de diâmetro na saída do feixe incidente, e o ângulo entre o eixo do feixe incidente e o detector foi de $90^{\circ}$. Algumas medidas foram também realizadas com os eixos do feixe incidente a $45^{\circ} \mathrm{com}$ a superfície, que são exp ressas no texto como "45EDXRF". Outras, denominadas como "0-EDXRF", foram feitas com um ângulo rasante. Para ambas, a distância mínima entre a amostra e do detector foi de $7 \mathrm{~mm}$. A refrigeração com água resfriada foi utilizada a fim de manter o detector abaixo de $20^{\circ} \mathrm{C}$, garantindo uma largura de pico de $150 \mathrm{eV}$ FWHM. A maioria das medições foram realizadas com $55 \mathrm{kV}$ e 0,3 $\mathrm{mA}$, por $600 \mathrm{~s}$.

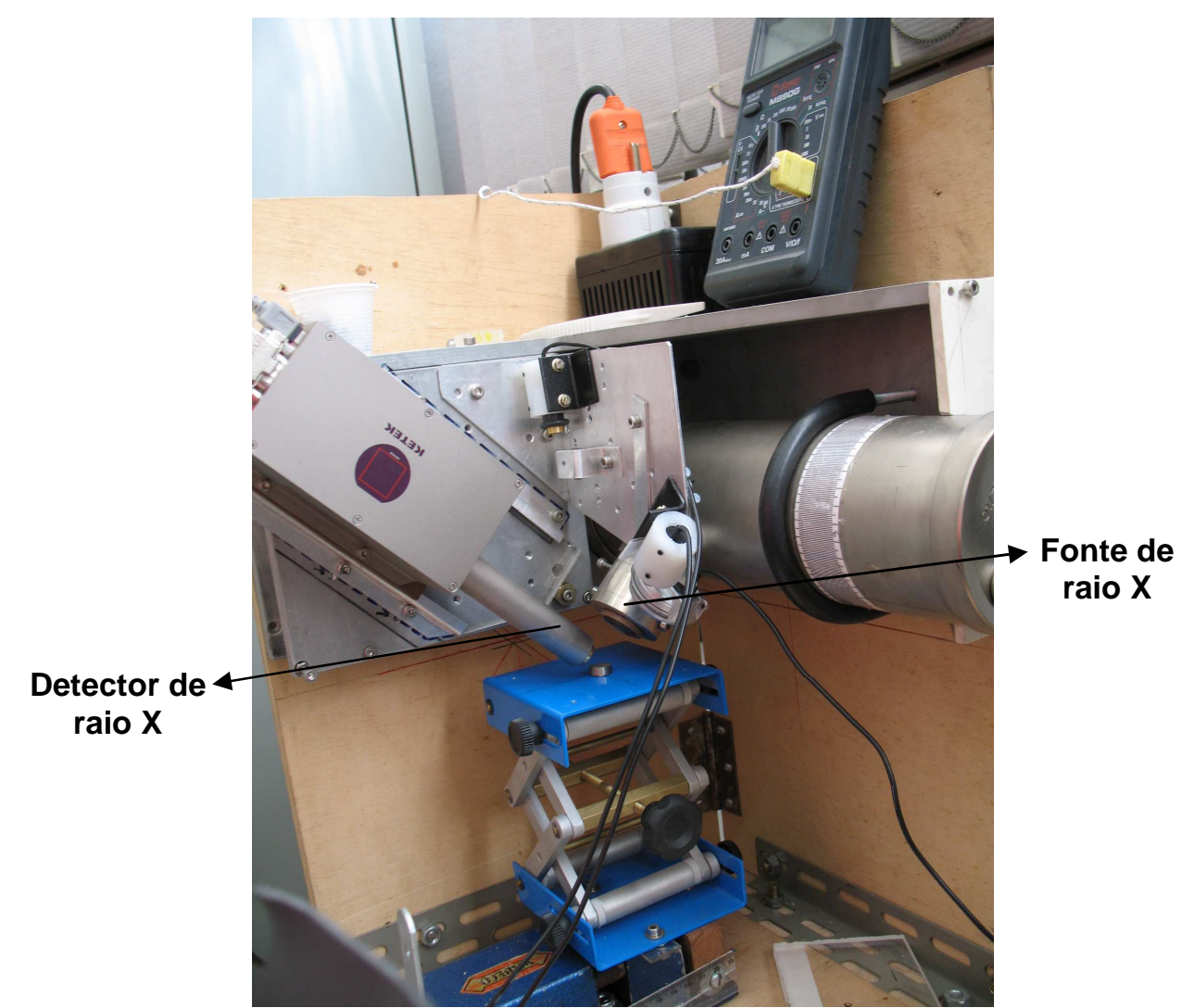

Figura 4.3 - Arranjo experimental para as medidas de ED-XRF feitas em conjunto com o Prof. Neiva no Departamento de Química da Poli, USP 


\subsection{Medidas PIXE}

As análises pelo método PIXE foram realizadas no Laboratório de Análise de Materiais por Feixes lônicos (LAMFI) do Instituto de Física da Universidade de São Paulo. O LAMFI foi criado em 1992, para desenvolver, aplicar e oferecer métodos de física nuclear para a análise e modificação de materiais e filmes finos.

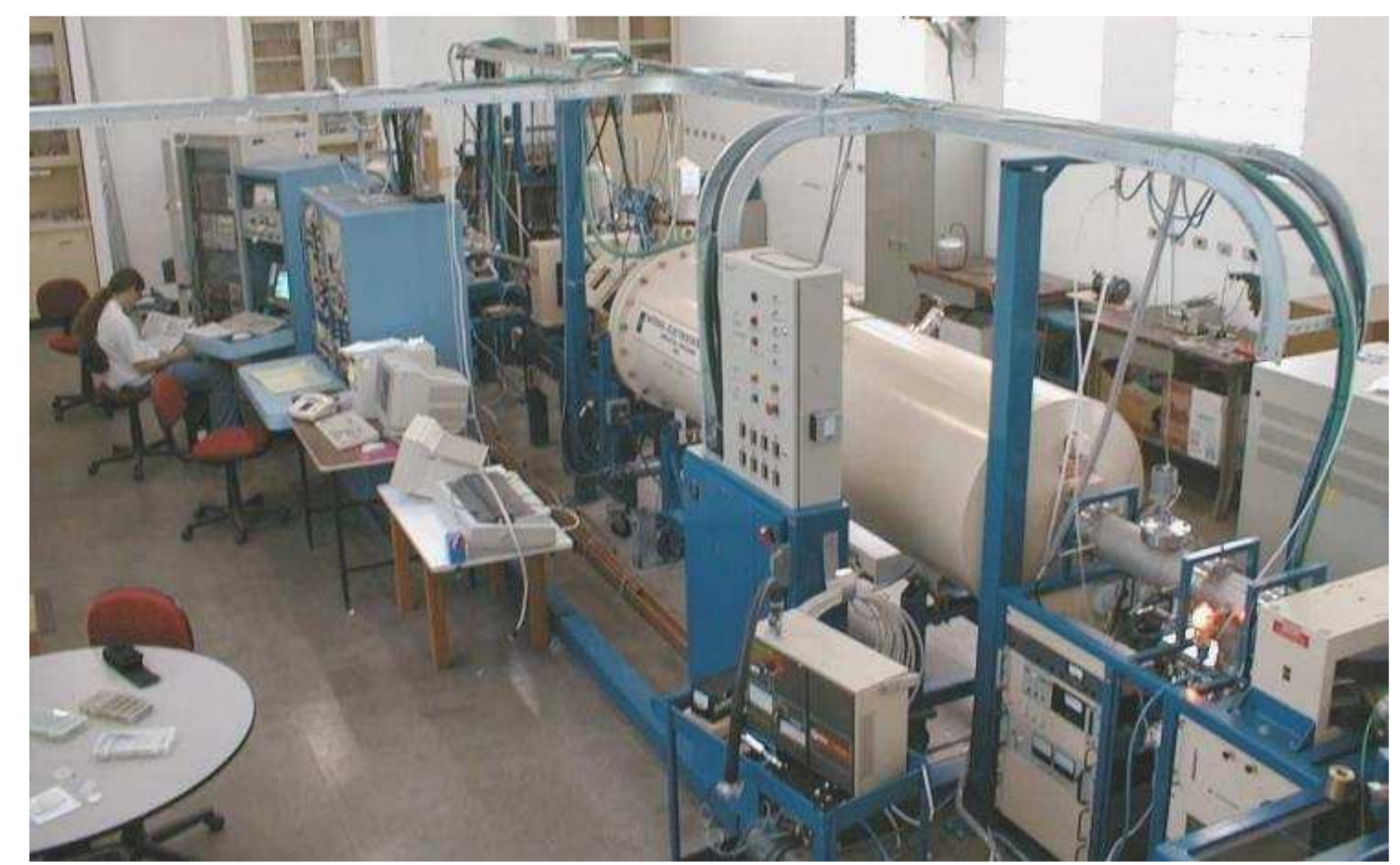

Figura 4.4 - Vista geral do LAMFI (Laboratório de Análise de Materiais por Feixes lônicos) do Instituto de Física da Universidade de São Paulo. (LAMFI).

O LAMFI possui acelerador eletrostático tipo Pelletron-Tandem, modelo $5 \mathrm{SDH}$, com "stripper" gasoso $\left(\mathrm{N}_{2}\right)$ para troca de carga do feixe, construído pela NEC (National Electrostatic Corporation), dos EUA, que pode alcançar até 1,7 MV de tensão no terminal. Duas fontes de íons alimentam o sistema, sendo uma de rádio frequência (Alphatross), com câmara de troca de carga com vapor de rubídio, e a outra do tipo SNICS (Source of Negative lons by Cesium Sputtering). O laboratório foi montando inicialmente com duas estações de trabalho, a estação de análise Multiuso RBS e a estação de análise PIXE. A estação multiuso possui uma câmara de espalhamento, com $43 \mathrm{~cm}$ de diâmetro interno e $15 \mathrm{~cm}$ de altura que permite análises por espalhamento elástico (RBS), canalização de feixe e reações nucleares (NRA). Esta câmara contém três detectores de barreira de superfície e um detector de raios $X$ tipo $\mathrm{Si}(\mathrm{Li})$ além de ser possível instalar uma janela para medidas de feixe externo (veja descrição posteriormente). A estação PIXE (interno) possui uma câmara de alto vácuo, projetada e construída no IFUSP (TABACNIKS, 1983) para 
análise de aerossóis atmosféricos. Contém um porta-amostras linear parcialmente automatizado com capacidade para 18 discos de $25 \mathrm{~mm}$ de diâmetro, com controles$\mathrm{XY}$ manuais e externos. Dispõe de dois detectores de raios $\mathrm{X}$, tipo $\mathrm{Si}(\mathrm{Li})$, e de eletrônica de controle, aquisição de espectros e integração de carga.

No laboratório LAMFI é possível acelerar vários feixes iônicos sobre uma grande gama de energias para utilização em experimentos de retro-espalhamento (RBS), PIXE, implantação iônica, reações nucleares, etc. A figura 4.5 mostra o diagrama esquemático da montagem do acelerador LAMFI, onde são localizados os elementos ópticos (imãs e quadrupolos), a câmara PIXE para medidas de PIXE interno e a canalização de feixe externo, acoplada a estação de análise Multiuso RBS.

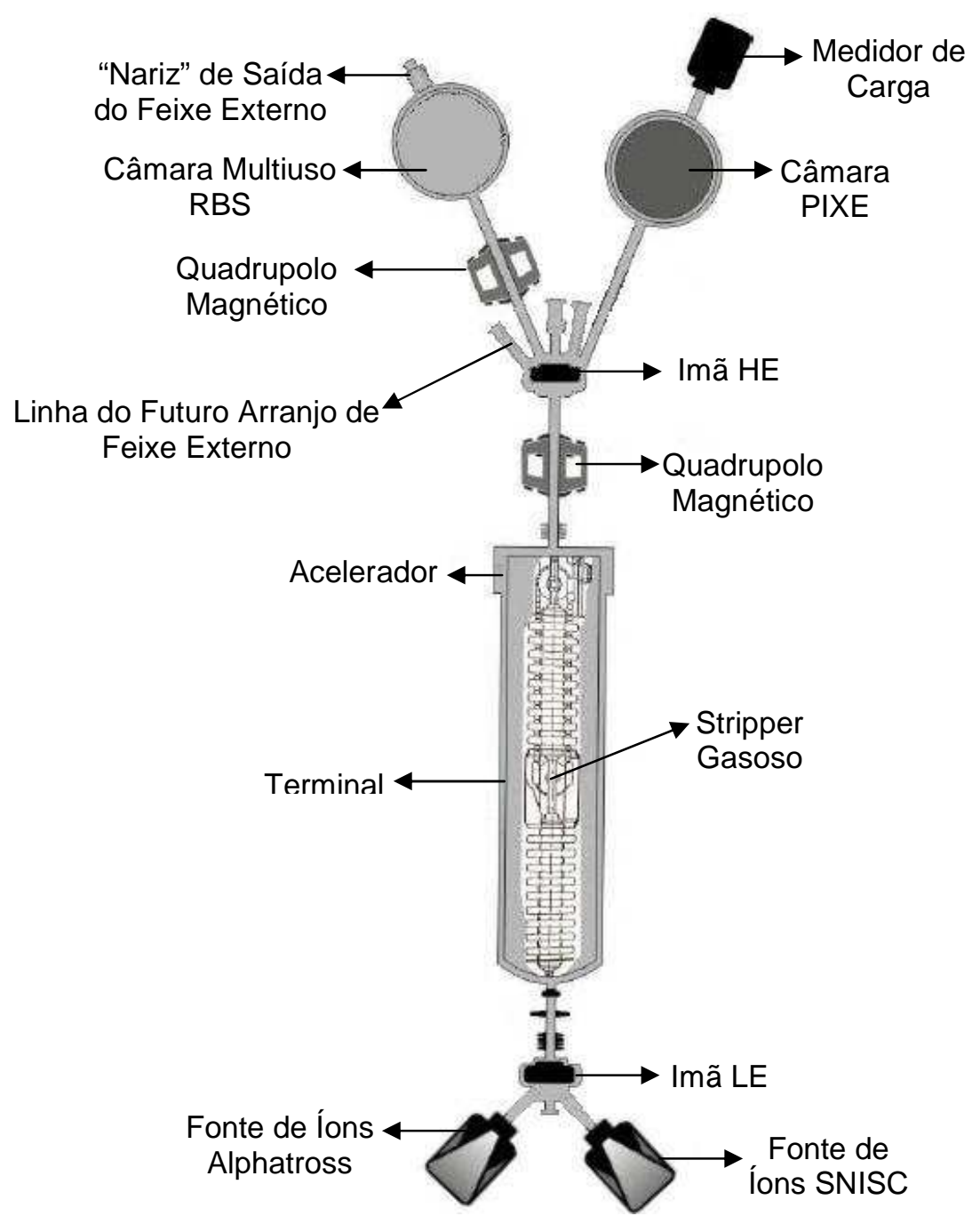

Figura 4.5 - Diagrama esquemático da montagem do acelerador do LAMFI (modificado de SANTOS, 2009). 


\subsubsection{Arranjo Experimental para medidas de PIXE interno}

Algumas amostras deste trabalho foram analisadas pela técnica PIXE no LAMFI em um arranjo interno, isto é, em vácuo (vide tabela 4.2). O sistema PIXE do LAMFI possui dois detectores Kevex de $\mathrm{Si}(\mathrm{Li})$ (FWHM 138eV @ 5,9 keV ${ }^{55} \mathrm{Fe}$ ) dispostos conforme a Figura 4.6. Um detector D1 para medidas de raios $\mathrm{X}$ de baixa energia e outro detector D2 para medidas de alta energia, posicionado atrás do alvo. O detector D1 está posicionado a $120^{\circ} \mathrm{em}$ relação ao feixe, e possui, imediatamente antes, um absorvedor de Be com $\sim 50 \mu \mathrm{m}$ de espessura. O detector D2 está posicionado a $90^{\circ} \mathrm{em}$ relação ao feixe e possui um filtro de mylar ${ }^{\circledR}$ de $\sim 300 \mu \mathrm{m}$. Foi utilizado apenas um, dos dois detectores disponíveis no arranjo D1 (Baixa), pois as amostras eram alvos grossos e nada pode ser observado pelo detector D2 (Alta) atrás do alvo. $O$ arranjo da estação de analise PIXE e a visão do interior da câmara de análise podem ser vistos na Figura 4.7.

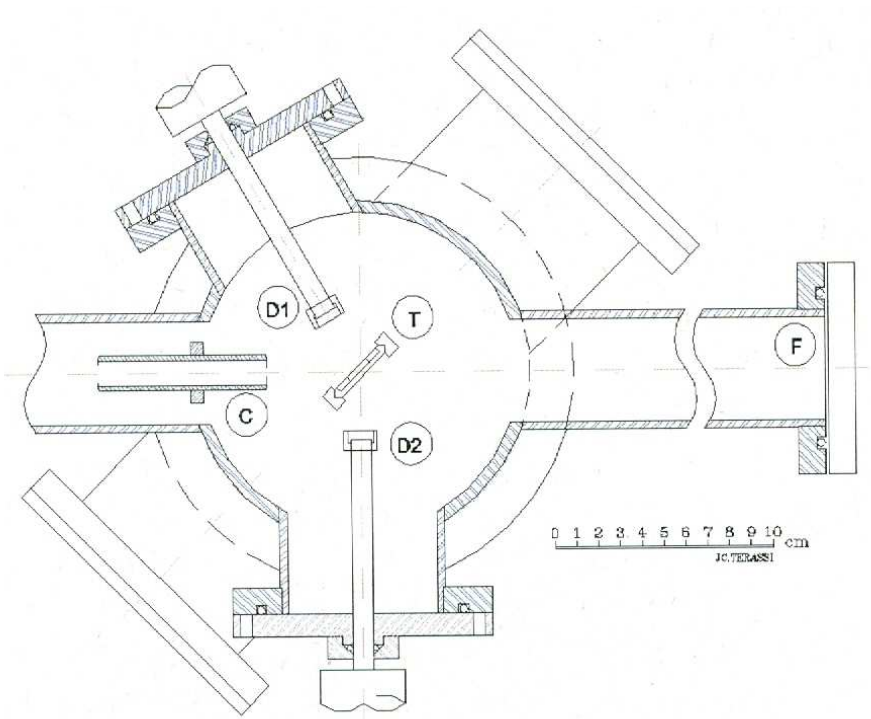

Figura 4.6 - Arranjo experimental para análise PIXE em vácuo do LAMFI. D1 [detector K(Baixa)] e D2 [detector $L$ (Alta)] são detectores de $\mathrm{Si}(\mathrm{Li})$, $C$ é um colimador, $T$ é o porta-alvo e $\mathrm{F}$ é o copo de Faraday, (ABURAYA, 2005). 


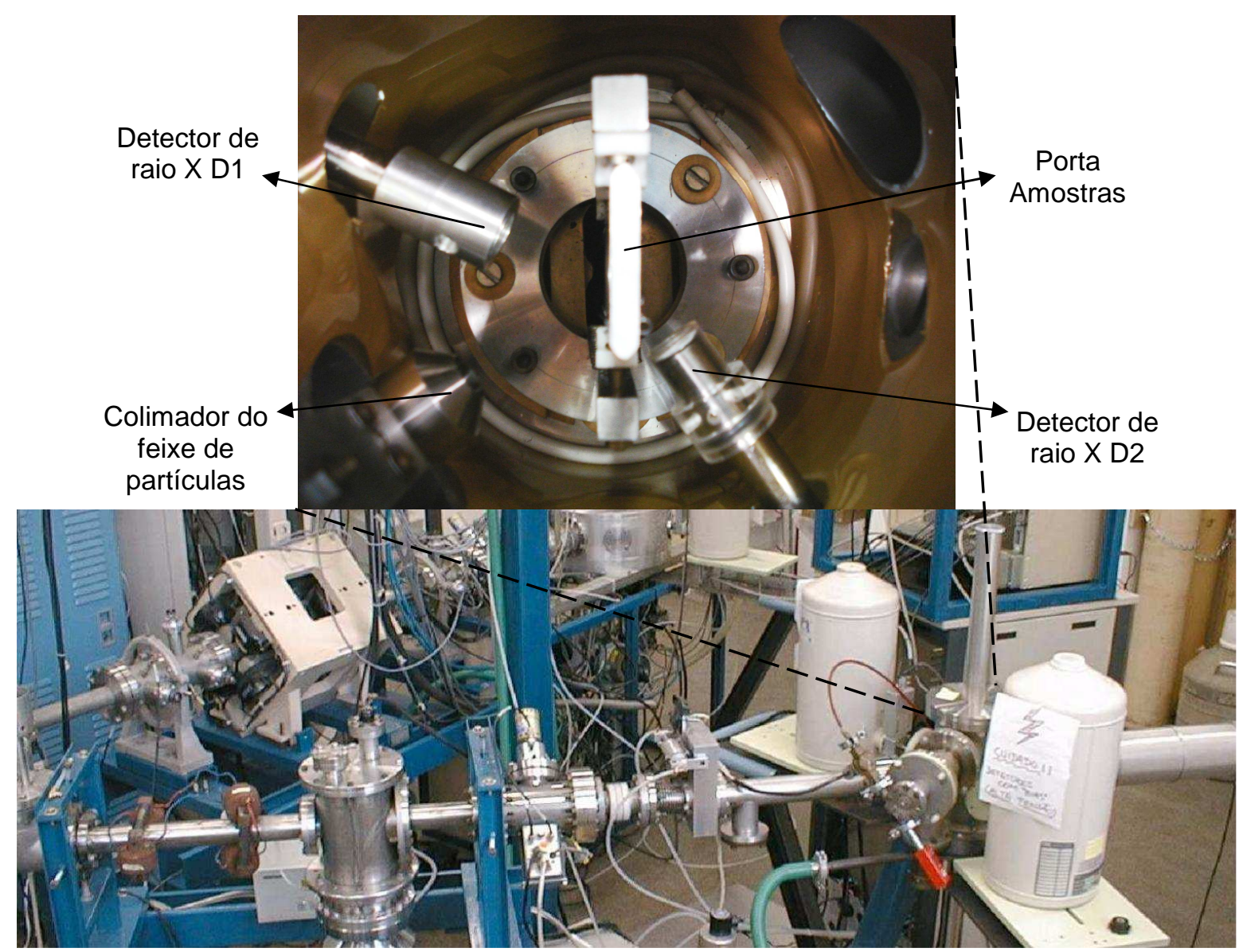

Figura 4.7 - Imagens do arranjo experimental PIXE no LAMFI. Na imagem inferior temos a vista da canalização a 30, juntamente com os detectores e a câmara PIXE. Na imagem superior temos a vista do interior da câmara de radiação para PIXE interno do LAMFI (ABURAYA, 2005).

A energia do feixe de prótons $\left(\mathrm{H}^{+}\right)$utilizada foi de $2,4 \mathrm{MeV}$ e o feixe incidiu a $135^{\circ}$ em relação à normal da amostra, minimizando a auto-absorção. O tempo de exposição de cada amostra foi de $600 \mathrm{~s}$. A medida de carga foi obtida pela medição da corrente, sem amostra, imediatamente posterior à medida de cada amostra, durante $100 \mathrm{~s}$.

\subsubsection{Arranjo Experimental para Medidas de PIXE Externo}

Com a finalidade de aplicarmos a técnica PIXE em peças metálicas de acervos arqueológicos e culturais e como as peças são delicadas e podem ser danificadas se expostas a alto vácuo, utilizou-se também neste trabalho uma montagem experimental de feixe externo para análise das pátinas. A fotografia, bem 
como o desenho esquemático, desta montagem de feixe externo são mostrados nas Figuras 4.8 e 4.9 , respectivamente. As facilidades de uso deste arranjo de feixe externo estão no manuseio das amostras no ambiente externo, e na não limitação das dimensões e das formas das amostras.

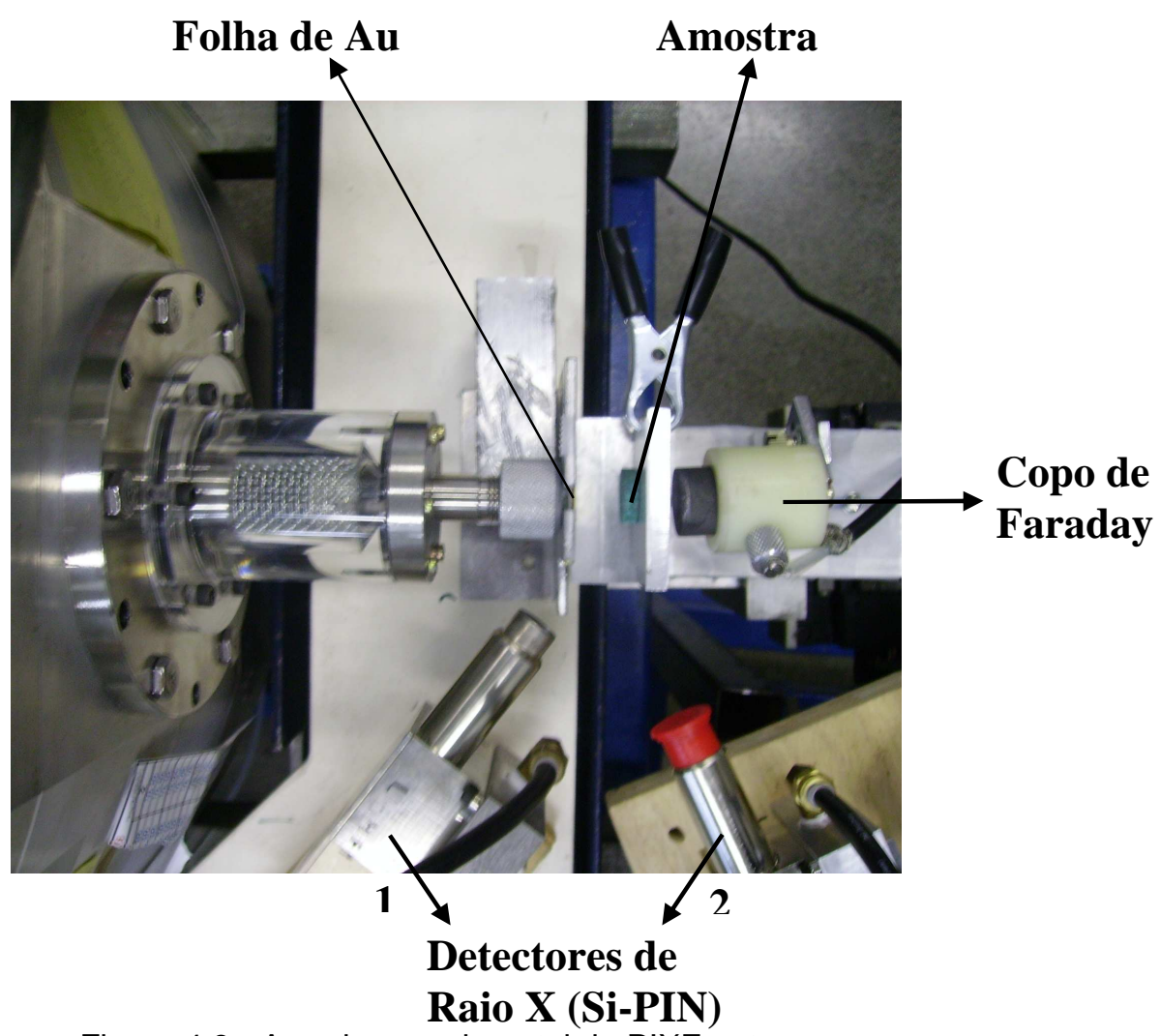

Figura 4.8 - Arranjo experimental do PIXE externo.

Como as pátinas analisadas são consideradas alvos grossos e não é possível utilizarmos um copo de Faraday para recolhermos a carga que atravessa a amostra (como para um alvo fino), não possibilitando determinar o número de partículas que chegam à mesma. Assim, a fim de quantificar os elementos presentes nas amostras, utilizamos, neste arranjo de feixe externo, uma folha de ouro entre a saída do feixe e a amostra. Para este procedimento de determinação da carga que chega à amostra, utilizamos também um detector de raio $X$ voltado para esta folha de Au (detector 2), de tal modo que podemos obter um espectro das linhas $L$ provenientes do filme de Au. Deste modo, foi possível encontrar uma relação entre a carga recolhida por um copo de Faraday (sem amostra) e áreas dos picos do espectro de raio $\mathrm{X}$ do ouro, e obter uma calibração de carga $(Q)$ e, consequentemente, uma medida desta para cada amostra (alvo grosso) analisada posteriormente. 
Vácuo

Atmosfera

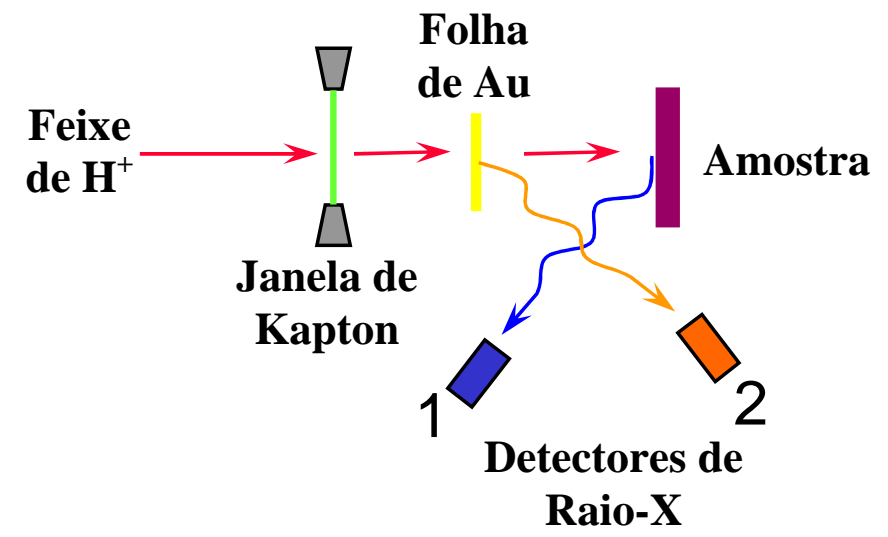

Figura 4.9 - Desenho esquemático do arranjo experimental do método PIXE para feixe externo.

Na configuração do método PIXE com feixe externo, mostrado na Figura 4.8, o feixe é levado para o ar através de um colimador de carbono colocado dentro de um tubo de acrílico transparente e uma janela de saída feita com uma folha de Kapton $\circledast$ de $50 \mu \mathrm{m}$ de espessura. Para evitar descargas elétricas na parede interna do tubo de acrílico, este foi coberto com uma rede metálica. Devido à passagem do feixe por uma janela de Kapton® e por uma camada de ar de $18-27 \mathrm{~mm}$, sua energia final ao chegar à amostra foi menor do que os 2,4 MeV, inicialmente gerado internamente, e variou dependendo da geometria do arranjo externo utilizado. A folha de ouro utilizada nas medidas foi de aproximadamente $100 \mu \mathrm{g} / \mathrm{cm}^{2}$ e os raios $X$ característicos do ouro foram detectados com um detector XR-100CR (Si-PIN, FWHM $220 \mathrm{eV} @ 5,9 \mathrm{keV}{ }^{55} \mathrm{Fe}$ ). Outro detector XR-100CR (Si-PIN, FWHM $160 \mathrm{eV}$ @ 5,9 keV ${ }^{55} \mathrm{Fe}$ ) foi utilizado para detectar os raios $X$ característicos da amostra. Este detector foi colocado aproximadamente $42 \mathrm{~mm}$ do alvo em um ângulo de aproximadamente $50^{\circ} \mathrm{em}$ relação ao feixe incidente. Ambos os detectores foram montados sobre uma base de Alumínio com resfriamento a água para melhorar e manter a resolução dos detectores. A correntes típicas do feixe usadas para analisar as amostras eram de 0,4-2,0 nA, pequena suficiente para manter um baixo tempo morto e não haver sobreposição (pile-up) dos picos. O tempo de aquisição foi de aproximadamente de 300-600 s para cada amostra. Devido à presença de raios $X$ 
de argônio, presente no ar houve uma piora nos limites de detecção para as linhas K de cloro $(\mathrm{Cl})$ e de potássio $(\mathrm{K})$.

\subsubsection{Curva de Rendimento para Medidas de PIXE}

A curva de rendimento experimental para o arranjo PIXE instalado no LAMFI (interno e externo) é obtida utilizando alvos finos padrão, normalmente da ordem de dezenas de $\mu \mathrm{g} / \mathrm{cm}^{2}$, irradiados nas mesmas condições das amostras (energia, distâncias, geometria, etc.). Sobre os pontos experimentais obtidos ajusta-se uma relação polinomial da secção de choque de ionização ECPSSR (MAXWELL; CAMPBELL; TEESDALE, 1989), os valores teóricos para a probabilidade de emissão (SCOFIELD, 1974) e os coeficientes de absorção de massa para raios X de Berger e Hubbel (1986). Um exemplo típico da curva de rendimento para o arranjo de PIXE é mostrado na Figura 4.10, onde é possível visualizar os pontos experimentais e a curva ajustada.

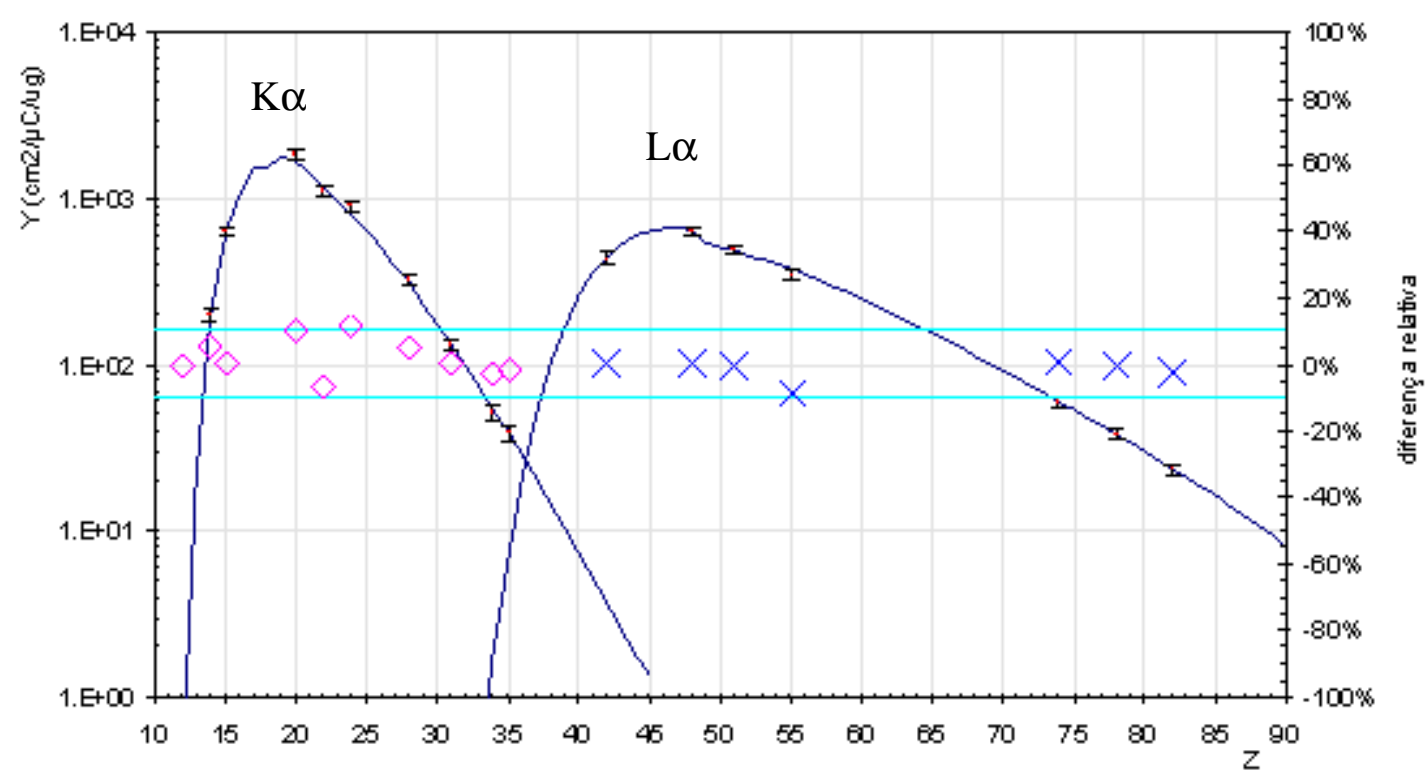

Figura 4.10 - Fator de resposta de alvo fino para linhas $\mathrm{K}_{\alpha}$ e $\mathrm{L}_{\alpha}$, para um arranjo de PIXE externo, com um feixe de prótons de 1,77MeV (curva obtida em outubro de 2007- LAMFI).

Devido à janela de Be presente no detector, há uma limitação da região sensível às linhas $K_{\alpha}$, possibilitando a detecção de elementos com $13<Z<40$, para as linhas $L_{\alpha}$ é possível detectar elementos com Z>38 (TABACNIKS, 2000). 


\section{Capítulo 5}

\section{Resultados Experimentais e Discussões}

\subsection{Espessura e Composição das camadas das amostras}

Hernández (2004), em seus estudos, obteve as medidas das espessuras das camadas e da composição química através da utilização de duas técnicas, MEV (Microscopia Eletrônica de Varredura) e XRD (Difração de Raio X), para amostras semelhantes às aqui analisadas, S1 e S2 sobre cobre e bronze, usando a mesma técnica de aplicação por umedecimento. A Tabela 5.1 mostra os resultados obtidos.

Tabela 5.1 - Medidas das espessuras das camadas e da composição, por MEV e XRD, para S1 e S2 sobre cobre e bronze (HERNÁNDEZ, 2004).

\begin{tabular}{|c|c|c|c|}
\hline Pátina & Camada & $\begin{array}{c}\text { Espessura } \\
(\mu \mathrm{m})\end{array}$ & $\begin{array}{c}\text { Posição da } \\
\text { Camada }\end{array}$ \\
\hline \multirow[t]{2}{*}{ Cobre + S1 } & $\begin{array}{c}\mathrm{Cu}_{2}\left(\mathrm{NO}_{3}\right)(\mathrm{OH})_{3}+ \\
\mathrm{Cu}_{2} \mathrm{O}\end{array}$ & 3,8 & Externa \\
\hline & $\mathrm{CuCl}$ & 2,7 & Interna \\
\hline \multirow[b]{2}{*}{ Bronze + S1 } & $\mathrm{Cu}_{2}\left(\mathrm{NO}_{3}\right)(\mathrm{OH})_{3}$ & 7,9 & Externa \\
\hline & $\begin{array}{c}\mathrm{CuCl}+\mathrm{Cu}_{2} \mathrm{O}+ \\
\mathrm{Cu}_{2} \mathrm{Cl}(\mathrm{OH})_{3}\end{array}$ & 2,4 & Interna \\
\hline Cobre + S2 & $\begin{array}{c}\mathrm{Cu}_{2}\left(\mathrm{NO}_{3}\right)(\mathrm{OH})_{3}+ \\
\mathrm{CuCl}+\mathrm{Cu}_{2} \mathrm{Cl}(\mathrm{OH})_{3}\end{array}$ & 3,4 & Única \\
\hline Bronze + S2 & $\begin{array}{c}\mathrm{Cu}_{2}\left(\mathrm{NO}_{3}\right)(\mathrm{OH})_{3}+ \\
\mathrm{CuCl}+\mathrm{Cu}_{2} \mathrm{Cl}(\mathrm{OH})_{3}\end{array}$ & - & Única \\
\hline
\end{tabular}

Tendo em mãos esta informação, poderemos simular a interação dos íons incidentes com tais amostras, a fim de determinar onde se dá o maior número de interações entre estes íons e amostra, para assim, determinarmos em que região da amostra há a maior contribuição de raios $\mathrm{X}$ característicos nas medidas PIXE.

Para tal simulação, utilizamos o programa TRIM/SRIM 2003 (ZIEGLER, 2004) baseado no método Monte Carlo. Simulamos um feixe de prótons, incidindo a $90^{\circ}$ em relação à amostra, com energia de 1,77 MeV (a menor energia dos feixes de prótons que chegaram às amostras nas medidas PIXE, pois possuía um arranjo com 
a maior camada de ar, percorrida pelo feixe externo), interagindo com a amostra de S1 sobre bronze [amostra que possui a maior camada de pátina, camada 1: $\mathrm{Cu}_{2}\left(\mathrm{NO}_{3}\right)(\mathrm{OH})_{3}$ com 7,9 $\mu \mathrm{m}$; camada 2: $\mathrm{CuCl}+\mathrm{Cu}_{2} \mathrm{O}+\mathrm{Cu}_{2} \mathrm{Cl}(\mathrm{OH})_{3} \operatorname{com} 2,4 \mu \mathrm{m}$; o restante é bronze, (Cu 96,6; Sn 1,7\%; Zn 1,7\%; em porcentagem atômica)], a fim visualizar a interação na configuração que teve a maior possibilidade de absorção de energia pela camada de pátina nas medidas PIXE.

Os resultados das simulações podem ser vistos nas Figuras 5.1 e 5.2.
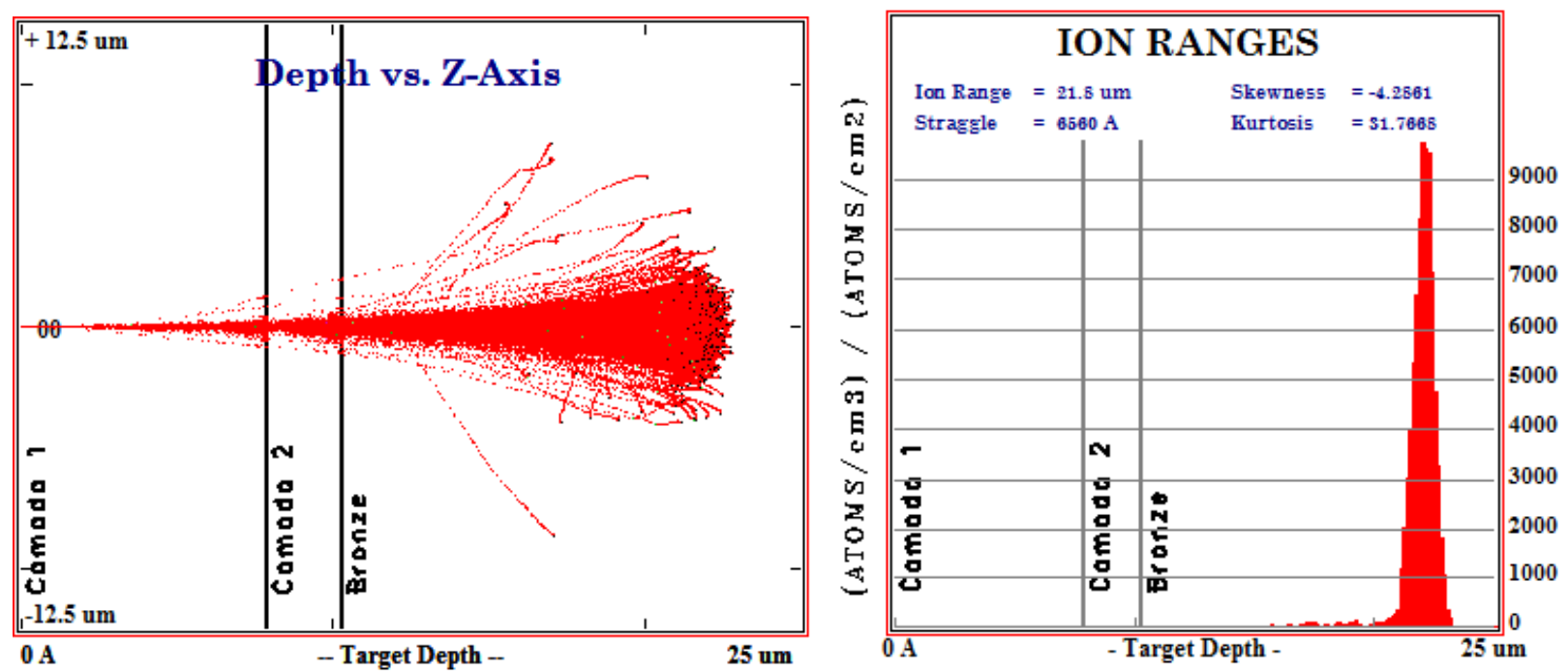

Figura 5.1 - Simulação de prótons incidindo a $90^{\circ} \mathrm{C}$ om $1,77 \mathrm{MeV}$ de energia, interagindo com a amostra de $\mathrm{S} 1$ sobre bronze (camada 1 de $7,9 \mu \mathrm{m}$; camada 2 de 2,4 $\mu \mathrm{m}$; o restante de bronze). À esquerda: a penetração dos íons e seu alcance na amostra. À direita: o histograma do alcance dos íons, com média de penetração de 21,8 $\mu \mathrm{m}$ (TRIM/SRIM 2003).

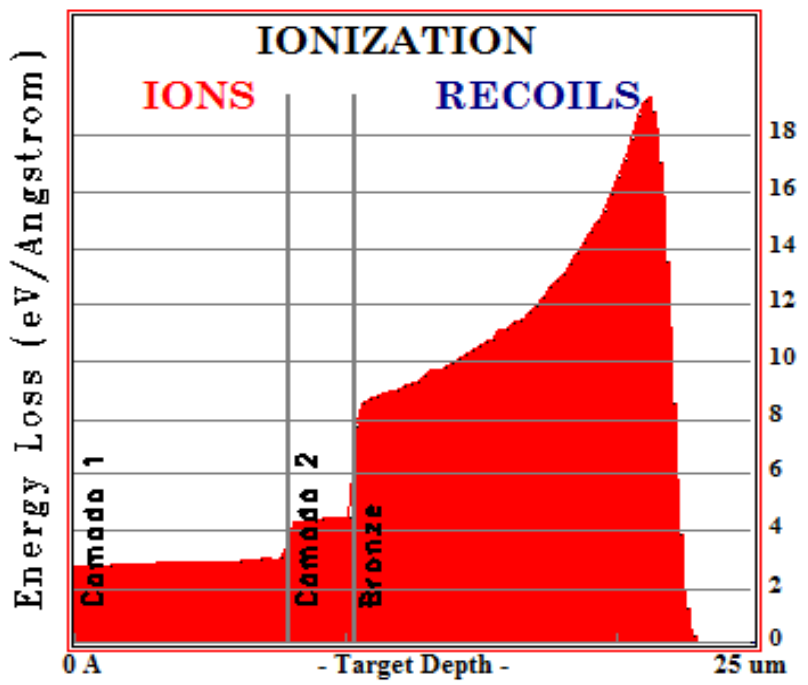

Figura 5.2 - Simulação de prótons incidindo a $90^{\circ} \mathrm{C} \mathrm{om} \mathrm{1,77} \mathrm{MeV} \mathrm{de} \mathrm{energia,} \mathrm{interagindo} \mathrm{com} \mathrm{a}$ amostra de S1 sobre bronze (camada 1 de com 7,9 $\mu$ m; camada 2 de 2,4 $\mu \mathrm{m}$; o restante é bronze). lonização pelos íons incidentes, pela perda de energia na amostra (TRIM/SRIM 2003). 
Observando os resultados obtidos pela simulação, podemos ver que o maior número de interações, que contribuem para a análise PIXE, se dá dentro da matriz de bronze, logo, a maior contribuição de raios $X$ característicos detectados são provenientes da matriz. Simulações semelhantes foram obtidas para a matriz de cobre.

Foi realizada também uma simulação semelhante para ED-XRF, utilizando o programa e base de dados XCOM 1.2 (Berger et al. 1998) para obter o coeficiente de atenuação e observar a absorção do raio X por uma amostra. No arranjo de ED$\mathrm{XRF}$, foi utilizado um tubo de raio $\mathrm{X}$ com alvo de $\mathrm{W}$, que possui um $k_{\alpha}$ na ordem de $59 \mathrm{keV}$ (Anexo A). Assim, determinamos o coeficiente de atenuação para três camadas diferentes, a camada 1, constituída de $\mathrm{Cu}_{2}\left(\mathrm{NO}_{3}\right)(\mathrm{OH})_{3}$ com 7,9 $\mu \mathrm{m}$ de espessura, a camada 2, constituída de $\mathrm{CuCl}+\mathrm{Cu}_{2} \mathrm{O}+\mathrm{Cu}_{2} \mathrm{Cl}(\mathrm{OH})_{3} \operatorname{com} 2,4 \mu \mathrm{m}$ de espessura, e a camada final de bronze. O resultado destas simulações pode ser observado na Tabela 5.2.

Tabela 5.2 - Simulação do coeficiente de atenuação de massa para o raios $X$ para uma amostra, sendo a camada 1: $\mathrm{Cu}_{2}\left(\mathrm{NO}_{3}\right)(\mathrm{OH})_{3}$; a camada 2: $\mathrm{CuCl}+\mathrm{Cu}_{2} \mathrm{O}+\mathrm{Cu}_{2} \mathrm{Cl}(\mathrm{OH})_{3}$; e a camada 3: bronze.

Os resultados foram gerados no programa e base de dados XCOM 1.2 (BERGER et al. 1998).

\begin{tabular}{|c|c|c|c|c|c|c|c|c|}
\hline & \multirow[b]{2}{*}{$\begin{array}{l}\text { Energia } \\
\text { do Fóton }\end{array}$} & \multicolumn{2}{|c|}{ Espalhamento } & \multirow{2}{*}{$\begin{array}{l}\text { Absorção } \\
\text { por efeito } \\
\text { foto- } \\
\text { elétrico }\end{array}$} & \multicolumn{2}{|c|}{ Produção de pares } & \multicolumn{2}{|c|}{ Atenuação Total } \\
\hline & & Coerente & Incoerente & & Nuclear & Eletrônico & $\begin{array}{c}\text { Com } \\
\text { Espalhamento } \\
\text { Coerente }\end{array}$ & $\begin{array}{c}\text { Sem } \\
\text { Espalhamento } \\
\text { Coerente }\end{array}$ \\
\hline & $\mathrm{MeV}$ & $\mathrm{cm}^{2} / \mathrm{g}$ & $\mathrm{cm}^{2} / \mathrm{g}$ & $\mathrm{cm}^{2} / \mathrm{g}$ & $\mathrm{cm}^{2} / \mathrm{g}$ & $\mathrm{cm}^{2} / \mathrm{g}$ & $\mathrm{cm}^{2} / \mathrm{g}$ & $\mathrm{cm}^{2} / \mathrm{g}$ \\
\hline $\begin{array}{c}\text { Camada } \\
1 \\
\end{array}$ & 0,06 & 0,0685 & 0,145 & 0,787 & 0 & 0 & 1 & 0,931 \\
\hline $\begin{array}{c}\text { Camada } \\
2\end{array}$ & 0,06 & 0,0872 & 0,137 & 0,984 & 0 & 0 & 1,21 & 1,12 \\
\hline Bronze & 0,06 & 0,112 & 0,131 & 1,51 & 0 & 0 & 1,75 & 1,64 \\
\hline
\end{tabular}

Como foi dito anteriormente, e podemos ver na Tabela 5.2, para esta faixa de energia há predomínio do efeito foto-elétrico na contribuição da absorção do raio $X$ pela matéria. $O$ efeito foto-elétrico é justamente a interação que acarreta a emissão de raios $X$ característicos. 
Pela lei de Beer-Lambert, um feixe de fótons com intensidade incidente de $I_{0}$ penetra uma camada de material com espessura de massa $x$ e densidade $\rho$, emergindo com intensidade $I$, dada pela atenuação:

(Eq. 49)

$$
\frac{I}{I_{0}}=e^{[-(\mu / \rho) x]},
$$

no qual $\mu$ é o coeficiente de atenuação e $(\mu / \rho)$ é o coeficiente de atenuação de massa. A espessura de massa é definida como a massa por unidade de área, e é obtida pela multiplicação da espessura $t$ pela densidade $\rho$, isto é:

$$
x=\rho . t
$$

Desse modo, podemos estimar a diminuição da intensidade do feixe que penetra na amostra, semelhante à utilizada na simulação para um feixe de íons. $O$ resultado obtido desta simulação pode ser visto na Tabela 5.3.

Tabela 5.3 - Resultado do cálculo de transmissão de um feixe de raio X passando inicialmente pela camada 1, e posteriormente pela camada 2 e bronze, respectivamente, para uma configuração estabelecida abaixo e também na Tabela 5.2.

\begin{tabular}{|c|c|c|c|}
\cline { 2 - 4 } \multicolumn{1}{c|}{} & $\begin{array}{c}\text { Densidade } \\
\left(\mathrm{g} / \mathrm{cm}^{3}\right) \\
(\mathrm{SRIM} / \mathrm{TRIM})\end{array}$ & $\begin{array}{c}\text { Espessura } \\
(\mathrm{cm})\end{array}$ & $\begin{array}{c}I \text { após passar } \\
\text { pela camada } \mathrm{e} \\
\text { todas as anteriores } \\
(\%)\end{array}$ \\
\hline Camada 1 & 2,3 & 0,00079 & 99,8 \\
\hline Camada 2 & 3,9 & 0,00024 & 99,7 \\
\hline Bronze & 8,9 & 0,00115 & 97,9 \\
\cline { 2 - 4 } & \multirow{2}{*}{8,25} & 1,99 \\
\hline
\end{tabular}

Mesmo após o feixe de raio $X$ ter passado pela espessura média de penetração dos íons de $\mathrm{H}$, de 21,8 $\mu \mathrm{m}$, simulados anteriormente para o PIXE, a intensidade do feixe de raio $X$ é de $97,9 \%$ da intensidade inicial do feixe incidente. Mostrando, desta forma, que o raio $X$ característico medido pela técnica ED-XRF provem de uma posição ainda mais profunda da amostra, tendo assim, uma predominância da contribuição dos raios $X$ característicos da matriz nas medidas de ED-XRF. 
Assim, deve-se ter cuidado ao comparar os espectros (PIXE ou ED-XRF) de amostras diferentes, pois há dependência conforme a espessura e a composição das camadas de pátina. As frações das informações espectrais que tem origem no substrato e nas camadas também são diferentes. Por exemplo, para uma fina camada de pátina, a razão da área do pico de $\mathrm{Cl} / \mathrm{Cu}$ e de $\mathrm{S} / \mathrm{Cu}$ devem ser menores do que as de uma pátina espessa, de mesma composição, pois no primeiro caso é maior a contribuição do cobre presente do substrato.

\subsection{Resultados qualitativos das medidas PIXE e ED-XRF}

Utilizando as técnicas PIXE e ED-XRF, foi possível obter os espectros de raio $X$ das amostras, que podem ser visualizados nas figuras a seguir.

Para as medidas realizadas de ED-XRF, foram observados falsos picos de $\mathrm{Zr}$, que não estão presentes nos espectros PIXE para as mesmas amostras. Isto é devido ao colimador dos detectores de SSD do fabricante Ketek $\circledast$, que são colimadores de zircônio. Esta mesma característica também foi observada em outro trabalho já publicado (FERRETTI, 2004).

Comparando os espectros das medidas ED-XRF e PIXE, podemos observar que o fundo do espectro ED-XRF para elementos de baixa energia é maior em comparação aos espectros PIXE. Logo, em relação o método PIXE, o método EDXRF possui maior limite de detecção para baixas energias, para um arranjo que utiliza um tubo de raio $\mathrm{X}$ com alvo de $\mathrm{W}$, que possui energia de excitação da ordem de $59 \mathrm{keV}$.

No entanto, para elemento de alta energia, a método ED-XRF possui menor limite de detecção em comparação com o método PIXE, como pode ser observado na comparação entre os diferentes espectros. 


\subsubsection{Matrizes das amostras}

Os resultados obtidos com o PIXE e com o ED-XRF para as amostras sem revestimento de cobre e de bronze são mostrados na Figura 5.3 e 5.4, respectivamente.

No cobre comercial, somente o PIXE interno detectou uma pequena quantidade de $\mathrm{Fe}, \mathrm{Al}$ e $\mathrm{Cr}$, que pode ser uma contribuição do arranjo experimental. PIXE interno e externo detectaram $S$ em pequena quantidade, um possível início de corrosão natural, pois estas medidas foram feitas após 16 meses. As medidas de PIXE interno também detectaram uma pequena quantidade de $\mathrm{Ca}$, possivelmente proveniente de contaminação. O Ar observado é proveniente da contribuição camada de ar, presente nos arranjos externos.
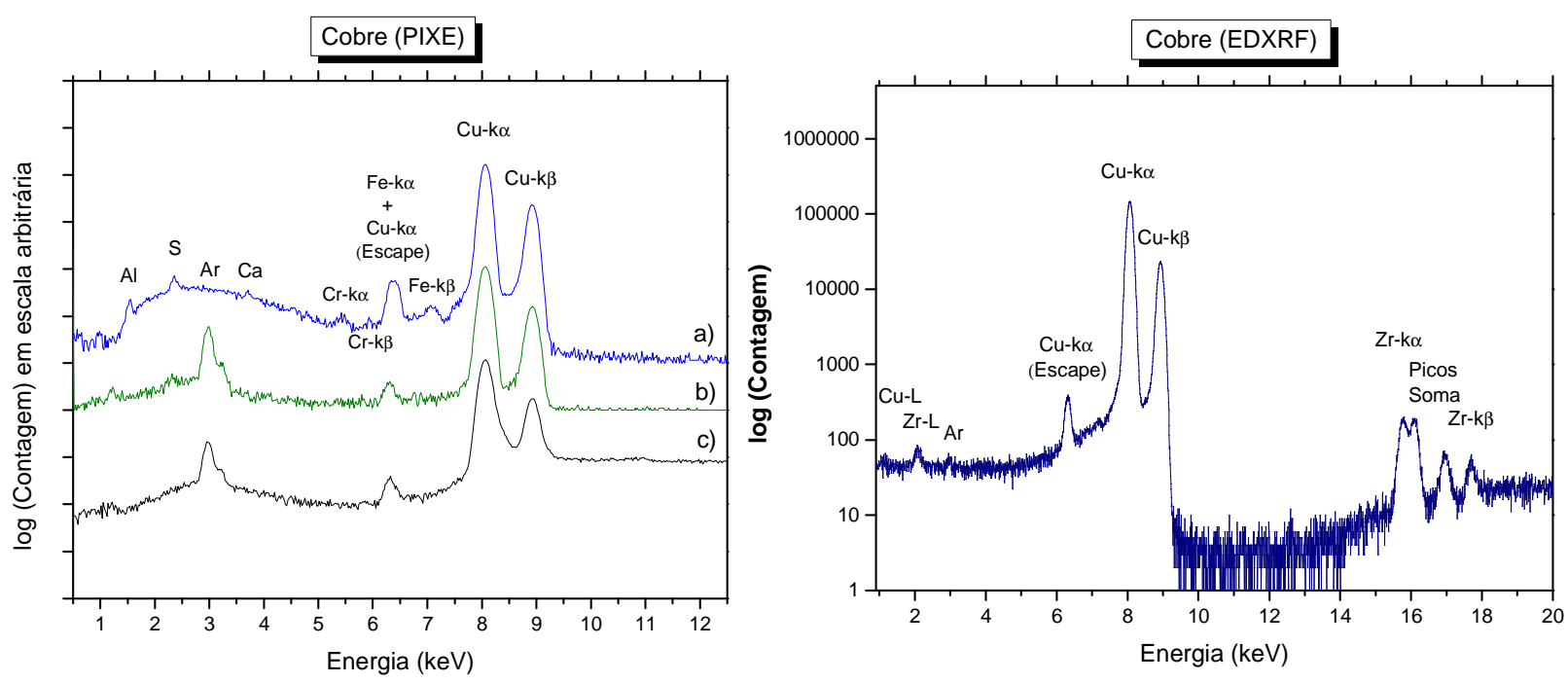

Figura 5.3 - Espectros PIXE (esquerda) e ED-XRF (direita) da matriz de cobre descoberto (pastilha). Para o espectro PIXE: a) Interno; b) Externo; c) Externo, 16 meses antes. 

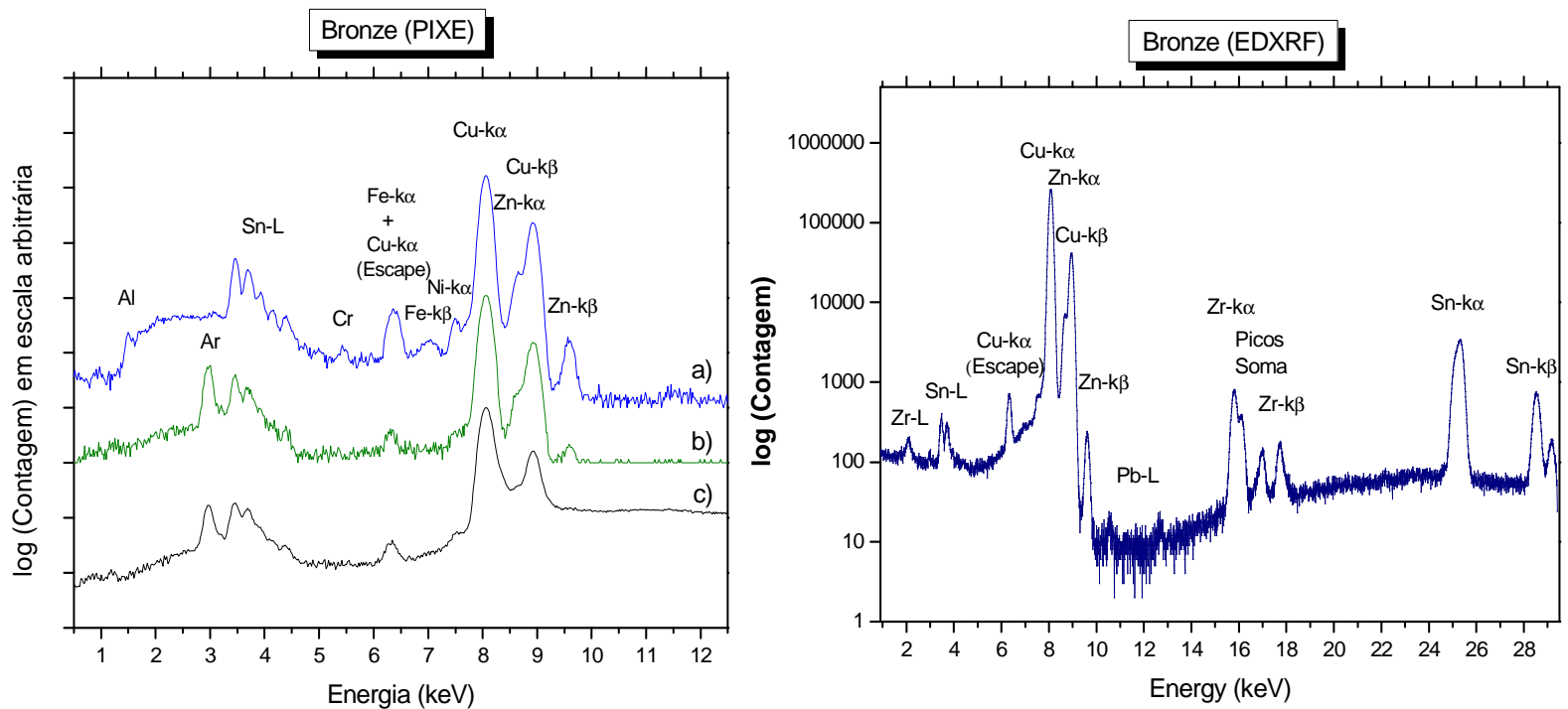

Figura 5.4 - Espectros PIXE (esquerda) e ED-XRF (direita) da matriz de bronze descoberto (pastilha). Para o espectro PIXE: a) Interno; b) Externo; c) Externo, 16 meses antes.

Para o bronze comercial, todos os arranjos detectaram os principais elementos da liga, $\mathrm{Cu}, \mathrm{Sn}$ e $\mathrm{Zn}$. Adicionalmente, o PIXE interno detectou pequenas quantidades de $\mathrm{Al}, \mathrm{Cr}$, $\mathrm{Fe}$ e $\mathrm{Ni}$, e o EDXRF detectou pequenas quantidades de $\mathrm{Pb}$. Os elementos $\mathrm{Ni}$ e $\mathrm{Pb}$ são possíveis "contaminações" da liga de bronze.

\subsubsection{Pátinas}

As Figuras 5.5, 5.6, 5.7 e 5.8 mostram os espectros obtidos por PIXE e por ED-XRF para, respectivamente, o cobre + S1 e cobre + S2, ambos em chapas, e para o cobre $+\mathrm{S} 4$ e bronze $+\mathrm{S} 1$, estes dois últimos em pastilhas. Os componentes aniônicos importantes das camadas das patinas que podem ser detectados por PIXE e por ED-XRF são $\mathrm{Cl}$ e S. Para as amostras $\mathrm{S} 1$ e S2, o $\mathrm{Cl}$ foi detectado por ambas as técnicas, pois a solução utilizada na produção de tais pátinas possuía $\mathrm{Cl}$. Por outro lado o $\mathrm{S}$ foi detectado em todas as amostras, exceto na amostra de bronze + $S 1$, que não possuía $S$ na solução. $O S$ foi detectado predominante em $S 4$, pois esta solução continha $S$ em sua composição. No entanto, a deteç̧ão de $S$ nas outras amostras, cobre + S1 e cobre + S2, pode indicar um princípio de corrosão, como mostra também o espectro da pastilha de cobre aplicação de solução, onde indica a presença de $\mathrm{S}$ para duas medidas, dezesseis meses depois de uma medida que não encontramos S. 
$\mathrm{Na}$ amostras de cobre, por não possuir Sn, foi possível observar pequenas quantidades de Ca pelo método PIXE, tanto o interno quanto o externo, o que indica, novamente, contaminação por manuseio. Para o PIXE interno, novamente foi possível observar $\mathrm{Cr}$ em todas as amostras. Ainda no PIXE interno, detectou-se uma pequena quantidade de Ti nas amostras de cobre + S1 e cobre + S2, uma possível contribuição presente na amostras em chapas. $\mathrm{O}$ Pb foi novamente observado pela medida ED-XRF para amostra de bronze + S1, indicando a contaminação do bronze.
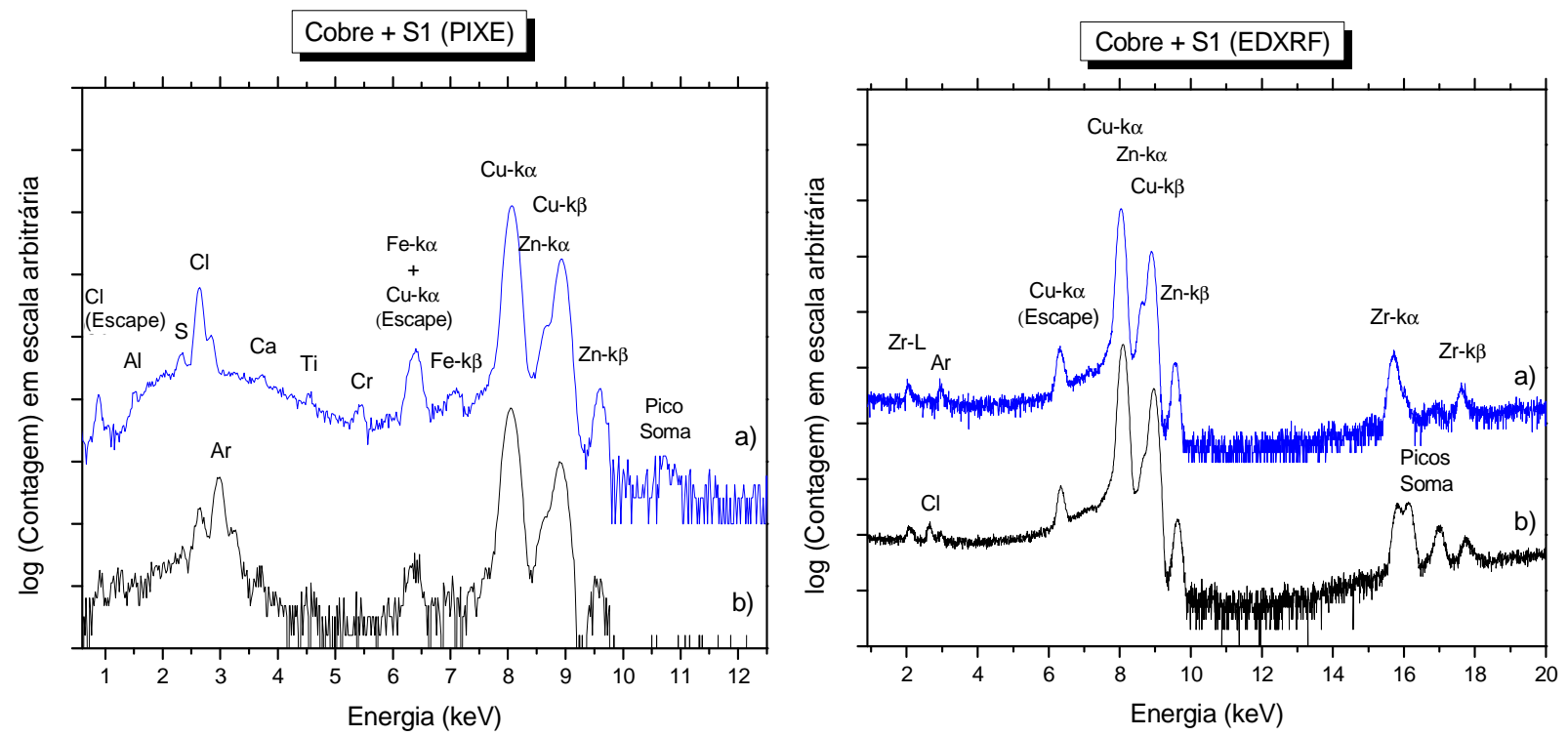

Figura 5.5 - Espectros PIXE (esquerda) e EDXRF (direita) do cobre coberto com a pátina S1 (chapa).

Para o espectro PIXE: a) Interno; b) Externo. Para o espectro ED-XRF: a) 45-edxrf; b) 0-edxrf.
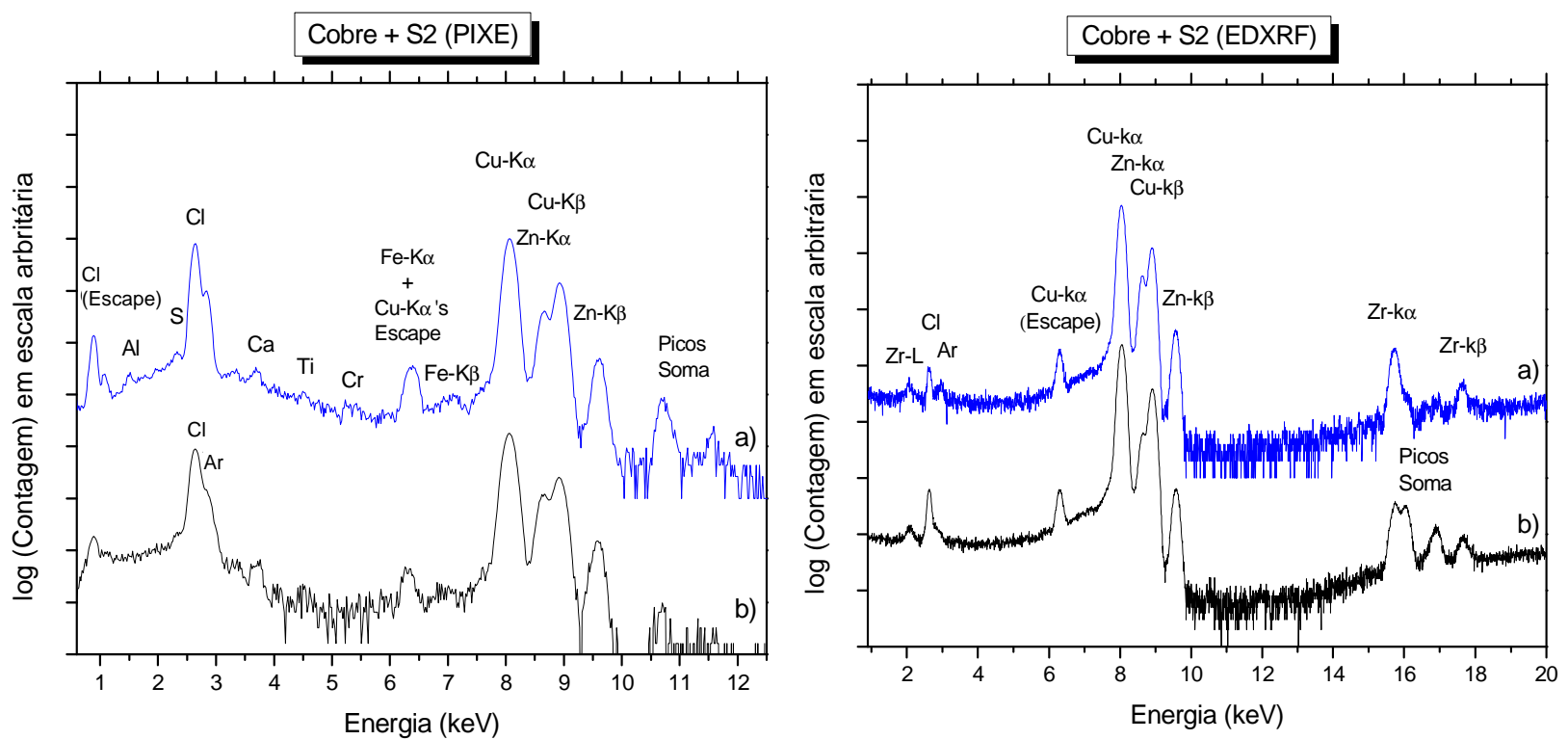

Figura 5.6 - Espectros PIXE (esquerda) e EDXRF (direita) do cobre coberto com a pátina S2 (chapa). Para o espectro PIXE: a) Interno; b) Externo. Para o espectro ED-XRF: a) 45-edxrf; b) 0-edxrf. 

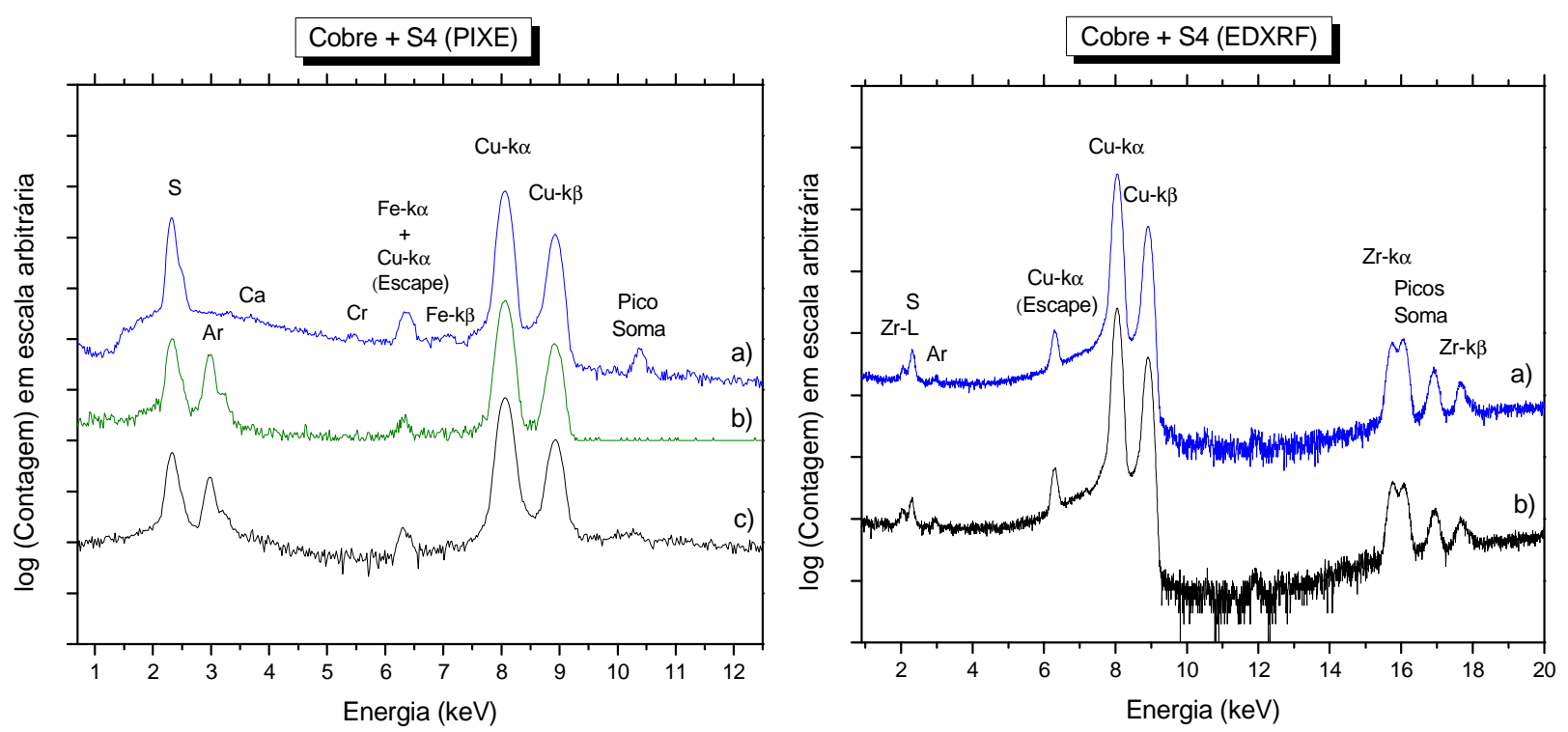

Figura 5.7 - Espectros PIXE (esquerda) e EDXRF (direita) do cobre coberto com a pátina S4 (pastilha). Para o espectro PIXE: a) Interno; b) Externo; c) Externo, 16 meses antes. Para o espectro ED-XRF: a) 45-edxrf; b) 0-edxrf.
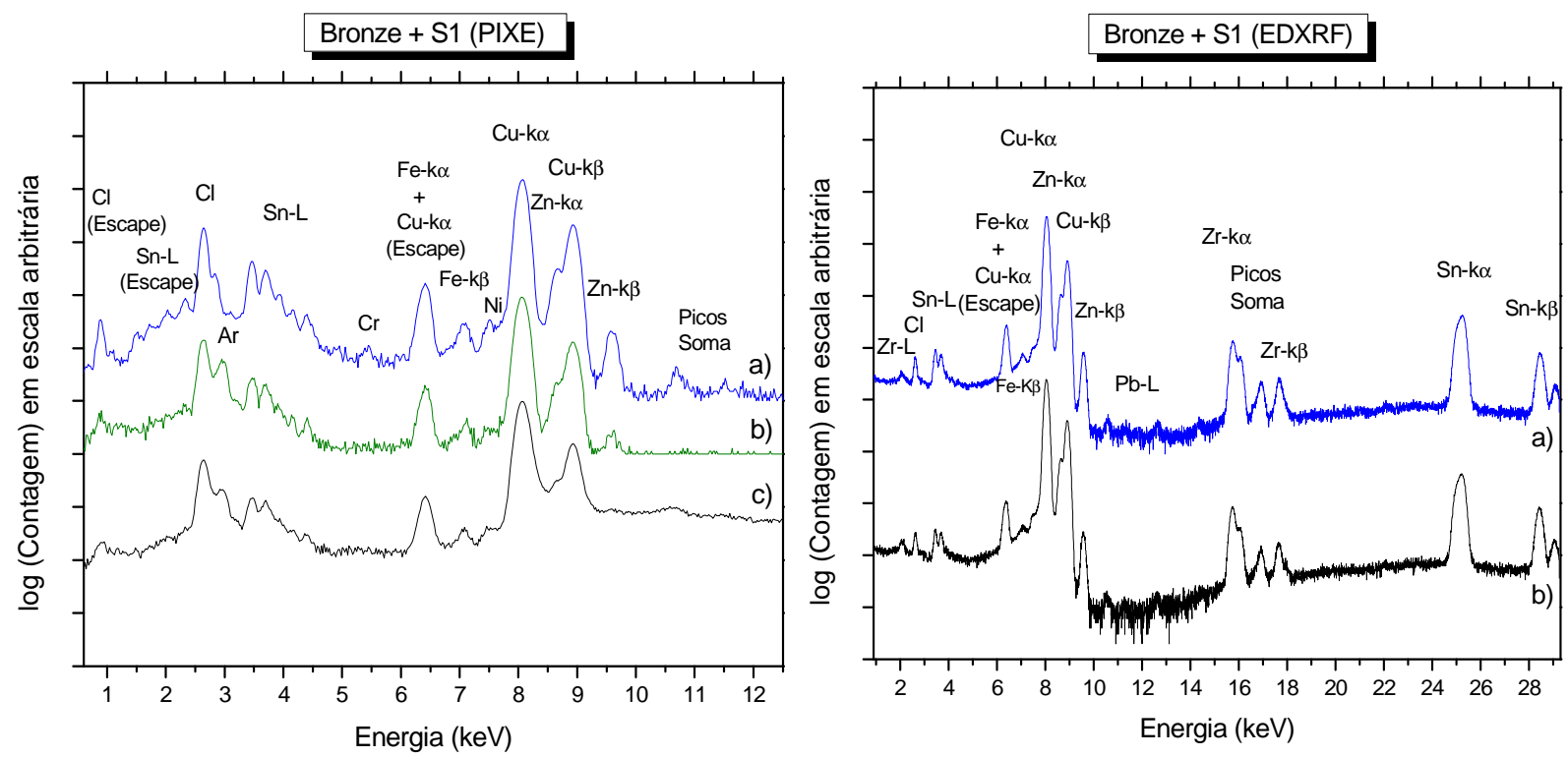

Figura 5.8 - Espectros PIXE (esquerda) e EDXRF (direita) do bronze coberto com a pátina S1 (pastilha). Para o espectro PIXE: a) Interno; b) Externo; c) Externo, 16 meses antes. Para o espectro ED-XRF: a) 45-edxrf; b) 0-edxrf. 
Estes resultados confirmam, como esperado, que o método PIXE, mesmo externo, é mais sensível do que ED-XRF, na a energia de excitação utilizada (da ordem de $59 \mathrm{keV}$ ), para elementos leves, como Al, S e Cl, e ED-XRF é mais sensível do que PIXE para elementos mais pesados, como o $\mathrm{Pb}$.

Além disso, pelas Figuras 5.5 e 5.6 é possível observar a diferença nos picos de $\mathrm{Cl}$ dos espectros ED-XRF entre os arranjos com ângulo do feixe incidente de $0^{\circ} \mathrm{e}$ $45^{\circ} \mathrm{em}$ relação à amostra, isto ocorre devido a pene tração do feixe de raio $X$ na amostra. No caso de $0^{\circ}$, o feixe de raio $X$ atinge a amostra de forma mais tangencial, logo, uma maior camada de pátina está sendo analisada.

$\mathrm{Na}$ amostra cobre + $\mathrm{S} 2$ o pico de $\mathrm{Cl}$ é muito maior, pois maior é a concentração de $\mathrm{Cl}$ na solução S2.

\subsection{Resultados quantitativos de PIXE}

A área de cada elemento do espectro PIXE foi obtida utilizando o programa WinQXAS, elaborado e disseminado pela Agencia Internacional de Energia Atômica (International Atomic Energy Agency, IAEA).

A partir da formulação para a técnica PIXE, deduzida na Secção 3.5.2, podese determinar da concentração do elemento $i\left(C_{i}\right)$ presente em uma amostra a partir do rendimento para alvos finos de cada elemento $\left(r_{i}\right)$, da carga coletada que chegou à amostra $(Q)$, da área do pico de cada elemento no espectro $\left(A_{i}\right)$, e do fator de correção para alvos grossos $\left(F_{i}\right)$. Esta concentração para cada elemento é então determinada pela Equação 51.

$$
C_{i}=\frac{A_{i}}{Q \cdot r_{i} \cdot F_{i}}
$$

Nas medidas externas, a carga de cada espectro foi determinada a partir da medida do espectro da folha de Au atravessada pelo feixe incidente (procedimento de obtenção da carga pela detecção de raios $X$ de $A u$ ). Mas para as medidas internas, o valor da carga para cada espectro foi obtida pela medição da corrente, sem amostra, imediatamente posterior à medida de cada amostra. 
O fator de correção para alvos grossos de cada elemento foi obtido utilizando o programa CLARA, que calcula este fator considerando a geometria do arranjo experimental, a energia inicial e final do feixe de prótons e a constituição da matriz da amostra. Para todas as amostras, a matriz considerada no cálculo foi a correspondente ao seu respectivo substrato homogêneo, pois como mostrado na secção 5.1, as interações que nos interessa ocorrem predominantemente no substrato sendo a pátina considerada apenas como uma amostra fina sobre um substrato infinito. As matrizes utilizadas no cálculo do programa foram respectivamente cobre puro (100\%) e bronze com composição de $96,6 \%$ de cobre, $1,7 \%$ de Sn, e $1,7 \%$ de $Z n$, em porcentagem atômica.

Uma limitação de tal programa está na não possibilidade de determinar tal fator de correção para uma matriz não homogênea.

\subsubsection{Resultados PIXE de Padrões Metálicos}

A fim de verificar a acurácia da técnica utilizada, fizemos conjuntamente às medidas das pátinas e suas matrizes descobertas, análises de padrões certificados de metais, sendo eles JK-49 (KIMAB, 2005) e CRM 298-1 (SIMR, 2002).

As Tabelas 5.4 e 5.5 mostram os valores de concentração em massa obtidos pela técnica PIXE para os padrões de aço JK-49 e CRM 298-1, respectivamente.

Tabela 5.4 - Resultado da concentração em massa obtido para o metal Certificado JK-49, pela técnica PIXE, a partir dos dados adquiridos em três períodos.

\begin{tabular}{|c|c|c|c|c|c|c|c|c|c|}
\hline \multicolumn{9}{|l|}{ JK-49 } & \multirow{3}{*}{$\begin{array}{c}\begin{array}{c}\text { Valores } \\
\text { Certificados }\end{array} \\
{[] \%}\end{array}$} \\
\hline \multicolumn{3}{|c|}{1 - PIXE Externo } & \multicolumn{3}{|c|}{$\begin{array}{c}2 \text { - PIXE Interno } \\
\text { (15 meses após a } 1 \text { a medida) }\end{array}$} & \multicolumn{3}{|c|}{$\begin{array}{c}3 \text { - PIXE Externo } \\
\text { (16 meses após a 1a medida) }\end{array}$} & \\
\hline Elemento & {[]$\%$} & Erro [ ]\% & Elemento & {[]$\%$} & Erro [ ]\% & Elemento & {[]$\%$} & Erro [ ]\% & \\
\hline $\mathrm{Fe}$ & 76 & 6 & $\mathrm{Fe}$ & 76 & 5 & $\mathrm{Fe}$ & 75 & 12 & 74,48 \\
\hline V & 9,8 & 0,7 & V & 10,1 & 0,7 & V & 10,0 & 1,6 & 9 \\
\hline $\mathrm{Cr}$ & 5,8 & 0,4 & $\mathrm{Cr}$ & 6,5 & 0,5 & $\mathrm{Cr}$ & 6,4 & $\overline{1,1}$ & 5 \\
\hline $\mathrm{W}$ & 2,80 & 0,25 & $\mathrm{~W}$ & 2,50 & 0,18 & W & 3,7 & 0,6 & 4 \\
\hline Mo & 3,07 & 0,25 & $\mathrm{Mo}$ & 2,51 & 0,19 & Mo & 2,6 & 0,4 & 3 \\
\hline $\mathrm{Si}$ & 1,8 & 0,3 & $\mathrm{Si}$ & 1,09 & 0,08 & $\mathrm{Si}$ & 1,6 & 0,3 & 0,5 \\
\hline$S$ & - & - & $S$ & - & - & $S$ & - & - & 0,01 \\
\hline Co & 0,94 & 0,08 & Co & 0,80 & 0,06 & Co & 0,82 & 0,14 & 0,3 \\
\hline $\mathrm{Ni}$ & - & - & $\mathrm{Ni}$ & 0,172 & 0,017 & $\mathrm{Ni}$ & 0,161 & 0,019 & 0,2 \\
\hline $\mathrm{Cu}$ & - & - & $\mathrm{Cu}$ & 0,103 & 0,011 & $\mathrm{Cu}$ & 0,148 & 0,017 & 0,1 \\
\hline
\end{tabular}


Tabela 5.5 - Resultado da concentração em massa obtido para o metal Certificado CRM 298-1, pela técnica PIXE, a partir dos dados adquiridos em três períodos.

\begin{tabular}{|c|c|c|c|c|c|c|c|c|c|}
\hline \multicolumn{9}{|c|}{$\begin{array}{l}\text { CRM 298-1 } \\
\text { CRM }\end{array}$} & \multirow{2}{*}{$\begin{array}{c}\text { Valores } \\
\text { Certificados }\end{array}$} \\
\hline \multicolumn{3}{|c|}{1 - PIXE Externo } & \multicolumn{3}{|c|}{$\begin{array}{c}2 \text { - PIXE Interno } \\
\text { (15 meses após a } 1 \underline{\underline{a} \text { medida) }}\end{array}$} & \multicolumn{3}{|c|}{$\begin{array}{c}3 \text { - PIXE Externo } \\
\text { (16 meses após a 1a medida) }\end{array}$} & \\
\hline Elemento & {$[\mathrm{]} \%$} & Erro [ ] $\%$ & Elemento & {[]$\%$} & Erro [ ]\% & Elemento & {[]$\%$} & Erro [ ] $\%$ & {[]$\%$} \\
\hline $\mathrm{Fe}$ & 62 & 4 & $\mathrm{Fe}$ & 62 & 4 & $\mathrm{Fe}$ & 62 & 7 & 63,68 \\
\hline $\mathrm{Cr}$ & 28,2 & 2,0 & $\mathrm{Cr}$ & 28,4 & 2,0 & $\mathrm{Cr}$ & 27 & 3 & 24,72 \\
\hline $\mathrm{Ni}$ & 5,8 & 0,4 & $\mathrm{Ni}$ & 6,1 & 0,4 & $\mathrm{Ni}$ & 6,4 & 1,0 & 7,056 \\
\hline Mo & 3,6 & 0,3 & $\mathrm{Mo}$ & 3,24 & 0,24 & Mo & 3,3 & 0,4 & 3,799 \\
\hline $\mathrm{Si}$ & - & - & $\mathrm{Si}$ & 0,277 & 0,022 & $\mathrm{Si}$ & - & - & 0,262 \\
\hline $\mathrm{Cu}$ & - & - & $\mathrm{Cu}$ & 0,195 & 0,017 & $\mathrm{Cu}$ & 0,24 & 0,04 & 0,201 \\
\hline
\end{tabular}

Observando os valores calculados para os padrões, pode-se afirmar que os valores obtidos estão estatisticamente compatíveis com os valores de referência com um intervalo de confiança de $95 \%$, exceto para os elementos $\mathrm{Si}$, Co e $\mathrm{W}$ do padrão JK-49. O elemento $\mathrm{W}$ apresenta valores discrepantes na primeira medida de PIXE externo e na medida de PIXE interno não sendo claro o motivo para tal já que na última medida de PIXE externo há consistência entre o valor medido e o referenciado. No caso dos elementos $\mathrm{Si}$ e Co todos os valores se encontram superiores aos valores referenciados. O Si está na borda da curva de rendimento, isto é, possivelmente este elemento está subestimado neste cálculo, e nesta região uma pequena variação no ajuste da curva de rendimento pode mudar muito os valores finais. O cobalto possui uma linha espectral muito próxima a do elemento majoritário da liga, o ferro, no qual o pico $\mathrm{K}_{\beta}$ se sobrepõe ao pico $\mathrm{K}_{\alpha}$ do Co, que é um elemento traço na liga, dificultando a determinação da concentração de Co no padrão JK-49.

Os resultados das concentrações elementares obtidos pela técnica PIXE para padrões de aço, em comparação com os valores certificados, mostram que os valores obtidos por esta técnica permitem a aplicação desta técnica para análise de alvos grossos. 


\subsubsection{Resultados PIXE das Amostras}

Em algumas medidas de PIXE interno, pode-se observar a presença de $\mathrm{Al}, \mathrm{Fe}$ e $\mathrm{Cr}$ em pequenas quantidades, o que pode ser uma contribuição do arranjo experimental nas medidas. Por isso, estes elementos não foram considerados no cálculo da concentração dos elementos presentes na amostra.

As tabelas 5.6 e 5.7 resumem os resultados das concentrações elementares obtidas pelo método PIXE para uma pastilha de cobre e uma pastilha de cobre + S4, respectivamente. Nas medidas da pastilha de cobre puro (base da pátina) é observado o surgimento de enxofre nas duas últimas medidas tanto no arranjo de PIXE externo como interno, o que sugere um princípio de absorção de $S$ pela amostra, o que pode representar um processo de corrosão inicial. Além disso, nas medidas de PIXE interno, o cobre + S4 tem uma pequena quantidade de $\mathrm{Ca}$, que sugere uma contaminação.

Tabela 5.6 - Resultado da concentração em massa obtido para a pastilha de cobre comercial descoberta, pela técnica PIXE, a partir dos dados adquiridos em três períodos.

\begin{tabular}{|c|c|c|c|c|c|c|c|c|}
\hline \multicolumn{9}{|c|}{ Cobre (Pastilha) } \\
\hline \multicolumn{3}{|c|}{1 - PIXE Externo } & \multicolumn{3}{|c|}{$\begin{array}{c}2-\text { PIXE Interno } \\
\text { (15 meses após a 1a medida) }\end{array}$} & \multicolumn{3}{|c|}{$\begin{array}{c}3 \text { - PIXE Externo } \\
\text { (16 meses após a } 1^{\underline{a}} \text { medida) }\end{array}$} \\
\hline Elemento & {[]$\%$} & Erro [ ]\% & Elemento & {[]$\%$} & Erro [ ]\% & Elemento & {[]$\%$} & Erro [ ]\% \\
\hline $\mathrm{Cu}$ & 100 & - & $\mathrm{Cu}$ & 99 & 7 & $\mathrm{Cu}$ & 99 & 7 \\
\hline & & & $\bar{S}$ & 0,106 & 0,009 & $S$ & 0,15 & 0,04 \\
\hline
\end{tabular}

Tabela 5.7 - Resultado da concentração em massa obtido para uma pastilha de cobre + S4, pela técnica PIXE, a partir dos dados adquiridos em três períodos.

\begin{tabular}{|c|c|c|c|c|c|c|c|c|}
\hline \multicolumn{9}{|c|}{ Cobre + S4 (Pastilha) } \\
\hline \multicolumn{3}{|c|}{1 - PIXE Externo } & \multicolumn{3}{|c|}{$\begin{array}{c}2-\text { PIXE Interno } \\
\text { (15 meses após a 1a medida) }\end{array}$} & \multicolumn{3}{|c|}{$\begin{array}{c}3 \text { - PIXE Externo } \\
(16 \text { meses após a 1aㅡ medida) }\end{array}$} \\
\hline Elemento & {$[$ ] $\%$} & Erro [ ]\% & Elemento & {[]$\%$} & Erro [ ] $\%$ & Elemento & {[]$\%$} & Erro [ ]\% \\
\hline $\mathrm{Cu}$ & 82 & 6 & $\mathrm{Cu}$ & 86 & 6 & $\mathrm{Cu}$ & 81 & 6 \\
\hline$S$ & 17,5 & 1,2 & $S$ & 13,5 & 1,0 & $S$ & 19,0 & $\overline{1,4}$ \\
\hline & & & $\mathrm{Ca}$ & 0,0122 & 0,0026 & & & \\
\hline
\end{tabular}


As Tabelas 5.8 e 5.9 mostram os valores obtidos pela técnica PIXE para a concentração em massa de uma pastilha de bronze e de uma pastilha de bronze + S1, respectivamente. Na primeira tabela observa-se basicamente a constituição da matriz de bronze (Cu, Zn e Sn) e no PIXE interno ainda aparece o elemento $\mathrm{Ni}$, que pode ser um "contaminante" da liga, pois está presente somente nesta matriz e nas medidas desta matriz + S1 (tabela 5.9).

Tabela 5.8 - Resultado da concentração em massa obtido para a pastilha de bronze comercial descoberta, pela técnica PIXE, a partir dos dados adquiridos em três períodos. Bronze (Pastilha)

\begin{tabular}{|c|c|c|c|c|c|c|c|c|}
\hline \multicolumn{3}{|c|}{1 - PIXE Externo } & \multicolumn{3}{|c|}{$\begin{array}{c}2-\text { PIXE Interno } \\
\text { (15 meses após a 1a medida) }\end{array}$} & \multicolumn{3}{|c|}{$\begin{array}{c}3-\text { PIXE Externo } \\
\text { (16 meses após a } 1^{\underline{a}} \text { medida) }\end{array}$} \\
\hline Elemento & {[]$\%$} & Erro [ ]\% & Elemento & {[]$\%$} & Erro [ ] \% & Elemento & {[]$\%$} & Erro [ ]\% \\
\hline $\mathrm{Cu}$ & 95 & 7 & $\mathrm{Cu}$ & 96 & 7 & $\mathrm{Cu}$ & 95 & 19 \\
\hline $\mathrm{Zn}$ & 3,02 & 0,21 & $\mathrm{Zn}$ & 2,10 & 0,15 & $\mathrm{Zn}$ & 2,1 & 0,4 \\
\hline $\mathrm{Sn}$ & 2,02 & 0,11 & $\mathrm{Sn}$ & 1,97 & 0,14 & $\mathrm{Sn}$ & 2,9 & 0,6 \\
\hline & & & $\mathrm{Ni}$ & 0,155 & 0,013 & & & \\
\hline
\end{tabular}

$\mathrm{Na}$ pastilha de bronze + $\mathrm{S} 1$ aparecem os elementos $\mathrm{Cl}$ e $\mathrm{Fe}$, pois são elementos constituintes da solução $\mathrm{S} 1$, na forma de $\mathrm{FeCl}_{3}$. Além disso, a medida de Zn para o primeiro PIXE externo mostrou-se muito reduzida, em comparação com as demais medidas, isto provavelmente se deve à aquisição de dados (eletrônica) nestas primeiras medidas, que pode ter afetado a quantificação deste elemento (vide Figura 5.8). Ainda nas medidas com PIXE interno, outros elementos foram mensurados com concentrações em torno de $0,1 \%$. 
Tabela 5.9 - Resultado da concentração em massa obtido para uma pastilha de bronze $+\mathrm{S} 1$, pela técnica PIXE, a partir dos dados adquiridos em três períodos.

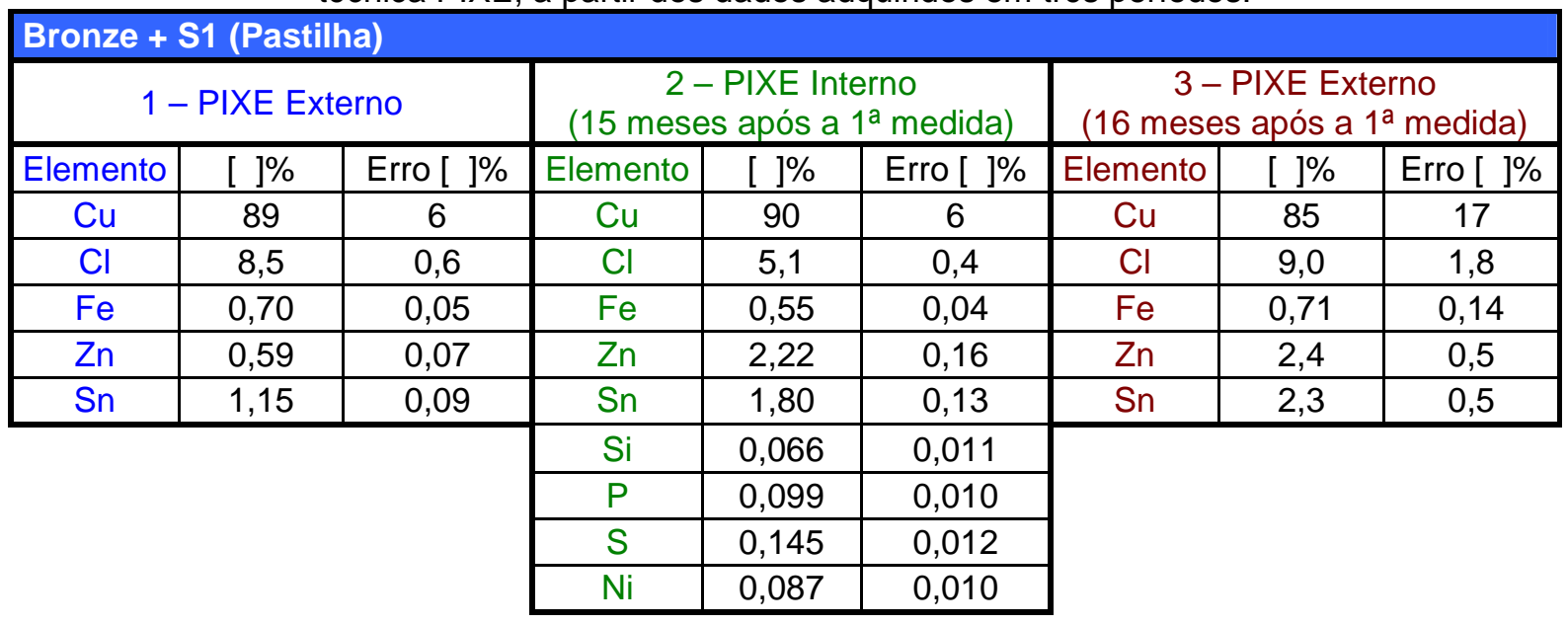

As tabelas 5.10, 5.11 e 5.12, mostram respectivamente os resultados obtidos para chapas de cobre sem aplicação de solução, com a aplicação da solução S1 por apenas 1 dia e com a aplicação da solução S1 durante 5 dias. As medidas mostram que diferentemente da chapa sem aplicação, as com aplicação possuem $\mathrm{Cl}, \mathrm{Zn}$ e Fe, que estão presentes na solução $S 1$ e os outros elementos são contaminações como anteriormente descritas. A não compatibilidade na concentração do elemento Fe nas duas medidas observadas na Tabela 5.11 pode ser devido à contribuição de Fe do arranjo nas medidas obtidas pelo PIXE interno.

Tabela 5.10 - Resultado da concentração em massa obtido para uma chapa de cobre comercial, pela técnica PIXE, a partir dos dados adquiridos em dois períodos.

\begin{tabular}{|c|c|c|c|c|c|}
\hline \multicolumn{6}{|c|}{ Cobre (Chapa) } \\
\hline \multicolumn{3}{|c|}{$\begin{array}{c}2-\text { PIXE Interno } \\
\text { (15 meses após a 1르 medida) }\end{array}$} & \multicolumn{3}{|c|}{$\begin{array}{c}3-\text { PIXE Externo } \\
\text { (16 meses após a } 1 \text { a medida) }\end{array}$} \\
\hline Elemento & [ ] $\%$ & Erro [ ]\% & Elemento & {[]$\%$} & Erro [ ]\% \\
\hline $\mathrm{Cu}$ & 99,9 & 7,1 & $\mathrm{Cu}$ & 100 & - \\
\hline $\mathrm{Ca}$ & 0,0148 & 0,0022 & & & \\
\hline
\end{tabular}


Tabela 5.11 - Resultado da concentração em massa obtido para uma chapa de cobre + S1 (com apenas um dia de aplicação da substância S1), pela técnica PIXE, a partir dos dados adquiridos em dois períodos.

\begin{tabular}{|c|c|c|c|c|c|}
\hline \multicolumn{3}{|c|}{$\begin{array}{c}2 \text { - PIXE Interno } \\
\text { (15 meses após a } 1 \underline{\underline{a}} \text { medida) }\end{array}$} & \multicolumn{3}{|c|}{$\begin{array}{c}3 \text { - PIXE Externo } \\
\text { (16 meses após a 1a medida) }\end{array}$} \\
\hline Elemento & [ ] $\%$ & Erro [ ]\% & Elemento & {[]$\%$} & Erro [ ]\% \\
\hline $\mathrm{Cu}$ & 98 & 7 & $\mathrm{Cu}$ & 97 & 5 \\
\hline $\mathrm{Cl}$ & 1,02 & 0,07 & $\mathrm{Cl}$ & 1,56 & 0,12 \\
\hline $\mathrm{Zn}$ & 0,92 & 0,07 & $\mathrm{Zn}$ & 1,11 & 0,09 \\
\hline $\mathrm{Fe}$ & 0,138 & 0,019 & $\mathrm{Fe}$ & 0,050 & 0,007 \\
\hline$S$ & 0,033 & 0,006 & $S$ & 0,031 & 0,006 \\
\hline $\mathrm{Ca}$ & 0,0163 & 0,0023 & $\mathrm{Ca}$ & 0,021 & 0,004 \\
\hline
\end{tabular}

Tabela 5.12 - Resultado da concentração em massa obtido para uma chapa de cobre + S1, pela técnica PIXE, a partir dos dados adquiridos em dois períodos.

\begin{tabular}{|c|c|c|c|c|c|}
\hline \multicolumn{6}{|c|}{ Cobre + S1 (Chapa) } \\
\hline \multicolumn{3}{|c|}{$\begin{array}{c}2-\text { PIXE Interno } \\
\text { (15 meses após a 1르 medida) }\end{array}$} & \multicolumn{3}{|c|}{$\begin{array}{c}3 \text { - PIXE Externo } \\
\text { (16 meses após a } 1^{\underline{a}} \text { medida) }\end{array}$} \\
\hline Elemento & {[]$\%$} & Erro [ ]\% & Elemento & {[]$\%$} & Erro [ ]\% \\
\hline $\mathrm{Cu}$ & 96 & 7 & $\mathrm{Cu}$ & 96 & 7 \\
\hline $\mathrm{Cl}$ & 1,77 & 0,13 & $\mathrm{Cl}$ & 1,23 & 0,13 \\
\hline $\mathrm{Zn}$ & 1,34 & 0,10 & $\mathrm{Zn}$ & 2,22 & 0,19 \\
\hline $\mathrm{Fe}$ & 0,195 & 0,029 & $\mathrm{Fe}$ & 0,078 & 0,016 \\
\hline S & 0,091 & 0,009 & $S$ & 0,10 & 0,08 \\
\hline $\mathrm{Ca}$ & 0,0155 & 0,0021 & $\mathrm{Ca}$ & 0,037 & 0,011 \\
\hline $\mathrm{Ti}$ & 0,0069 & 0,0014 & & & \\
\hline
\end{tabular}

As tabelas 5.13 e 5.14 apresentam as medidas obtidas para uma chapa de cobre com a aplicação da solução S2 durante 1 dia e durante 5 dias, respectivamente. Ao comparar as tabelas 5.10, 5.13 e 5.14, é possível observar a também a presença de $\mathrm{CI}$ nas amostras com pátinas (isto é, tanto na solução $\mathrm{S} 1$ ou S2).

Nas amostras de chapa de cobre com pátina (tabelas 5.12, 5.13 e 5.14), observou-se um aumento na concentração de $\mathrm{Zn}$ para medidas realizadas um mês depois, o que pode sugerir um processo de corrosão seletiva deste elemento. 
Tabela 5.13 - Resultado da concentração em massa obtido para uma chapa de cobre + S2 (com apenas um dia de aplicação da substância S2), pela técnica PIXE, a partir dos dados adquiridos em dois períodos.

\begin{tabular}{|c|c|c|c|c|c|}
\hline \multicolumn{3}{|c|}{$\begin{array}{c}2-\text { PIXE Interno } \\
\text { (15 meses após a } 1^{\mathrm{a}} \text { medida) }\end{array}$} & \multicolumn{3}{|c|}{$\begin{array}{c}3 \text { - PIXE Externo } \\
\text { (16 meses após a } 1^{\text {a }} \text { medida) }\end{array}$} \\
\hline Elemento & [ ]\% & Erro [ ]\% & Elemento & {[]$\%$} & Erro [ ]\% \\
\hline $\mathrm{Cu}$ & 69 & 5 & $\mathrm{Cu}$ & 75 & 5 \\
\hline $\mathrm{Cl}$ & 29,1 & 2,1 & $\mathrm{Cl}$ & 23,0 & 1,6 \\
\hline $\mathrm{Zn}$ & 1,67 & 0,12 & $\mathrm{Zn}$ & 2,49 & 0,19 \\
\hline$S$ & 0,108 & 0,011 & $S$ & 0,048 & 0,006 \\
\hline $\mathrm{Ca}$ & 0,0158 & 0,0021 & $\mathrm{Ca}$ & 0,030 & 0,004 \\
\hline
\end{tabular}

Tabela 5.14 - Resultado da concentração em massa obtido para uma chapa de cobre + S2, pela técnica PIXE, a partir dos dados adquiridos em dois períodos.

\begin{tabular}{|c|c|c|c|c|c|}
\hline \multicolumn{6}{|c|}{ Cobre + S2 (Chapa) } \\
\hline \multicolumn{3}{|c|}{$\begin{array}{c}2-\text { PIXE Interno } \\
\text { (15 meses após a } 1 \underline{a} \text { medida) }\end{array}$} & \multicolumn{3}{|c|}{$\begin{array}{c}3 \text { - PIXE Externo } \\
\text { (16 meses após a 1aㅡ medida) }\end{array}$} \\
\hline Elemento & {[]$\%$} & Erro [ ]\% & Elemento & {[]$\%$} & Erro [ ]\% \\
\hline $\mathrm{Cu}$ & 73 & 5 & $\mathrm{Cu}$ & 67 & 5 \\
\hline$\overline{\mathrm{Cl}}$ & 23,5 & 1,7 & $\mathrm{Cl}$ & 26,8 & 1,9 \\
\hline $\mathrm{Zn}$ & 3,66 & 0,26 & $\mathrm{Zn}$ & 5,9 & 0,4 \\
\hline$S$ & 0,121 & 0,011 & $S$ & 0,305 & 0,028 \\
\hline $\mathrm{Ca}$ & 0,0260 & 0,0027 & $\mathrm{Ca}$ & 0,036 & 0,005 \\
\hline
\end{tabular}

Em todas as amostras com pátinas sobre chapas de cobre os elementos contaminantes são os mesmos presentes nas analises anteriores, a diferença esta na presença de enxofre nas medidas, o que sugere uma absorção de $S$ pela amostras, pois o $S$ não está presente na solução $S 1$, nem em S2. No entanto, os valores obtidos de $\mathrm{S}$ para a amostra $\mathrm{Cu}+\mathrm{S} 2$ não são consistentes pois deveria, conforme nossa sugestão, aumentar com o tempo e não diminuir como o observado na tabela 5.13 e ter aumentado um fator 3 na tabela 5.14. Esta medida de $S$ apenas mostra que há a presença deste elemento, mas sua quantificação possui problemas provavelmente devido à curva de rendimento que possui uma incerteza grande para energias baixas. 


\subsection{Comparação quantitativa das medidas PIXE e ED- XRF}

Os espectros de EDXRF também foram analisados utilizando o programa WinQXAS. O programa de análise quantitativa usado para o EDXRF foi desenvolvido na EPUSP (Escola Politécnica da Universidade de São Paulo) (NEIVA et al., 2007), é baseado no modelo fundamental dos parâmetros proposto por Criss e Birks (1968), e utiliza amostras padrão para constantes de calibração. Para estes cálculos quantitativos usaram-se três ligas de cobre BAS (Bureau of Analyzed Samples, Reino Unido) como padrões.

Os valores quantitativos estimados por ED-XRF para a principal constituição do bronze comercial é comparado com PIXE e apresentado na Tabela 5.15. Ambos os resultados indicam uma maior quantidade de $\mathrm{Sn}$ do que $\mathrm{Zn}$ na liga, mas a partir das concentrações obtidas, não foi possível vincular a amostra a um único padrão, dentre os padrões de ligas de cobre (ASTM, 1998), que se encaixa de forma adequada a estes valores. Com base nos valores calculados, e considerando seus erros estatísticos, obtivemos duas ligas de latão-estanho que mais se aproximaram dos valores obtidos, $\mathrm{C} 41000$ ( $\mathrm{Cu}$ 91,0-93,0\%; Pb <0,05\%; Fe <0,05\%; Sn 2,0-2,8; restante $\mathrm{Zn}$ ), e C41500 (Cu 89,0-93,0\%; Pb <0,09\%; Fe <0,5\%; Sn 1,5-2,2\%; restante $\mathrm{Zn}$ ), podendo caracterizar a amostra como sendo um latão-estanho, denominação usada na referência utilizada. $\mathrm{Na}$ Tabela 5.15, podemos ainda observar que os valores obtidos pela técnica PIXE para as concentrações dos elementos presentes no bronze comercial são compatíveis com os valores obtidos pela técnica ED-XRF para a mesma amostra, dentro de um intervalo de confiança de $95 \%$.

Tabela 5.15 - Concentrações em massa (\%) dos elementos presentes no bronze comercial sem pátina, obtidas pelas técnicas PIXE e ED-XRF

\begin{tabular}{|c|c|c|c|c|}
\cline { 2 - 5 } \multicolumn{1}{c|}{} & $\begin{array}{c}\text { PIXE } \\
\text { Externo } \\
(\%)\end{array}$ & $\begin{array}{c}\text { Erro PIXE } \\
\text { Externo } \\
(\%)\end{array}$ & $\begin{array}{c}\text { ED-XRF } \\
(\%)\end{array}$ & $\begin{array}{c}\text { Erro ED- } \\
\text { XRF } \\
\text { Externo (\%) }\end{array}$ \\
\hline $\mathrm{Zn}$ & 2,1 & 0,4 & 1,7 & 0,2 \\
\hline $\mathrm{Sn}$ & 2,9 & 0,6 & 3,4 & 0,4 \\
\hline $\mathrm{Cu}$ & 95 & 19 & 93 & 10 \\
\hline
\end{tabular}


Os valores relativos do cloro e do enxofre em S1, S2 e S4, como estimado das medidas de PIXE, seguem o mesmo padrão que as relações das áreas dos picos de $\mathrm{Cl} / \mathrm{Cu}$ e de $\mathrm{S} / \mathrm{Cu}$ obtidas com o ED-XRF, como pode ser visto em Figura 5.9. Para ambas as técnicas, há um pequeno aumento de cloro em $\mathrm{S} 1$ (com uma ligeira exceção para os resultados de 0-EDXRF), e um grande aumento em S2, pois como discutindo anteriormente, o $\mathrm{Cl}$ esta presente nas soluções S1 e S2 (em maior concentração neste último caso). Para o enxofre é observado uma grande quantidade deste elemento nas pátinas tratadas com a solução $S 4$ em relação às tratadas com as soluções $\mathrm{S} 1$ e S2, já que a solução S4 possuía em sua constituição original $\mathrm{Na}_{2} \mathrm{SO}_{4}$ e $\mathrm{CuSO}_{4}$, e no caso de $\mathrm{S} 1$ e S2 o enxofre presente é resultado da absorção ambiental (como discutido anteriormente nas medidas PIXE).
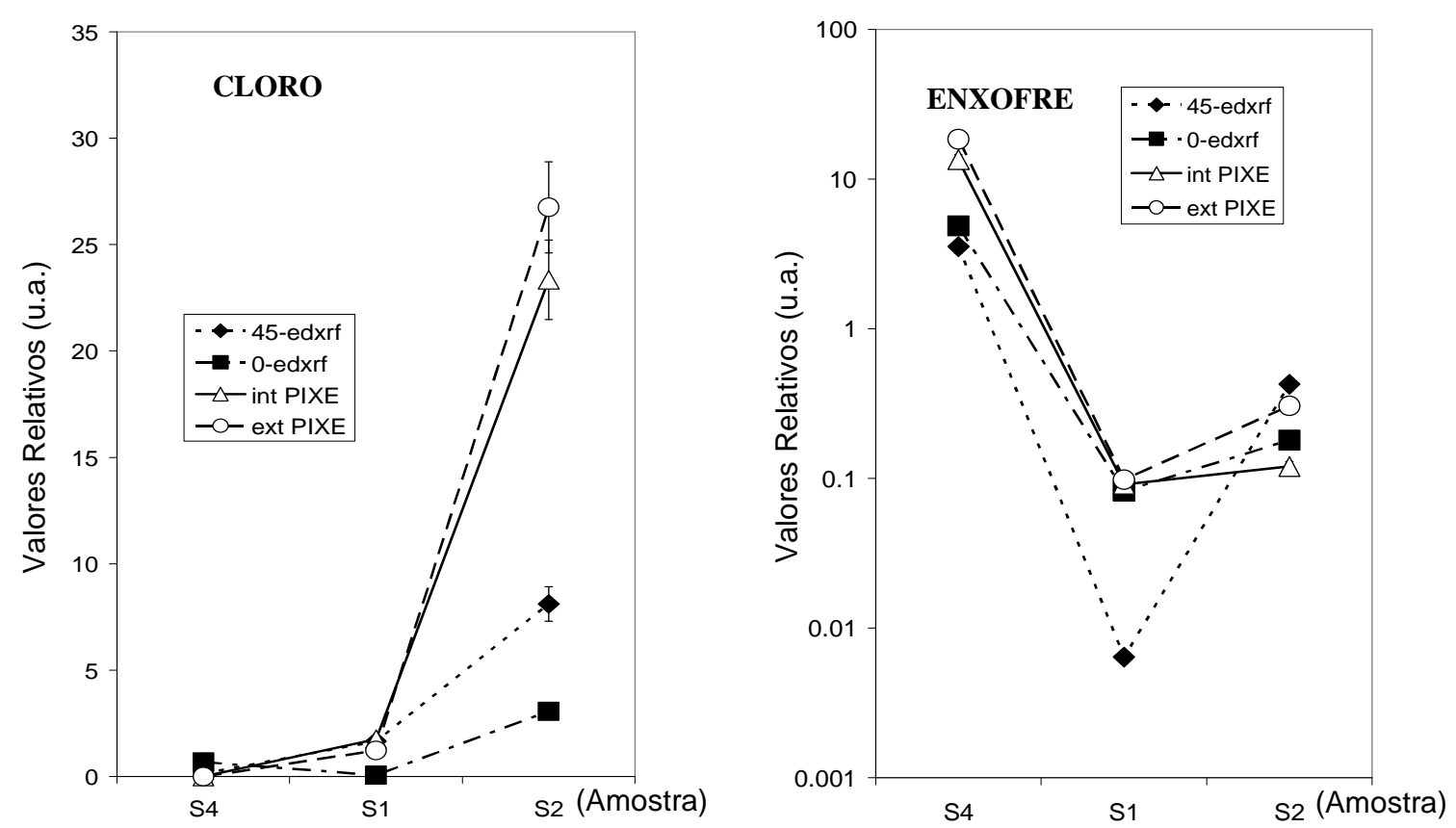

Figura 5.9 - Comparação dos valores relativos de cloro e enxofre contido nas pátinas sobre cobre. Para o PIXE, os valores representam o cálculo de concentração obtido pelo programa CLARA.Para o ED-XRF, eles representam a razão da área do pico de Cl/Cu e S/Cu, multiplicados por 10000.

A Figura 5.9 também permite a comparação dos resultados entre o PIXE interno e o externo, e entre 45-EDXRF e o 0-EDXRF. Quanto ao PIXE, nenhuma diferença notável é observada para $\mathrm{Cl}$ e $\mathrm{S}$ entre os dois tipos de montagem. A respeito do ED-XRF, no entanto, grandes diferenças, mas, em alguns casos, o seu significado não é claro. Seria de esperar que a utilização de um ângulo rasante 
melhorasse as razões $\mathrm{Cl} / \mathrm{Cu}$ e $\mathrm{S} / \mathrm{Cu}$, porque haveria menos cobre do substrato afetando os espectros. Isto foi observado para as medidas $\mathrm{S} 4$, isto é, a razão $\mathrm{Cl} / \mathrm{S}$ aumentou 4,6 vezes, e a razão $S / C$ u aumentou 1,4 vezes. Isto também foi verdade para S1 em bronze (não mostrado na Figura 5.9): os valores são 1,8 e 1,1, respectivamente. Para S1 em cobre, no entanto, os resultados são aparentemente contraditórios: houve um grande aumento para a razão S/Cu (12 vezes), mas simultaneamente uma grande diminuição na $\mathrm{Cl} / \mathrm{Cu}$ (24 vezes). Para S2, ambos os valores diminuíram. Embora algumas razões fundamentais, como a estrutura das camadas, pode eventualmente explicar as diferenças entre $\mathrm{S}$ e $\mathrm{Cl}$ no cobre $\mathrm{S} 1$, talvez uma observação de que, como mencionado anteriormente as amostras possuem áreas de superfície diferentes. Para as amostras com maior área $\left(\sim 1 \mathrm{~cm}^{2}\right)$ os resultados foram os esperados tanto para o cobre + S4 (Figura 5.9) e bronze + S1 (não mostrado na Figura 5.9). Para as amostras com áreas menores $\left(\sim 0,3 \mathrm{~cm}^{2}\right)$, eles não são consistentes com o esperado. A utilização de uma área menor não deve afetar as medições de 45-EDXRF, porque o ponto da análise é muito menor do que a amostra. Mas, para a medida rasante de 0-EDXRF, o volume da análise aumenta e pode incluir regiões fora da amostra (no caso desta ser pequena). 


\section{Capítulo 6}

\section{Conclusões e Perspectivas}

As análises das amostras de pátinas artificiais utilizando as técnicas PIXE e ED-XRF foram capazes de caracterizar e quantificar os elementos presentes nas matrizes e nas pátinas e ainda verificar possível variação dos elementos presentes das pátinas através do tempo.

Pela técnica PIXE, foi possível quantificar, em concentração de massa, os elementos presentes nas amostras. Mas tanto PIXE, quanto ED-XRF, mostraram em suas análises a presença dos elementos que compunham as soluções aplicadas na produção das pátinas artificiais.

A comparação entre as duas técnicas mostrou que para a energia de excitação utilizada o PIXE possui uma maior sensibilidade para elementos leves, enquanto que o ED-XRF é mais sensível para elemento pesados. A comparação ainda mostrou que os valores obtidos pela técnica PIXE para as concentrações dos elementos presentes no bronze comercial são compatíveis com os valores obtidos pela técnica ED-XRF para a mesma amostra, dentro de um intervalo de confiança de 95\%. Para as análises com a técnica PIXE, deve-se tomar cuidado com os cálculos quantitativos das concentrações elementares a partir das medidas das linhas $L$, pois estes cálculos também mostraram discrepâncias na concentração de W no padrão JK-49. Nas medidas PIXE dos padrões CRM 298-1 e JK-49, os valores obtidos estão estatisticamente compatíveis com os valores de referência, com um intervalo de confiança de $95 \%$, exceto para três elementos ( $\mathrm{Si}$, Co e W) do padrão JK-49.

Nas medidas de ED-XRF foi possível observar uma diferença entre medidas com diferentes angulações do feixe incidente, mostrando que com ângulos rasantes o arranjo favorece a observação dos componentes presentes nas camadas superficiais de uma amostra, com é o caso das pátinas nas amostras analisadas. Mas observou-se também que se deve tomar cuidado com tais medidas que utilizas 
ângulo rasante nos seus arranjos, pois dependendo do tamanho das amostras, o feixe incidente pode irradiar regiões fora da amostras, comprometendo a análise.

A comparação entre o PIXE externo e o interno mostra que, como esperado, as medições internas são muito mais sensíveis, mas, mesmo assim, o PIXE externo foi capaz de detectar elementos de baixa concentração, mostrando que a montagem externa é suficiente na análise de metais e suas pátinas.

A análise PIXE ainda mostra que entre as amostras, o elemento enxofre é observado em uma grande quantidade nas pátinas tratadas com a solução $S 4$, já que a solução possuía em sua constituição original $\mathrm{Na}_{2} \mathrm{SO}_{4}$ e CuSO 4 , mas nas amostras de cobre tratadas com as soluções $\mathrm{S} 1$ e $\mathrm{S} 2$ (que não possuem $\mathrm{S}$ na sua formulação), e até mesmo em uma pastilha de cobre sem aplicação de solução, foi detectado a presença do $\mathrm{S}$. Estes resultados mostram uma absorção de $\mathrm{S}$ pela amostra, que pode provir do ambiente, o que pode ser um indicativo do princípio de processo de corrosão.

Nas três amostras analisadas de chapa de cobre com pátina, observou-se um aumento na concentração de $\mathrm{Zn}$ para medidas realizadas um mês depois a medida de PIXE interno, o que pode sugerir um processo de corrosão seletiva deste elemento.

O elemento $\mathrm{Ca}$ foi encontrado em varias amostras distintas, e pode ser uma contaminação proveniente do ambiente ou da manipulação das amostras. A partir desta observação, manipulações e armazenamento mais cuidadosos devem ser realizados nos próximos estudos.

Deve-se comentar que foram observadas algumas mudanças na cor das superfícies após 12 meses de exposição ao ar, e este fator pode estar correlacionado presença e/ou as variações de $\mathrm{S}$ e $\mathrm{Zn}$ em alguns casos. Esta mudança de cor pode ser devido às modificações que ocorreram principalmente na superfície da camada da pátina, podendo estar associadas às mudanças na composição dos elementos leves $(\mathrm{C}, \mathrm{O}, \mathrm{N}, \mathrm{H}$, etc.), como o aumento do número de moléculas de hidratação nos compostos, as mudanças de estados de oxidação 
(HERNÁNDEZ, 2004, 2009), e assim por diante, mas infelizmente estes elementos leves não são medidos com as técnicas aqui utilizadas.

Em comparação ao estudo anterior (HERNÁNDEZ, 2004, 2009), que caracterizou a composição das camadas de pátinas em amostras semelhantes, pode-se mostrar que PIXE e ED-XRF quantificam os elementos presentes nas amostras sem que seja necessária a retirada do material a ser analisado, que é um fator importante na analise de peças metálicas com valor histórico e cultural. Um estudo utilizando as técnicas PIXE e/ou ED-XRF, quantitativas, juntamente com técnicas qualitativas, como EIS, SEM e XRD, torna o estudo mais completo, mas o que nem sempre isso é possível em se tratando de patrimônio histórico.

Enfim, é possível afirmar que, as análises PIXE em ar e EDXRF in sito podem ser usadas para estimar os elementos contidos em diferentes tipos de camadas de pátinas e em metais diversos, bem como em determinar com precisão a composição de ligas.

O presente estudo possibilitou agregar e desenvolver conhecimentos técnicos e científicos que criam uma perspectiva para futuras análises de ligas metálicas e pátinas naturais, presentes em peças do patrimônio cultural. 


\section{Capítulo 7 \\ Referências Bibliográficas}

ABRAHAM, M. Ion beam analysis in art and archaeology: attacking the power precisions paradigm. Nuclear Instruments and Methods in Physics Research Section B, v. 219-220, p. 1-6, 2004.

ABURAYA, J. H. Padronização de análises PIXE de amostras Sólidas em Alvos espessos. 2005. 81 p. Dissertação (Mestrado em Física) - Instituto de Física, Universidade de São Paulo, São Paulo, 2005.

ABURAYA, J. H.; ADDED N.; TABACNIKS, M. H.; RIZZUTTO, M. A.; BARBOSA, M. D. L. X-ray production yield in standardized thick target PIXE. Nuclear Instruments and Methods in Physics Research B, v. 249, p. 792-795, 2006.

ABURAYA, J. H. CLARA. São Paulo: Instituto de Física, Universidade de São Paulo, 2003, Disponível em: <http://www2.if.usp.br/ lamfi/Programas/clara.zip>. Acessado em: 20 de novembro de 2009.

ADRIAENS, A. Non-destructive analysis and testing of museum objects: An overview of 5 years of research. Spectrochimica Acta Part B, v. 60, p. 1503-1516, 2005.

ASTM - AMERICAN SOCIETY FOR TESTING AND MATERIALS, 1998 Annual Book of ASTM Standards, vol. 02.01 Copper and Copper Alloys, American Society for Testing and Material, USA, 1998.

AMPTEK. Disponível em: <http://www.amptek.com>. Acessado em: 1 de dezembro de 2009.

APPOLONI, C. R.; PARREIRA, P. S. Doze anos de atividades em arte e arqueometria no laboratório de física nuclear aplicada da universidade estadual de londrina. Revista Brasileira de Arqueometria, Restauração e Conservação, v. 1, n. 6, p. 301-304, 2007.

BALDINUCCI, F., Vocabolaro toscano dell'arte del disegno, Florence: Santi Franchi, 1681.

BALTA, I. Z.; ROBBIOLA, L. Study of black patinas on copper and bronze obtained by using 19th century western traditional techniques of artificial patination. Proceedings of the NACE 2003 (National Association of Corrosion Engineeers), Ottawa, Canadá, 2003.

BERGER, M. J.; HUBBELL, J. H. XCOM 1.2. National Bureau of Standards Report (NBSIR), 87-3597, 1986. 
BERGER, M. J.; HUBBELL, J.H.; SELTZER, S.M.; CHANG, J.; COURSEY, J.S.; SUKUMAR, R.; ZUCKER, D.S. XCOM: Photon Cross Sections Database. National Institute of Standards and Technology, USA, 1998.

BERNARDI, E.; CHIAVARI, C.; LENZA, B.; MARTINI, C.; MORSELLI, L.; OSPITALI, F.; ROBBIOLA, L. The atmospheric corrosion of quaternary bronzes: the leaching action of acid rain. Corrosion Science, v. 51, p. 159-170, 2009.

BERTIN, E. P. Principles and practice of x-ray spectrometry, 2 ed., New York: Plenum, 1975.

BOUTAINE, J. L. The modern museum. In: BRADLEY, D.; CREAGH, D. Physical Techniques in the Study of Art Archaeology and Cultural Heritage, v. 1. Elsevier, 2006. Cap. 1, p. 1-39.

BUTCHER, K.; PONTING, M.; CHANDLER, G. A study of the chemical composition of Roman silver coinage, AD 196-197'. American Journal of Numismatics, v. 9, p. 17-36, 1997.

CALLIGARO, T.; DRAN, J. -C.; KLEIN M. Application of photo-detection to art and archaeology at the C2RMF. Nuclear Instruments and Methods in Physics Research Section A, v. 504, p. 213-221, 2003.

CALLIGARO, T.; DRAN, J.-C.; SALOMON, J. Ion beam microanalysis. In: Janssens, K.; Gricken, R.V. (Org.). Non-destructive microanalysis of cultural heritage materials, v. 42, Elsevier, 2004. v. 42, Cap. 5, p. 227-276.

CANBERRA. Disponível em: <http://www.canberra.com>. Acessado em: 1 de dezembro de 2009.

CESAREO, R. X-ray physics: Interaction with matter, production, detection. La Revista del Nuovo Cimento, Ed. Compositori, Bologna, Itália, 2000.

CHIAVARI, C.; RAHMOUNI, K.; TAKENOUTI, H.; JOIRET, S.; VERMAUT, P.; ROBBIOLA, L. Composition and electrochemical properties of natural patinas of outdoor bronze monuments. Electrochimica Acta, v. 52, p. 7760-7769, 2007.

CICILEO, G. P.; CRESPO, M. A.; ROSALES, B. M. Comparative study of patinas formed on statuary alloys by means of electrochemical and surface analysis techniques, Corrosion Science, v. 46, p. 929-953, 2004.

CLIMENT-FONT, A.; DEMORTIER, G.; PALACIO, C.; MONTERO, I.; RUVALCABASIL, J. L.; DIAZ, D. Characterisation of archaeological bronzes using PIXE, PIGE, RBS and AES spectrometries. Nuclear Instruments and Methods in Physics Research B, v. 134, p. 229-236, 1998.

COMPTON A. H. A quantum theory of the scattering of X-rays by light elements. Physical Review, v. 21, n. 5, p. 483-502, 1923. 
COMPTON A. H. The spectrum of scattered X-Rays. Physical Review, v. 22, n. 5, p. 409-413, 1923.

CRISS, J. W.; BIRKS L. S. Calculation methods for fluorescent x-ray spectrometry. Empirical coefficients versus fundamental parameters. Analytical Chemistry, v. 40, p. 1080-1086, 1968.

CSA - THE COPPER DEVELOPMENT ASSOCIATION. A Brief History of Copper. Disponível em: <http://www.csa.com/discoveryguides/copper/overview.php>. Acessado em: 01 de novembro de 2009.

DACCÀ, A.; PRATI, P.; ZUCCHIATTI, A.; LUCARELLI, F.; MANDÒ, P. A.; GEMME, G.; PARODI, R.; PERA, R. Combined PIXE and XPS analysis on republican and imperial Roman coins. Nuclear Instruments and Methods in Physics Research B, v. 161-163, p. 743-747, 2000.

DE RYCK, I.; ADRIAENS, A.; ADAMS, F. An overview of Mesopotamian bronze metallurgy during the 3rd millennium BC. Journal of Cultural Heritage, v. 6, n. 3, p. 261-268, 2005.

DENKER, A.; OPITZ-COUTUREAU, J.; GRIESSER, M.; DENK, R.; WINTER, H.; Non-destructive analysis of coins using high-energy PIXE. Nuclear Instruments and Methods in Physics Research B, v. 226, p. 163-171, 2004.

DRAN, J. -C. Accelerators in art and archaeology, $8^{\text {th }}$ European Particle Accelerator Conference (EPAC 2002), Paris, France, 2002.

DRAN, J. -C. Ion beam analysis of art works: 14 years of use in the Louvre.Nuclear Instruments and Methods in Physics Research Section B, v. 219-220, p. 7-15, 2004.

FERRETTI, M. Fluorescence from the collimator in Si-PIN and Si-drift detectors: problems and solutions for the XRF analysis of archaeological and historical materials. Nuclear Instruments and Methods in Physics Research Section B, v. 226, n. 3, p. 453-460, 2004.

FIKRLE, M.; FRÁNA, J.; DROBERJAR, E. Neutron activation and X-ray fluorescence analyses of Early Roman Age Bohemian artifacts. Journal of Physics: Conference Series, v. 41, p. 267-274, 2006.

FITZGERALD, K. P.; NAIRN, J.; SKENNERTON, G.; ATRENS, A. Atmospheric corrosion of copper and the colour, structure and composition of natural patinas on copper. Corrosion Science, v. 48, p. 2480-2509, 2006.

GIUMLIA-MAIR, A. Alchemy and surface treatments in antiquity. Surface Engineering, v. 17, n. 3, p. 217-223, 2001.

GOFFER, Z. Physical studies of archaeological materials. Reports on Progress in Physics, v. 46, p. 1193-1234, 1983. 
GRAEDEL T. E.; NASSAU, K.; FRANEY, J. P. Copper patinas formed in the atmosphere - I. Introduction. Corrosion Science, v. 27, n. 7, p. 639-657, 1987.

GYÓDI, I.; DEMETER, I.; HOLLÓS-NAGY, K.;KOVÁCS, I.; SZÖKEFALVI-NAGY, Z. External-beam PIXE analysis of small sculptures. Nuclear Instruments and Methods in Physics Research B, v. 150, p. 605-610, 1999.

HERNÁNDEZ, R. P. B. Caracterização micro estrutural e eletroquímica de produtos de corrosão naturais e artificiais de cobre e ligas de cobre. 2004. 145 p. Dissertação (Mestrado em Engenharia) - Escolha Politécnica, Universidade de São Paulo, São Paulo, 2004.

HERNÁNDEZ, R. P. B. Estudo do comportamento de cobre em águas de chuva sintéticas de São Paulo e Rio de Janeiro e sua proteção contra corrosão por revestimento e pátinas expostos à ação climática. 2009. 239 p. Tese (Doutorado em Engenharia) - Escolha Politécnica, Universidade de São Paulo, São Paulo, 2009.

HERNÁNDEZ, R. P. B.; PÁSZTI, Z.; DE MELO, H. G.; AOKI I. V. Chemical characterization and anticorrosion properties of corrosion products formed on pure copper in synthetic rainwater of Rio de Janeiro and São Paulo. Corrosion Science, v. 52, p. 826-837, 2010.

HUBIN, A.; TERRYN, H. X-ray photoelectron and Auger electron spectroscopy. In: JANSSENS, K.; GRICKEN, R.V. (Org.). Non-destructive microanalysis of cultural heritage materials, v. 42, Elsevier, 2004. v. 42, Cap. 6, p. 277-312.

HUGHES, R.; ROWE, M. The colouring, bronzing and patination of metals, 1.ed. New York: Watson-Guptill Publications, 1991.

INGO, G. M.; DE CARO, T.; RICCUCCI, C.; ANGELINI, E.; GRASSINI, S.; BALBI, S.; BERNARDINI, P.; SALVI, D.; BOUSSELMI, L.; ÇILINGIROGLU, A.; GENER, M.; GOUDA, V. K.; AL JARRAH, O.; KHOSROFF, S.; MAHDJOUB, Z.; AL SAAD, Z.; ELSADDIK, W.; VASSILIOU, P. Large scale investigation of chemical composition, structure and corrosion mechanism of bronze archaeological artefacts from Mediterranean basin. Applied Physics A, v. 83, p. 513-520, 2006.

INTERNATIONAL ATOMIC ENERGY AGENCY LABORATORIES, WinQXAS 1.40, 1997-2001. Disponível em: <http://www.iaea.or.at/programmes/ripc/physics/faznic/winqxas.htm>. Acessado em: 20 de novembro de 2009.

JANSSENS, K. X-ray based methods of analysis. In: JANSSENS, K.; GRICKEN, R.V. (Org.). Non-destructive microanalysis of cultural heritage materials, v. 42, Elsevier, 2004. v. 42, Cap. 4, p. 129-226.

JOHANSSON, T. B.; AKSELSSON, K. R.; JOHANSSON, S. A. E. X-ray analysis: elemental trace analysis at the $10^{-12} \mathrm{~g}$ level. Nuclear Instruments and Methods, $\mathrm{v}$. 84, p. 141-143, 1970. 
JOHANSSON, S. A. E.; JOHANSSON, T. B. Analytical application of particle induced x-ray emission. Nuclear Instruments and Methods, v. 137, p. 473-516, 1976.

JOHANSSON, S. A. E.; CAMPBELL, J. L. PIXE, A novel technique for elemental analysis. Chichester: John Wiley \& Sons, 1988.

JOHANSSON, S. A. E.; CAMPBELL, J. L.; MALMQVIST, K. G. Particle induced xray emission spectrometry (PIXE). Chichester: John Willey \& Sons, 1995.

KALHTHRAKAS-KONTOS, N.; KATSANOS, A. A.; POTIRIADIS, C.; OECONOMLDOU, M.; TOURATSOGLOU, J. PIXE analysis of ancient greek copper coins minted in Epirus, Illyria, Macedonia and Thessaly. Nuclear Instruments and Methods in Physics Research B, v. 109/110, p. 662-666, 1996.

KALLIABAKOS, G.; KOSSIONIDES, S.; MISAILIDES P.; PAPADOPOULOS, C. T.; VLASTOU, R. Determination of sulphur and copper depth distribution in patina layers using nuclear reaction techniques. Nuclear Instruments and Methods in Physics Research B, v. 170, p. 467-473, 2000.

KATSANOS, A. A. Applications of ion beam analysis in archaeology and the arts. Nuclear Instruments and Methods in Physics Research B, v. 14, p. 82-85, 1986.

KHAN, M. R.; CRUMPTON, D.; JOHANSSON, S. Proton induced x-ray emission analysis. Critical Reviews in Analytical Chemistry, v. 11, n. 3, p. 161-193, 1981.

KIMAB (CORROSION AND METALS RESEARCH INSTITUTE). JK 49, Certified Reference Materials. Sweden, 2005.

KNOLL, G. F. Radiation Detection and Measurement. Chichester: John Wiley and Sons, 1979.

KORTRIGHT, J. B.; THOMPSON, A. C. X-ray emission energies. In: THOMPSON, A. C.; ATTWOOD D. T.; GULLIKSON E. M.; HOWELLS M. R.; KORTRIGHT, J. B.; ROBINSON A. L.; UDERWOOD, J. H.; KIM, K. -J.; KIRZ J.; LINDAU, I.; PIANETTA, P.; WINICK, H.; WILLIAMS G.; SCOFIELD J. H.; VAUGHAN, D. X-Ray Data Booklet. Lawrence Berkeley National Laboratory, University of California, Berkeley, 2001. Seção 1.2.

KRÄTSCHMER, A.; ODNEVALL WALLINDER, I.; LEYGRAF, C. The evolution of outdoor copper patina. Corrosion Science, v. 44, p. 425-450, 2002.

LAGO, D. C. B.; MIRANDA, L. R. M.; SATHLER, L. Aplicação de pátinas artificiais na restauração de monumentos de bronze da cidade do Rio de Janeiro. In: PRIMEIRO CONGRESSO LATINOAMERICANO DE RESTAURAÇÃO DE METAIS, 2003, Santiago do Chile. Anais do Primeiro Congresso Latinoamericano de Restauração de Metais. Santiago do Chile: Universidade do Chile, 2003.

LAMFI - LABORATÓRIO DE ANÁLISE DE MATERIAIS POR FEIXES IÔNICOS. Disponível em: <http://www2.if.usp.br/ lamfi/>. Acessado em: 11 de dezembro de 2009. 
LEIGHTON, R. B. Principles of Modern Physics, McGraw-Hill, 1959, 795 p.

LEYGRAF, C.; GRAEDEL, T. Atmospheric Corrosion. Wiley-Interscience, 2000. p. 354.

LINKE, R.; SCHREINER, M.; DEMORTIER, G.; The application of photon, electron and proton induced $\mathrm{X}$-ray analysis for the identification and characterization of medieval silver coins. Nuclear Instruments and Methods in Physics Research B, v. 226 , p. $172-178,2004$.

MABILLE, I.; BERTRAND, A.; SUTTER, E. M. M.; FIAUD, C. Mechanism of dissolution of a $\mathrm{Cu}-13 \mathrm{Sn}$ alloy in low aggressive conditions, Corrosion Science, v. 45, p. 855-866, 2003.

MATHIS, F.; ELISABETH DELANGE, E.; ROBCIS, D.; AUCOUTURIER, M. HMTYKM (black copper) and the Egyptian bronzes' collection of the Musée du Louvre. Journal of Cultural Heritage, v. 10, p. 63-72, 2009.

MAXWELL, J. A.; CAMPBELL, J. L.; TEESDALE, W. J. The Guelph PIXE software package. Nuclear Instruments and Methods in Physics Research Section B, v. 43, p. 218-230, 1989.

MENDOZA, A. R.; CORVO, F.; GÓMEZ, A.; GÓMEZ, J. Influence of the corrosion products of copper on its atmospheric corrosion kinetics in tropical climate. Corrosion Science, v. 46, n. 5, p. 1189-1200, 2004.

MOENS, L.; BOHLEN, A. V.; VANDENABEELE, P. X-ray fluorescence. In: CILIBERTO, E.; SPOTO, G. (Ed.) Modern Analytical Methods in Art and Archaeology, v. 155 in Chemical Analysis. John Wiley \& Sons, 2000. Cap. 4, p. 55-79.

MURESAN, L.; VARVARA, S.; STUPNIŠEK-LISAC, E.; OTMACIC, H.; MARUŠIC, K.; HORVAT-KURBEGOVIC, S.; ROBBIOLA, L.; RAHMOUNIF, K.; TAKENOUTI, H. Protection of bronze covered with patina by innoxious organic substances, Electrochimica Acta , v. 52, p. 7770-7779, 2007.

NAIXIN X.; LINGYUAN Z.; CUIHONG D.; CHENGDIAN Z.; RUNSHEN L.; QINGDONG Z. Laboratory observation of dew formation at an early stage of atmospheric corrosion of metals. Corrosion Science, v. 44, n. 1, p. 163-170, 2002.

NASCIMENTO FILHO, V. F. Técnicas analíticas nucleares de fluorescência de raios $X$ por dispersão de energia (ED-XRF) e reflexão total (TXRF). Piracicaba: CENA-ESALQ/USP, 1999, 32 p. (apostila didática).

NASSAU, K.; MILLER, A. E.; GRAEDEL, T. E. The reaction of simulated rain with copper, copper patina, and some copper compounds. Corrosion Science, v. 27, n. 7, p. 703-719, 1987. 
NAVE, C. R. Compton scattering data, Department of Physics and Astronomy, Georgia State University. Disponível em: <http://hyperphysics.phystr.gsu.edu/Hbase/quantum/compdat.html\#c1>. Acessado em: 20 de novembro de 2009.

NEIVA, A. C.; DRON, J. N.; LOPES, B. F.; APPOLONI, C. R.; PARREIRA, P. S.; TSCHIPTSCHIN, A. P.; LANDGRAF, F. J. G. Development of EDXRF Quantitative Analysis Methodology for the Study of Ferrous Alloys of Historical Importance. In: $1^{\circ}$ SIMPÓSIO LATINO AMERICANO SOBRE MÉTODOS FÍSICOS E QUÍMICOS EM ARQUEOLOGIA, ARTE E CONSERVAÇÃO DO PATRIMÔNIO CULTURAS (LASMAC 2007), 2007, São Paulo. Anais do 1 Simpósio Latino Americano sobre Métodos Físicos e Químicos em Arqueologia Arte e Conservação do Patrimônio Cultural, p.168-177, 2007.

NEIVA, A. C.; DRON, J. Caracterização de bens culturais por espectroscopia de fluorescência de raios X. Revista CPC, São Paulo, n. 6, p. 188-197, 2008.

OLARIU, A.; BADICA, T.; ALEXANDRESCU, E.; AVRAM, A. Archaeometric study of a bronze age sword discovered at Giurgiu, Romania. Romanian Reports in Physics, v. 60, p. 563-570, 2008.

PaBAAC - PAESAGGIO BELLE ARTI ARCHITETTURA E ARTE CONTEMPORANEE. La Commissione Franceschini. Disponível em: <http://arti.beniculturali.it/>. Acessado em: 10 de fevereiro de 2010.

PANTAZIS J. A.; HUBER A. C.; OKUN P.; SQUILLANTE M. R.; WAER P.; ENTINE G. New, high performance nuclear spectroscopy system using Si- PIN diodes and CdTe detectors, IEEE Transactions on Nuclear Science, v. 41, n. 4, 1994.

PAPARAZZO, E.; MORETTO, L. X-ray photoelectron spectroscopy and scanning Auger microscopy studies of bronzes from the collections of the Vatican Museums. Vacuum, v. 55, p. 59-70, 1999.

PAPPALARDO, L.; ROMANO, F. P.; GARRAFFO, S. The improved Ins pixe-alpha portable system: archaeometric applications. Archaeometry, v. 45, p. 333-339, 2003.

PINHOS, A. G.; MONTENEGRO, E. C.; BARROS LEITE, C. V.; BAPTISTA, G. B.; PASCHOA, A. S. Potencialidades e possíveis aplicações de um novo método analítico (PIXE). Anais da Academia Brasileira de Ciência, v. 51, n. 3, p. 365-393, 1979.

RESPALDIZA, M. A.; GÓMEZ-TUBíO, B. M.; SÁNCHEZ DEL JUNCO, A.; BARRANCO, F.; SÁIZ-JIMÉNEZ, C. Non-destructive analysis of archaeological bronzes by nuclear techniques. Nuclear Instruments and Methods in Physics Research B, v. 89, p. 109-113, 1994. 
RIZZUTTO, M. A.; ADDED, N.; TABACNIKS, M. H.; LIGUORI NETO, R.; ACQUADRO, J. C.; MACHADO, L. P.; VILELA, M.; OLIVEIRA, T. R. C. F.; MARKARIAN, R. A.; MORI, M. External PIGE-PIXE measurements at the São Paulo 8UD tandem accelerator. Nuclear Instruments and Methods in Physics Research Section B, v. 190, n.1-4, p. 186-189. 2002.

RIZZUTTO, M. A.; TABACNIKS, M. H.; ADDED, N.; BARBOSA, M. D. L.; CURADO, J. F.; SANTOS JR., W. A.; LIMA, S. C.; MELO, H. G; NEIVA, A. C. The external beam facility used to characterize corrosion products in metallic statuettes. Nuclear Instruments and Methods in Physics Research Section B, v. 240, n. 1-2, p. 549553. 2005.

RIZZUTTO, M. A.; TABACNIKS, M. H.; ADDED, N.; BARBOSA, M. D. L.; CURADO, J. F.; PASCHOLATTI, P. R.; NEVES, G.; LIMA, S. C.; MELO, H. G.; NEIVA, A. C.; PIXE externo para análises de objetos de arte e arqueologia. Revista Brasileira de Arqueometria, Restauração e Conservação, v. 1, n. 6, p. 309-312, 2007.

ROBBIOLA, L.; BLENGINO, J. -M.; FIAUD, C. Morphology and mechanisms of formation of natural patinas on archaeological Cu-Sn alloys. Corrosion Science, v. 40, n. 12, p. 2083-2111, 1998.

ROBBIOLA, L.; RAHMOUNI, K.; CHIAVARI, C.; MARTINI, C.; PRANDSTRALLER, D.; TEXIER, A.; TAKENOUTI, H.; VERMAUT, P. New insight into the nature and properties of pale green surfaces of outdoor bronze monuments. Applied Physics A, v. 92, p. 161-169, 2008.

RÖNTGEN, W. C. Über eine neue Art von Strahlen. Sitzungsberichte der Würzburger Physik.-medic. Gesellschaft, 1895.

SANTOS, H. C. Análise de elementos traço em amostra de sedimento da região do Rio Toledo. Dissertação (Mestrado em Física) - Instituto de Física, Universidade de São Paulo, São Paulo, 2009.

SCOFIELD, J. H. Exchange corrections of $K \mathrm{x}$-ray emission rates. Physical Review A, v. 9, p. 1041-1049, 1974.

SERGHINI-IDRISSI, M.; BERNARD, M. C.; HARRIF, F. Z.; JOIRET, S.; RAHMOUNI, K.; SRHIRI, A.; TAKENOUTI, H.; VIVIER, V.; ZIANI, M. Electrochemical and spectroscopic characterizations of patinas formed on an archaeological bronze coin. Electrochimica Acta, v. 50, p. 4699-4709, 2005.

SIDOT, E.; SOUISSI, N.; BOUSSELMI, L.; TRIKI, E.; ROBBIOLA, L. Study of the corrosion behaviour of $\mathrm{Cu}-10 \mathrm{Sn}$ bronze in aerated Na2SO4 aqueous solution. Corrosion Science, v. 48, p. 2241-2257, 2006.

SIMR (Swedish Institute for Metals Research). CRM 298-1, Certified Reference Materials. Sweden, 2002. 
SOUISSI, N.; BOUSSELMI, L.; KHOSROF, S.; TRIKI, E. Electrochemical behaviour of an archaeological bronze alloy in various aqueous media: new method for understanding artefacts preservation. Materials and Corrosion, v. 54, p. 318-325, 2003.

SQUARCIALUPI, M. C.; BERNARDINI, G. P.; FASO, V.; ATREI, A.; ROVIDA, G.; Characterisation by XPS of the corrosion patina formed on bronze surfaces. Journal of Cultural Heritage, v. 3, p. 199-204, 2002.

STRANDBERG, H. Reactions of copper patina compounds - I. Influence of some air pollutants. Atmospheric Environment, v. 32, n. 20, p. 3511-3520, 1998a.

STRANDBERG, H. Reactions of copper patina compounds - II. Influence of sodium chloride in the presence of some air pollutants. Atmospheric Environment, v. 32, n. 20, pp. 3521-3526, 1998b.

TABACNIKS, M. H. Calibração do sistema PIXE-SP de Análise Elementar. 1983. 106 p. Dissertação (Mestrado em Física) - Instituto de Física, Universidade de São Paulo, São Paulo, 1983.

TABACNIKS, M. H. Análise de Filmes Finos por PIXE e RBS. São Paulo: Instituto de Física da Universidade de São Paulo, 2000 (Didática).

TABACNIKS, M. H. Os elementos na matéria. 2005. 152 p. Tese (Livre Docência em Física) - Intituto de Física, Universidade de São Paulo, São Paulo, 2005.

TYLECOTE, R. F. A History of Metallurgy, 2 ed., The Institute of Materials, London, 1992.

UDA, M.; DEMORTIER, G.; NAKAI, I. X-rays Archaeology. Springer, 2005. 308 p.

WEIL, P. D.; Technical art history and archeometry I - Patina: Historical scientific and practical considerations. Revista Brasileira de Arqueometria, Restauração e Conservação, v. 1, n. 2, p. 60-66, 2007.

XUEYUAN ZHANG; WENLE HE; WALLINDER, I. O.; JINSHAN PAN; LEYGRAF, C. Determination of instantaneous corrosion rates and runoff rates of copper from naturally patinated copper during continuous rain events. Corrosion Science, v. 44, n. 9, p. 2131-2151, 2002.

ZIEGLER, J. F. SRIM-2003. Nuclear Instruments and Methods in Physics Research Section B, v. 219-220, p. 1027-1036, 2004. 
Tabela A.1 - Energia dos fótons, em elétrons volts, das principais linhas de emissão das camadas $K, L$ e $M$ (KORTRIGH; THOMPSON, 2001).

\begin{tabular}{|c|c|c|c|c|c|c|c|c|c|c|}
\hline \multicolumn{2}{|c|}{ Elemento } & $K_{\alpha 1}$ & $K_{\alpha 2}$ & $K_{\beta 1}$ & $L_{\alpha 1}$ & $L_{\alpha 2}$ & $L_{\beta 1}$ & $L_{\beta 2}$ & $L_{\gamma 1}$ & $M_{\alpha 1}$ \\
\hline 3 & Li & \multicolumn{9}{|l|}{54.3} \\
\hline 4 & $\mathrm{Be}$ & \multicolumn{9}{|l|}{108.5} \\
\hline 5 & B & \multicolumn{9}{|l|}{183.3} \\
\hline 6 & C & \multicolumn{9}{|l|}{277} \\
\hline 7 & $\mathbf{N}$ & \multicolumn{9}{|l|}{392.4} \\
\hline 8 & 0 & \multicolumn{9}{|l|}{524.9} \\
\hline 9 & $\mathbf{F}$ & \multicolumn{9}{|l|}{676.8} \\
\hline 10 & $\mathrm{Ne}$ & \multicolumn{9}{|c|}{848.6} \\
\hline 11 & $\mathrm{Na}$ & 1040.98 & 1040.98 & \multicolumn{7}{|l|}{1071.1} \\
\hline 12 & Mg & 1253.60 & 1253.60 & \multicolumn{7}{|l|}{1302.2} \\
\hline 13 & Al & 1486.70 & 1486.27 & \multicolumn{7}{|l|}{1557.45} \\
\hline 14 & Si & 1739.98 & 1739.38 & \multicolumn{7}{|l|}{1835.94} \\
\hline 15 & $\mathbf{P}$ & 2013.7 & 2012.7 & \multicolumn{7}{|l|}{2139.1} \\
\hline 16 & $S$ & 2307.84 & 2306.64 & \multicolumn{7}{|l|}{2464.04} \\
\hline 17 & $\mathrm{Cl}$ & 2622.39 & 2620.78 & \multicolumn{7}{|l|}{2815.6} \\
\hline 18 & $\mathrm{Ar}$ & 2957.70 & 2955.63 & \multicolumn{7}{|l|}{3190.5} \\
\hline 19 & $\mathbf{K}$ & 3313.80 & 3311.10 & \multicolumn{7}{|l|}{3589.6} \\
\hline 20 & $\mathrm{Ca}$ & 3691.68 & 3688.09 & 4012.7 & 341.3 & 341.3 & \multicolumn{4}{|l|}{344.9} \\
\hline 21 & Sc & 4090.6 & 4086.1 & 4460.5 & 395.4 & 395.4 & \multicolumn{4}{|l|}{399.6} \\
\hline 22 & $\mathrm{Ti}$ & 4510.84 & 4504.86 & 4931.81 & 452.2 & 452.2 & \multicolumn{4}{|l|}{458.4} \\
\hline 23 & $\mathbf{V}$ & 4952.20 & 4944.64 & 5427.29 & 511.3 & 511.3 & \multicolumn{4}{|l|}{519.2} \\
\hline 24 & $\mathrm{Cr}$ & 5414.72 & 5405.509 & 5946.71 & 572.8 & 572.8 & \multicolumn{4}{|l|}{582.8} \\
\hline 25 & Mn & 5898.75 & 5887.65 & 6490.45 & 637.4 & 637.4 & \multicolumn{4}{|l|}{648.8} \\
\hline 26 & $\mathrm{Fe}$ & 6403.84 & 6390.84 & 7057.98 & 705.0 & 705.0 & \multicolumn{4}{|l|}{718.5} \\
\hline 27 & Co & 6930.32 & 6915.30 & 7649.43 & 776.2 & 776.2 & \multicolumn{4}{|l|}{791.4} \\
\hline 28 & $\mathrm{Ni}$ & 7478.15 & 7460.89 & 8264.66 & 851.5 & 851.5 & \multicolumn{4}{|l|}{868.8} \\
\hline 29 & $\mathrm{Cu}$ & 8047.78 & 8027.83 & 8905.29 & 929.7 & 929.7 & \multicolumn{4}{|l|}{949.8} \\
\hline 30 & Zn & 8638.86 & 8615.78 & 9572.0 & 1011.7 & 1011.7 & 1034.7 & & & \\
\hline 31 & $\mathrm{Ga}$ & 9251.74 & 9224.82 & 10264.2 & 1097.92 & 1097.92 & 1124.8 & & & \\
\hline 32 & $\mathrm{Ge}$ & 9886.42 & 9855.32 & 10982.1 & 1188.00 & 1188.00 & 1218.5 & & & \\
\hline
\end{tabular}


Continuação

\begin{tabular}{|c|c|c|c|c|c|c|c|c|c|}
\hline Elemento & $K_{\alpha 1}$ & $K_{\alpha 2}$ & $K_{\beta 1}$ & $L_{\alpha 1}$ & $L_{\alpha 2}$ & $L_{\beta 1}$ & $L_{\beta 2}$ & $L_{\gamma 1}$ & $M_{\alpha 1}$ \\
\hline 33 As & 10543.72 & 10507.99 & 11726.2 & 1282.0 & 1282.0 & 1317.0 & & & \\
\hline $34 \mathrm{Se}$ & 11222.4 & 11181.4 & 12495.9 & 1379.10 & 1379.10 & 1419.23 & & & \\
\hline $35 \mathrm{Br}$ & 11924.2 & 11877.6 & 13291.4 & 1480.43 & 1480.43 & 1525.90 & & & \\
\hline $36 \mathrm{Kr}$ & 12649 & 12598 & 14112 & 1586.0 & 1586.0 & 1636.6 & & & \\
\hline $37 \mathrm{Rb}$ & 13395.3 & 13335.8 & 14961.3 & 1694.13 & 1692.56 & 1752.17 & & & \\
\hline $38 \mathrm{Sr}$ & 14165 & 14097.9 & 15835.7 & 1806.56 & 1804.74 & 1871.72 & & & \\
\hline $39 Y$ & 14958.4 & 14882.9 & 16737.8 & 1922.56 & 1920.47 & 1995.84 & & & \\
\hline $40 \mathrm{Zr}$ & 15775.1 & 15690.9 & 17667.8 & 2042.36 & 2039.9 & 2124.4 & 2219.4 & 2302.7 & \\
\hline $41 \mathrm{Nb}$ & 16615.1 & 16521.0 & 18622.5 & 2165.89 & 2163.0 & 2257.40 & 2367.0 & 2461.8 & \\
\hline 42 Mo & 17479.34 & 17374.3 & 19608.3 & 2293.16 & 2289.85 & 2394.81 & 2518.3 & 2623.5 & \\
\hline $43 \mathrm{Tc}$ & 18367.1 & 18250.8 & 20619 & 2424 & 2420 & 2538 & 2674 & 2792 & \\
\hline $44 \mathrm{Ru}$ & 19279.2 & 19150.4 & 21656.8 & 2558.55 & 2554.31 & 2683.23 & 2836.0 & 2964.5 & \\
\hline $45 \mathrm{Rh}$ & 20216.1 & 20073.7 & 22723.6 & 2696.74 & 2692.05 & 2834.41 & 3001.3 & 3143.8 & \\
\hline $46 \mathrm{Pd}$ & 21177.1 & 21020.1 & 23818.7 & 2838.61 & 2833.29 & 2990.22 & 3171.79 & 3328.7 & \\
\hline $47 \mathrm{Ag}$ & 22162.92 & 21990.3 & 24942.4 & 2984.31 & 2978.21 & 3150.94 & 3347.81 & 3519.59 & \\
\hline $48 \mathrm{Cd}$ & 23173.6 & 22984.1 & 26095.5 & 3133.73 & 3126.91 & 3316.57 & 3528.12 & 3716.86 & \\
\hline 49 In & 24209.7 & 24002.0 & 27275.9 & 3286.94 & 3279.29 & 3487.21 & 3713.81 & 3920.81 & \\
\hline $50 \mathrm{Sn}$ & 25271.3 & 25044.0 & 28486.0 & 3443.98 & 3435.42 & 3662.80 & 3904.86 & 4131.12 & \\
\hline $51 \mathrm{Sb}$ & 26359.1 & 26110.8 & 29725.6 & 3604.72 & 3595.32 & 3843.57 & 4100.78 & 4347.79 & \\
\hline $52 \mathrm{Te}$ & 27472.3 & 27201.7 & 30995.7 & 3769.33 & 3758.80 & 4029.58 & 4301.7 & 4570.9 & \\
\hline 531 & 28612.0 & 28317.2 & 32294.7 & 3937.65 & 3926.04 & 4220.72 & 4507.5 & 4800.9 & \\
\hline $54 X e$ & 29779 & 29458 & 33624 & 4109.9 & - & - & - & - & \\
\hline $55 \mathrm{Cs}$ & 30972.8 & 30625.1 & 34986.9 & 4286.5 & 4272.2 & 4619.8 & 4935.9 & 5280.4 & \\
\hline $56 \mathrm{Ba}$ & 32193.6 & 31817.1 & 36378.2 & 4466.26 & 4450.90 & 4827.53 & 5156.5 & 5531.1 & \\
\hline $57 \mathrm{La}$ & 33441.8 & 33034.1 & 37801.0 & 4650.97 & 4634.23 & 5042.1 & 5383.5 & 5788.5 & 833 \\
\hline $58 \mathrm{Ce}$ & 34719.7 & 34278.9 & 39257.3 & 4840.2 & 4823.0 & 5262.2 & 5613.4 & 6052 & 883 \\
\hline $59 \mathrm{Pr}$ & 36026.3 & 35550.2 & 40748.2 & 5033.7 & 5013.5 & 5488.9 & 5850 & 6322.1 & 929 \\
\hline $60 \mathrm{Nd}$ & 37361.0 & 36847.4 & 42271.3 & 5230.4 & 5207.7 & 5721.6 & 6089.4 & 6602.1 & 978 \\
\hline $61 \mathrm{Pm}$ & 38724.7 & 38171.2 & 43826 & 5432.5 & 5407.8 & 5961 & 6339 & 6892 & - \\
\hline $62 \mathrm{Sm}$ & 40118.1 & 39522.4 & 45413 & 5636.1 & 5609.0 & 6205.1 & 6586 & 7178 & 1081 \\
\hline $63 \mathrm{Eu}$ & 41542.2 & 40901.9 & 47037.9 & 5845.7 & 5816.6 & 6456.4 & 6843.2 & 7480.3 & 1131 \\
\hline $64 \mathrm{Gd}$ & 42996.2 & 42308.9 & 48697 & 6057.2 & 6025.0 & 6713.2 & 7102.8 & 7785.8 & 1185 \\
\hline $65 \mathrm{~Tb}$ & 44481.6 & 43744.1 & 50382 & 6272.8 & 6238.0 & 6978 & 7366.7 & 8102 & 1240 \\
\hline 66 Dy & $45 \varsigma$ & 45207.8 & 19 & 2 & .7 & .7 & 76 & 8418.8 & 1293 \\
\hline $67 \mathrm{Ho}$ & 47546.7 & 46699.7 & 53877 & 6719.8 & 6679.5 & 7525.3 & 7911 & 8747 & 1348 \\
\hline
\end{tabular}


Continuação

\begin{tabular}{|c|c|c|c|c|c|c|c|c|c|c|}
\hline \multicolumn{2}{|c|}{ Elemento } & $K_{\alpha 1}$ & $K_{\alpha 2}$ & $K_{\beta 1}$ & $L_{\alpha 1}$ & $L_{\alpha 2}$ & $L_{\beta 1}$ & $L_{\beta 2}$ & $L_{\gamma 1}$ & $M_{\alpha 1}$ \\
\hline 68 & $\mathrm{Er}$ & 9127.7 & 321.1 & 55681 & 6948.7 & 6905.0 & 7810.9 & 8189.0 & 9089 & 1406 \\
\hline 69 & $\mathbf{T}$ & 6 & 6 & 575 & ה & 保 & 8101 & $1+00$ & 9426 & 62 \\
\hline 70 & $\mathbf{Y b}$ & 52388.9 & 51354.0 & 59370 & 7415.6 & 7367.3 & 8401.8 & 8758.8 & 9780.1 & 1521.4 \\
\hline 71 & Lu & 54069.8 & 52965.0 & 61283 & 7655.5 & 7604.9 & 8709.0 & 9048.9 & 10143.4 & 1581.3 \\
\hline 72 & $\mathrm{Hf}$ & 55790.2 & 54611.4 & 63234 & 7899.0 & 7844.6 & 9022.7 & 347.3 & 10515.8 & 644.6 \\
\hline 73 & $\mathrm{Ta}$ & 57532 & 56277 & 65223 & 8146.1 & 8087.9 & 9343.1 & 9651.8 & 10895.2 & 1710 \\
\hline 74 & W & 59318.24 & 57981.7 & 67244.3 & 8397.6 & 8335.2 & 9672.35 & 9961.5 & 11285.9 & 1775.4 \\
\hline 75 & $\mathbf{R e}$ & 61140.3 & ט. דותושי & 69310 & $000<.5$ & 0000.6 & 10010.0 & 10275.2 & 11685.4 & 1842.5 \\
\hline 76 & Os & 63000.5 & 61486.7 & 71413 & 8911.7 & 8841.0 & 10355.3 & 10598.5 & 12095.3 & 1910.2 \\
\hline 77 & Ir & 6485 & 63286.7 & 73560.8 & .1 & 9099.5 & 10708.3 & .3 & 12.6 & 1979.9 \\
\hline 78 & $\mathrm{Pt}$ & 2 & r & 8 & 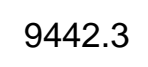 & (2) & 11070.7 & 11250.5 & 12942.0 & 2050.5 \\
\hline 79 & $\mathrm{Au}$ & 68803.7 & 66989.5 & 77984 & 9713.3 & 9628.0 & 11442.3 & 11584.7 & 13381.7 & 2122.9 \\
\hline 80 & $\mathrm{Hg}$ & 819 & 68895 & 80253 & 9988.8 & 9897.6 & 11822.6 & 11924.1 & 13830.1 & 2195.3 \\
\hline 81 & $\mathbf{T}$ & 7 & 7 & 82576 & 5 & 8 & 3 & 5 & .5 & .6 \\
\hline 82 & $\mathrm{~Pb}$ & 74969.4 & 72804.2 & 84936 & 10551.5 & 10449.5 & 12613.7 & 12622.6 & 14764.4 & 2345.5 \\
\hline 83 & $\mathbf{B i}$ & 77107.9 & 74814.8 & 87343 & 10838.8 & 10730.91 & 13023.5 & 12979.9 & 15247.7 & 2422.6 \\
\hline 84 & Po & 79290 & 76862 & 0 & 1 & 8 & 7 & 4 & 1 & - \\
\hline 85 & At & o & 0 & 92300 & 8 & 8 & 13876 & - & 16251 & - \\
\hline 86 & $\mathbf{R n}$ & 83780 & 81070 & 94870 & 11727.0 & 11597.9 & 14316 & - & 16770 & - \\
\hline 87 & $\mathbf{F}$ & 86100 & 30 & 70 & 120 & .0 & 70 & 14 & 02 & - \\
\hline 88 & $\mathbf{R a}$ & 70 & 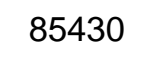 & 100130 & 1 & .2 & 15235.8 & 1404 & 17849 & - \\
\hline 89 & Ac & 90884 & 70 & 102850 & 12652.0 & 12500.8 & 15713 & - & 18408 & - \\
\hline 90 & Th & 93350 & 53 & 105609 & 12968.7 & 12809.6 & 16202.2 & 15623.7 & 18982.5 & 2996.1 \\
\hline 91 & $\mathrm{~Pa}$ & 95868 & 9228 & 108427 & 13290.7 & 131 & 16702 & 16024 & 19568 & 3082.3 \\
\hline 92 & U & 98439 & 94665 & 111300 & 13614.7 & 13438.8 & 17220.0 & 16428.3 & 20167.1 & 3170.8 \\
\hline 93 & $\mathbf{N}$ & - & - & - & 13944.1 & 13759.7 & 17750.2 & 16840.0 & 2078 & - \\
\hline 94 & $\mathrm{Pu}$ & - & - & - & 14278.6 & 14084.2 & 18293.7 & 17255.3 & 21417.3 & - \\
\hline 95 & $A m$ & - & - & - & 14617.2 & 14411.9 & 18852.0 & 17676.5 & 22065.2 & - \\
\hline
\end{tabular}

Conclusão 